\title{
Peroxynitrite - matrix metalloproteinase and erythropoietin receptor signaling pathways in ischemic heart disease
}

\author{
Krisztina Kiss MD \\ Ph.D. Thesis \\ Department of Biochemistry, Faculty of Medicine, \\ University of Szeged \\ Doctoral School of Multidisciplinary Medical Science
}

Supervisors: Péter Bencsik MD, PhD, Tamás Csont MD, PhD

Szeged

2017 


\section{List of scientific publications related directly to the subject of the Thesis}

I. Peter Bencsik, Viktor Sasi, Krisztina Kiss, Krisztina Kupai, Marton Kolossvary, Pal Maurovich-Horvat, Tamas Csont, Imre Ungi, Bela Merkely and Peter Ferdinandy: Serum lipids and cardiac function correlate with nitrotyrosine and MMP activity in coronary artery disease patients, Eur. J. Clin. Invest. 45 (2015) 692-701

IF: 2.687

II. Krisztina Kiss*, Csaba Csonka*, János Pálóczi, Judit Pipis, Anikó Görbe, Gabriella F Kocsis, Zsolt Murlasits, Márta Sárközy, Gergő Szűcs, Christopher P Holmes, Yijun Pan, Ashok Bhandari, Tamás Csont, Mehrdad Shamloo, Kathryn W Woodburn, Péter Ferdinandy, Péter Bencsik: Novel, selective EPO receptor ligands lacking erythropoietic activity reduce infarct size in acute myocardial infarction in rats, Pharm. Res. 113 (2016) $62-70$

*The authors contributed equally to this work.

IF: 4.816

\section{List of full papers not related to the subject of the Thesis}

I. Krisztina Kiss, Veronika Fekete, János Pálóczi, Márta Sárközy, Zsolt Murlasits, Judit Pipis, Irina A. Kheyfets, Julia L. Dugina, Svetlana A. Sergeeva, Oleg I. Epstein, Csaba Csonka, Tamás Csont, Péter Ferdinandy, Péter Bencsik: Renin-Angiotensin-Aldosterone Signaling Inhibitors-Losartan, Enalapril, and Cardosten-Prevent Infarction-induced Heart Failure Development in Rats, Altern. Ther. Health Med. 22(2) (2016) 10-7

IF: 1.327

II. Brockhoff B, Schreckenberg R, Forst S, Heger J, Bencsik P, Kiss K, Ferdinandy P, Schulz $\mathrm{R}$, Schlüter KD: Effect of nitric oxide deficiency on the pulmonary PTHrP system, J. Cell. Mol. Med. (2016) doi: 10.1111/jcmm.12942 IF: 4.938

Total impact factor: 13.77 [1] 


\section{Table of contents}

List of scientific publications related to the subject of thesis ................................................. 2

List of scientific publications not related to the subject of thesis ........................................... 2

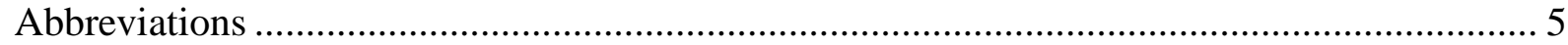

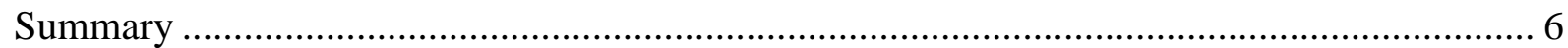

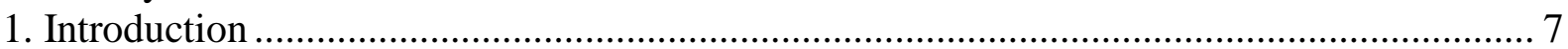

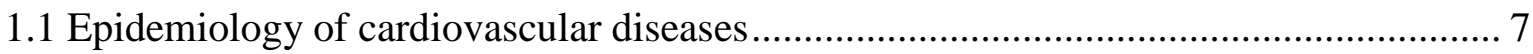

1.2 Pathomechanism of coronary artery disease and myocardial ischemia .......................... 8

1.3 Smoking and dyslipidemia as risk factors in CAD and myocardial ischemia................. 9

1.4 Predictive and diagnostic biomarkers applied clinically in CAD and myocardial

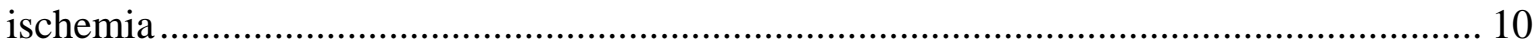

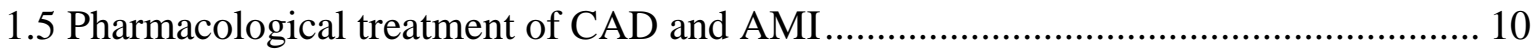

1.6. Signaling pathways for further analysis in CAD and myocardial ischemia................. 11

1.6.1 The role of nitro-oxidative stress in CAD and myocardial ischemia .................. 11

1.6.2 Matrix metalloproteinases in CAD and myocardial ischemia............................ 12

1.6.3 Erythropoietin induced protective pathways in CAD and myocardial ischemia 13

1.6.4 Non-erythropoietic EPO analogues against myocardial ischemia ..................... 14

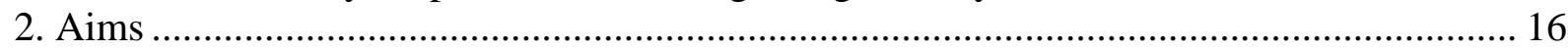

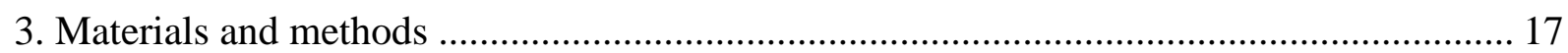

3.1 Characterization of the correlations of $\mathrm{ONOO}^{-}$and MMPs in patients with CAD ....... 17

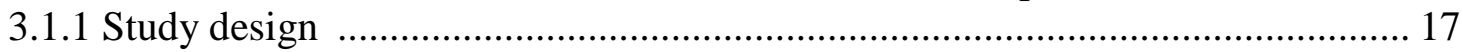

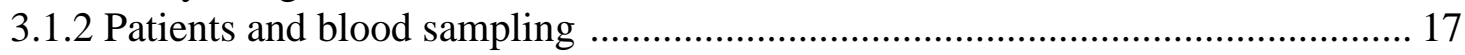

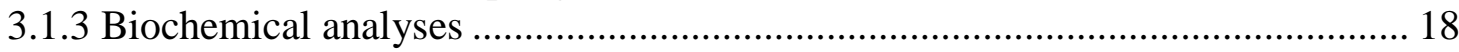

3.1.3.1 Determination of routine laboratory parameters ................................... 18

3.1.3.2 Measurement of MMP-2 and MMP-9 activity by gelatin zymography . 18

3.1.3.3 Measurement of nitrotyrosine in the serum by ELISA ........................... 19

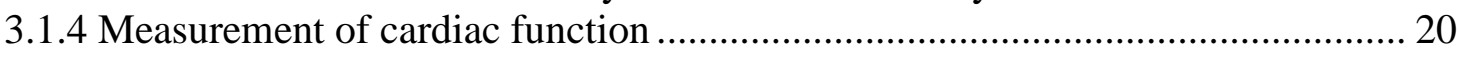

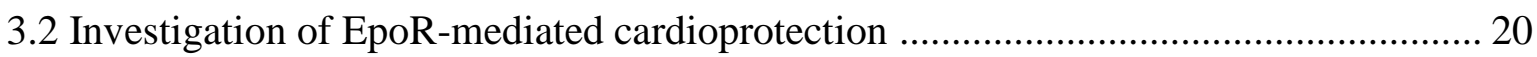

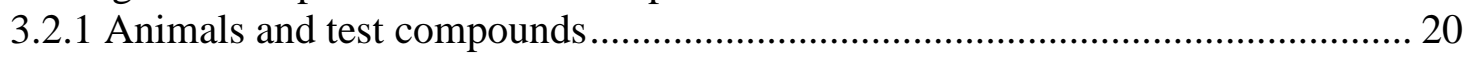

3.2.2 Characterization of non-erythropoietic EPO receptor ligands .......................... 20

3.2.2.1 Structure of non-erythropoietic EPO receptor ligands........................... 21

3.2.2.2 Investigation of erythropoietic activity of test compounds..................... 21

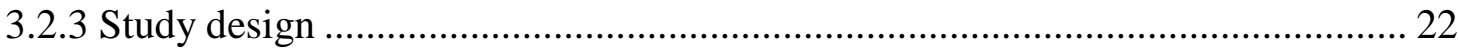

3.2.3.1 Investigation of direct cardio-cytoprotective effect by EPO .................. 22

3.2.3.2 Investigation of myocardial infarct size limiting effect of EPO, Dpa and

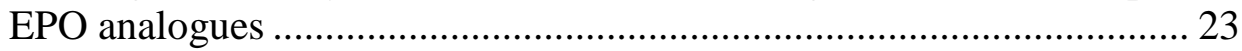

3.2.4 Simulated ischemia/reperfusion in cultured neonatal cardiomyocytes ............... 24

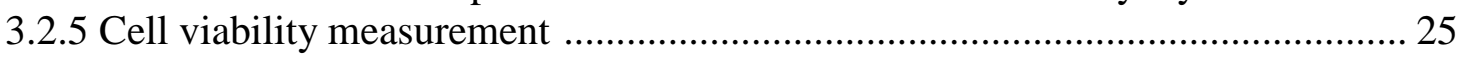

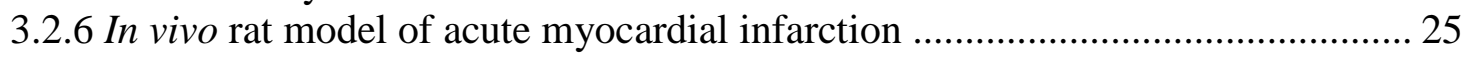

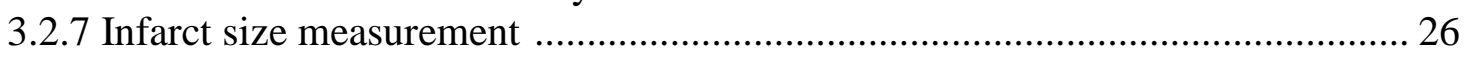

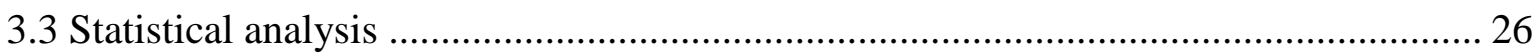

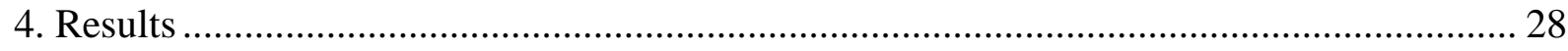

4.1 Characterization of the correlations of $\mathrm{ONOO}^{-}$and MMPs in patients with CAD ....... 28

4.1.1 Correlation between serum nitrotyrosine and MMP-2 or MMP-9 activities ...... 29

4.1.2 Correlation between serum lipids and nitrotyrosine or MMPs activity ............. 29

4.1.3 Correlation between myocardial function and serum nitrotyrosine or MMPs

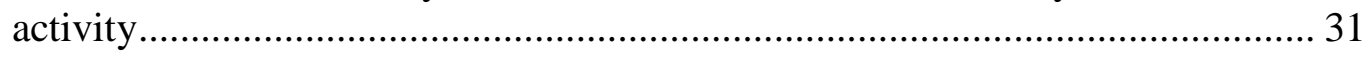

4.1.4 Serum nitrotyrosine or MMPs activity in statin-treated patients....................... 32

4.1.5 Serum nitrotyrosine or MMPs activity in smoking patients............................. 32

4.1.6 Correlation between renal function and serum nitrotyrosine or MMPs activity. 33

4.2 Investigation of EpoR-mediated cardioprotection.................................................... 35 


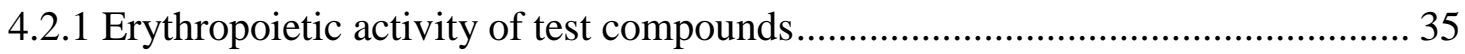

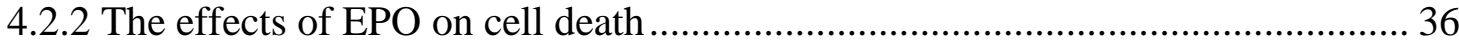

4.2.3 The effects of EPO on infarct size and hemodynamics (Study1)....................... 37

4.2.4 The effects of darbepoetin on infarct size and hemodynamics (Study 2) ........... 39

4.2.5 The effects of AF41676 on infarct size and hemodynamics (Study 3) ................ 40

4.2.6 The effects of AF43136 on blood pressure, survival and infarct size (Study 4). 42

5. Discussion 44

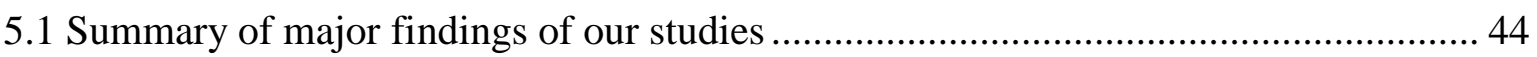

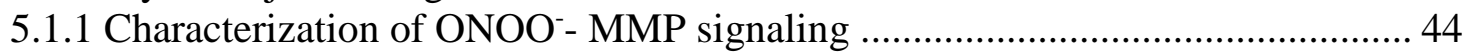

5.1.2 Cardioprotection by two selective non-erythropoietic EPO receptor ligand

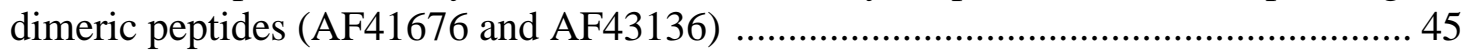

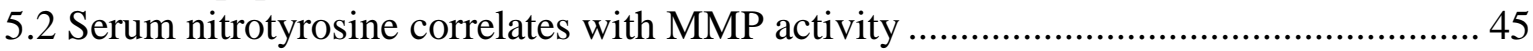

5.3 Serum lipids correlate with nitrotyrosine and MMPs activity........................................ 45

5.4 Myocardial function correlates with serum nitrotyrosine and MMPs activity.............. 46

5.5 Decreased serum nitrotyrosine in statin-treated patients ........................................... 47

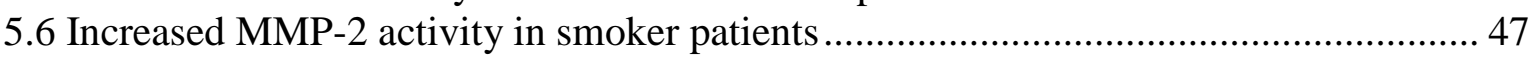

5.7 Renal function correlates with serum nitrotyrosine and MMPs activity ..........................48

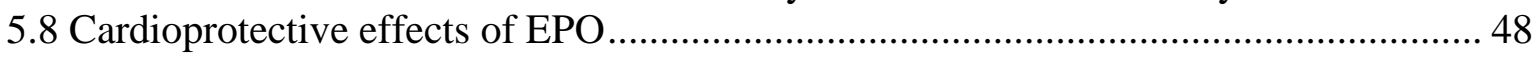

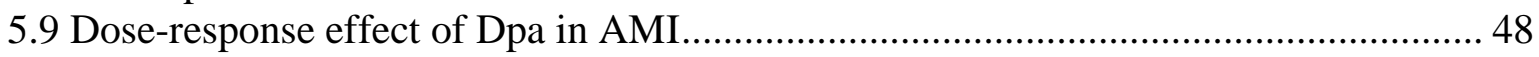

5.10 Cardioprotective effect of AF41676 and AF43136 ...................................................... 49

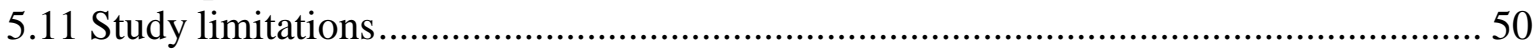

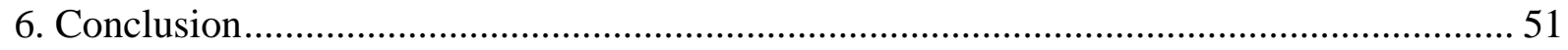

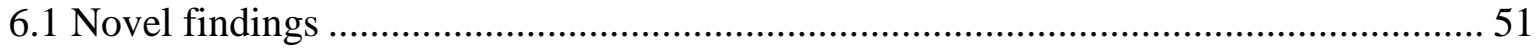

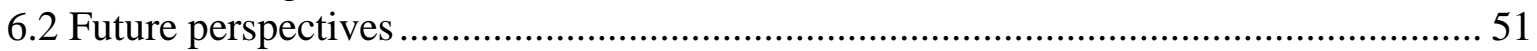

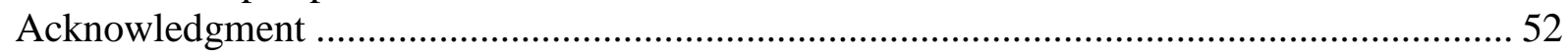

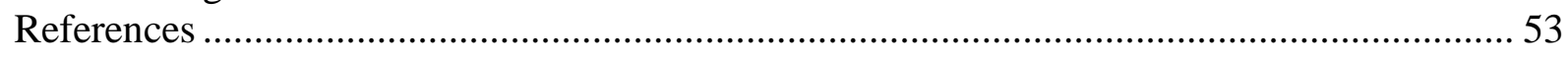

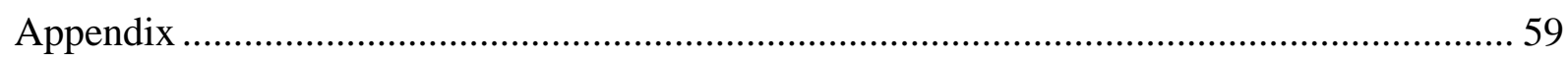




\section{Abbreviations}

AAR

ACEI

AMI

AsialoEpo

ßcR

BFU-E

BNP

BUN

CAD

CEPO

CHD

$\mathrm{CO}_{3}{ }^{-}$

CsA

CVD

Dpa

$\mathrm{EC}_{50}$

ECM

EPO

EpoR

IHD

ip

IS

iv

HDL

HR

LDL

LVEF

MABP

MMP

${ }^{\circ} \mathrm{NO}_{2}$

NT-proBNP

NTyr

NYHA

$\mathrm{OH}^{\circ}$

$\mathrm{ONOO}^{-}$

$\mathrm{ONOOH}$

PCI

PHBSP

SI/ R

SR

STEMI

TTC

TIMP area at risk

angiotensin-converting-enzyme inhibitors

acute myocardial infarction

asialo-erythropoietin

beta common receptor

erythroid blood forming unit

B-type natriuretic peptide

blood urea nitrogen

coronary artery disease

carbamylated erythropoietin

coronary heart disease

carbonate radical

cyclosporine A

cardiovascular disease

darbepoetin alpha

half maximal effective concentration

extracellular matrix

erythropoietin

erythropoietin receptor

ischemic heart disease

intraperitoneal

infarct size

intravenous

high density liporotein

heart rate

low density lipoprotein

left ventricular ejection fractions

mean arterial blood pressure

matrix metalloproteinase

nitrogen dioxide radical

$\mathrm{N}$-terminal pro-brain natriuretic peptide

nitrotyrosine

New York Heart Association

hydroxyl radical

peroxynitrite

peroxynitrous acid

percutan coronary intervention

pyroglutamate helix B surface peptide

simulated ischemia/ reperfusion

survival ratio

ST-segment elevation myocardial infarction

2,3,5-triphenyltetrazolium-chloride

tissue inhibitors of matrix metalloproteinase 


\section{Summary}

In the industrialized world, cardiovascular diseases (CVD) are responsible for almost $50 \%$ of the total cause of death, and among CVD, ischemic heart disease (IHD) represents the highest subpopulation. In spite of huge number of many preclinical and clinical studies, there is still no cardioprotective drug on the market to reduce infarct size in IHD.

In the pathomechanism of myocardial ischemia/reperfusion injury, peroxynitrite(ONOO$\left.{ }^{-}\right)$ - matrix metalloproteinase (MMP) signaling as well as erythropoietin (EPO)-induced cytoprotective pathways have well-established roles. $\mathrm{ONOO}^{-}-\mathrm{MMP}^{-}$pathway is influenced by hyperlipidemia, which is one of the most common comorbidity of IHD. Moreover, in spite of the promising preclinical findings with EPO against acute myocardial infarction (AMI), EPO failed to reduce infarct size in clinical trials and showed significant safety problems.

Therefore, our aims were (i) to obtain novel information on the role of $\mathrm{ONOO}^{-}-\mathrm{MMP}^{-}$ and (ii) EPO receptor- mediated signaling pathways in IHD. Therefore, we investigated i) the correlation of markers of peroxynitrite-MMP signaling with hyperlipidemia and with cardiac function in patients with significant coronary stenosis and ii) the cardioprotective effects of EPO, the prolonged half-life EPO analogue, darbepoetin alpha (Dpa), and two novel selective non-erythropoietic EPO receptor ligand dimeric peptides (AF41676 and AF43136) in a rat model of AMI.

We found in coronary artery disease patients, that serum nitrotyrosine (NTyr), a widely accepted marker of $\mathrm{ONOO}^{-}$generation, positively correlated with MMP-9 activity, but not with MMP-2 activity. NTyr positively correlated with total and LDL cholesterol, serum triglyceride, and creatinine, while it negatively correlated with HDL cholesterol and with left ventricular ejection fraction (LVEF). MMP-2 activity correlated positively with total and LDL cholesterol. In statin-treated patients, a significantly reduced serum NTyr level was found compared to statin-naives; however, MMP activities were not different in statin-treated and in statin-naive patients. MMP-2 activity was significantly increased in smoker patients compared to the non-smokers, while NTyr or MMP-9 activity did not show any difference related to smoking. MMP-9 activity correlated positively with urea nitrogen and negatively with LVEF, respectively. Serum creatinine correlated negatively with LVEF.

In a pilot cell culture study, EPO at $100 \mathrm{U} / \mathrm{mL}$ significantly decreased cell death compared to vehicle in rat neonatal cardiomyocytes subjected to simulated ischemia/reperfusion. In further studies (studies 1-4), in vivo AMI was induced by 30 min coronary occlusion and 120 min reperfusion in male Wistar rats. Test compounds and positive controls (B-type natriuretic peptide, BNP or cyclosporine A, CsA) were administered iv. before the onset of reperfusion. Infarct size (IS) was measured by standard TTC staining. In study 1, $5000 \mathrm{U} / \mathrm{kg}$ EPO reduced infarct size significantly compared to vehicle. In study 2, Dpa showed maximal infarct size-reducing effect at $5 \mu \mathrm{g} / \mathrm{kg}$ compared to the vehicle. In study 3 , in the dose-response curve of AF41676, $3 \mathrm{mg} / \mathrm{kg}$ was the most effective dose compared to the vehicle. The positive control BNP significantly decreased infarct size in studies 1-3 by approximately 35\%. In study 4, AF43136 at $10 \mathrm{mg} / \mathrm{kg}$ decreased infarct size, similarly to the positive control CsA compared to the appropriate vehicle.

We demonstrated for the first time in the literature that (i) serum NTyr correlates with MMP-9 activity, (ii) lipid parameters correlate with NTyr and MMP-2 activity, (iii) myocardial function correlates with creatinine, NTyr and MMP-9 activity, and (iv) creatinine correlates with NTyr and urea nitrogen with MMP-9 activity in patients with CAD. Therefore, studying the biomarkers of peroxynitrite-MMP pathway in large prospective trials may reveal their predictive or diagnostic avails.

Moreover, we proved first time in the literature, that selective, non-erythropoietic EPO receptor ligand dimeric peptides AF41676 and AF43136 administered before reperfusion are able to reduce infarct size in a rat model of AMI. Non-erythropoietic EPO receptor peptide ligands may be promising cardioprotective agents in IHD. 


\section{Introduction}

1.1 Epidemiology of cardiovascular diseases

Cardiovascular diseases (CVD) are still the most common cause of death worldwide, and responsible for approx. $45 \%$ of all death in Europe [2]. It means more than 4 million people across Europe year by year, and a quarter of these deaths (1.4 million people) belong to the premature death, before the age of 75 years (Fig. 1) [2]. Within CVD, coronary heart disease (CHD or coronary artery disease (CAD)) represents the largest component (Fig. 1) [2].

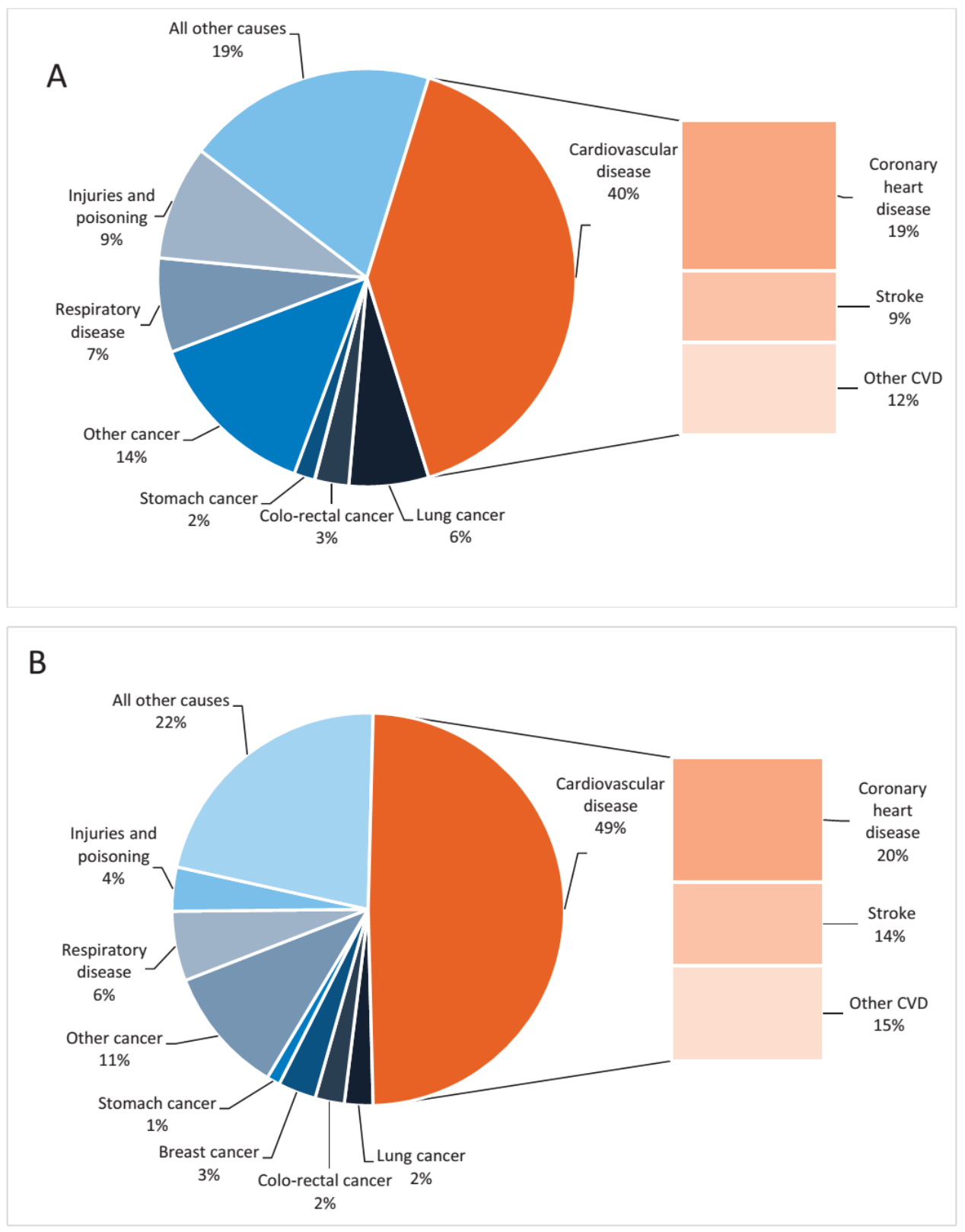

Figure 1. Proportion of all deaths due to major causes in Europe. Last available data (after 2014) in WHO Mortality Database, among men (A) and women (B) [2]. 
Although, the death rate from CHD shows a mild improvement in the last 15 years in most European countries including Hungary (Fig. 2) [3], the epidemiological data above support the relevance of extensive further research in this field.
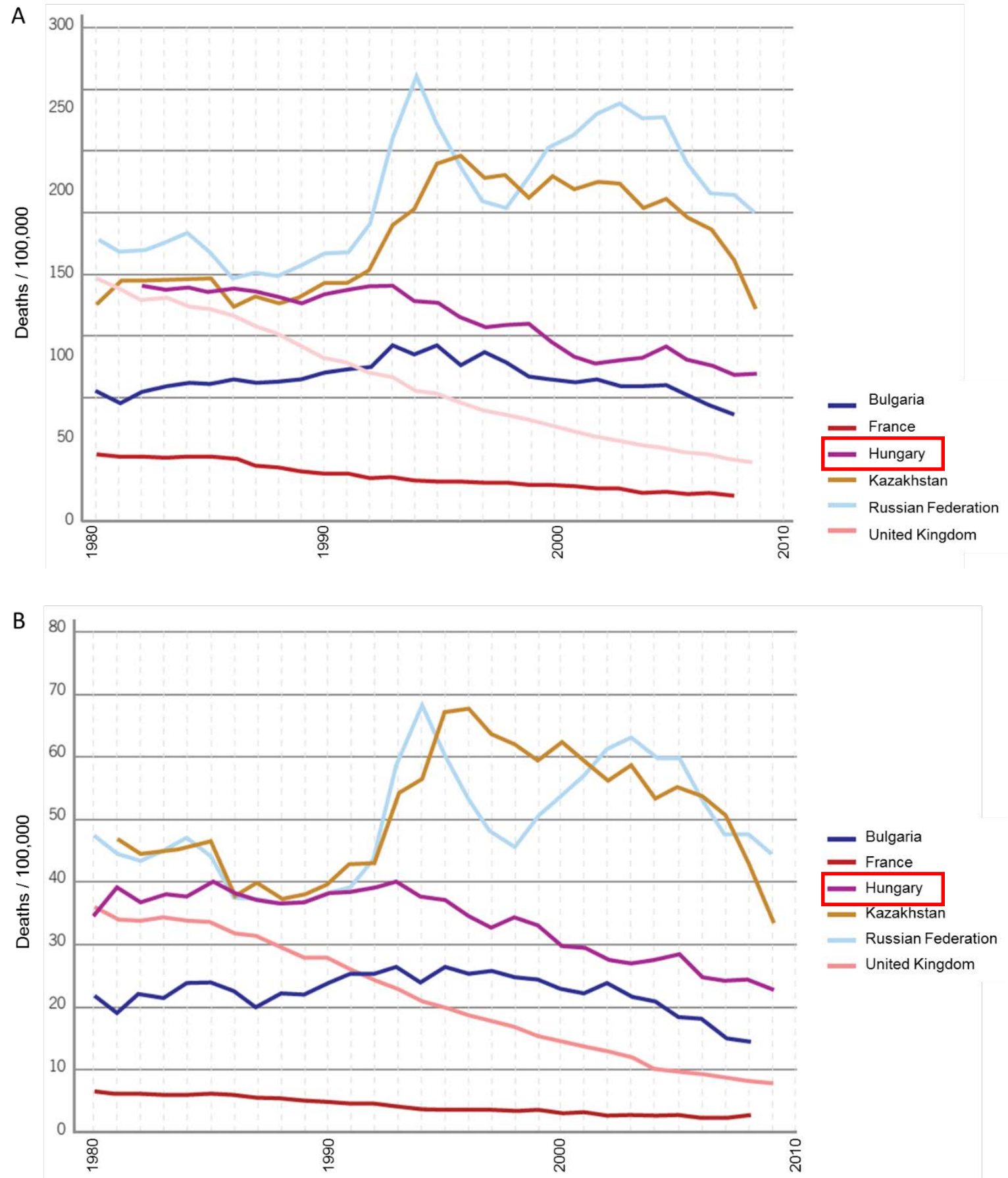

Figure 2. Death rates from CHD. Men (A) and women (B) aged under 65, from 1980 to 2010, selected countries. Hungary is labelled in red frame and with purple line [3].

1.2 Pathomechanism of coronary artery disease and myocardial ischemia

Previously, atherosclerosis and its major consequence, CAD, were considered as cholesterol storage diseases, but recently, they are considered as chronic inflammatory 
diseases [see for review 4]. When the arterial endothelium and risk factors (dyslipidemia, bacterial end products, etc.) coincide, leukocytes attach to the arterial wall and secrete proinflammatory cytokines and matrix metalloproteinases (MMPs) [4]. MMPs destroy the extracellular matrix (ECM) of the artery and components of the ECM bind lipoproteins, and make them more sensitive to oxidation [4]. Oxidized phospholipids contribute to the exacerbation of the inflammatory response [4]. During the progression, calcification may occur and the atherosclerotic plaque with a lipid-rich core is formed [4]. The rupture of coronary atherosclerotic plaques leads to myocardial ischemia or even acute myocardial infarction (AMI) [4]. Besides the novel pathways of the pathomechanism of CAD, there are novel studies investigating other aspects, e.g. microRNAs in coronary disease [5] or the genetic background of CAD [6], whose aim is the personalized medicine in the future [6]. However, further investigation of the known molecules of CAD's pathomechanism has still high relevance to characterize novel prognostic or diagnostic biomarkers and develop new molecules as therapeutic targets in ischemic heart disease (IHD).

1.3 Smoking and dyslipidemia as risk factors in CAD and myocardial ischemia

Beside the complex pathomechanism of CAD, many risk factors (e.g. smoking, inactivity, excess alcohol intake) and comorbidities (e.g. hyperlipidemia, obesity, diabetes mellitus, hypertension, etc.) may influence the clinical appearance of CAD and make the diagnostic or therapeutic possibilities even harder [3, 7].

Smoking remains one of the most important modifiable risk factors for premature mortality. About 20\% of deaths from CVD in men and 3\% in women are due to smoking [3].

Dyslipidemia is a well-characterized risk factor of CVD, which consists of elevated triglyceride and decreased high density lipoprotein (HDL) levels and it is associated with high level of total cholesterol and low density lipoprotein (LDL) [7]. Patients with dyslipidemia have increased risk for CVD [8]. Hyperlipidemia due to enhanced nitro-oxidative stress [9, 10] and deteriorate the endogenous cardioprotective mechanisms, such as ischemic preconditioning $[11,12]$. The contribution of increased nitrotyrosine (NTyr) formation to the development of atherosclerosis and thereby to CAD has been described in patients with hypercholesterolemia-combined CAD [13]. 
1.4 Predictive and diagnostic biomarkers applied clinically in CAD and myocardial ischemia

There are numerous biomarkers used by clinicians in the daily practice [14]. Measurement of lipid parameters (e.g. cholesterol, LDL, HDL, oxidized-LDL) can be used as predictive biomarkers for atherosclerosis development [14]. In case of myocardial necrosis, cardiac troponin T or I, creatine-kinase MB or myoglobin are currently the best available biomarkers of choice for the diagnosis of AMI [14]. In chronic states, e.g. in heart failure, Nterminal pro-brain natriuretic peptide (NT-proBNP) is the most valuable prognostic marker [14].

Despite the large number of the biomarkers, the presence of myocardial ischemia and simultaneously prediction the individual prognosis of AMI is still hard [14]. Therefore, there is an utmost need for seeking further molecules, which can complement the prediction or diagnosis of CAD, e.g. nitrotyrosine or MMPs, which are not established and standardized yet [14]. The correlations between serum nitrotyrosine and MMP-2 and MMP-9 activities are still unknown in patients with CAD. Moreover, the correlation between serum nitrotyrosine, MMPs and lipid levels is not consistent in the literature.

\subsection{Pharmacological treatment of CAD and AMI}

Similarly to the biomarkers, a broad spectrum of pharmacological therapy is available in case of CAD or AMI. Control of risk factors is an essential component of the prevention in CAD including the life-style habits (exercise, diet) or medical possibilities (anti-hypertensive drugs or statins against hyperlipidemia) [4]. In case of AMI, percutan coronary intervention (PCI) is the gold-standard therapy to reduce myocardial infarct size [15]. Guidelines for the medical treatment of patients with AMI include ß-receptor antagonists, angiotensinconverting-enzyme inhibitors (ACEI), statins, nitroglycerin, oxygen or morphine [15]. Moreover, there are novel anti-inflammatory drugs against atherosclerosis, 'the root of all evil', e.g. interleukin-1 $\beta$, P-selectin and 5-lipoxygenase, which mean promising therapy [16].

However, clinicians still do not have an established cardioprotective drug on the market to reduce the size of the infarcted area, attenuate the consequences of myocardial ischemia/reperfusion injury thereby to improve survival and/or the quality of life for AMI patients. Furthermore, because of the high prevalence of CAD (see above) and the diversity of patient's comorbidities, which may strongly influence the pharmacokinetic properties as well as the effects of the potentially cardioprotective drugs, there is an immense demand for the discovery of novel cardioprotective approaches, and for the development of new cardioprotective drug candidates. 
1.6. Signaling pathways for further analysis in CAD and myocardial ischemia

1.6.1 The role of nitro-oxidative stress in CAD and myocardial ischemia

Nitro-oxidative stress plays a pivotal role in the pathomechanism of several cardiovascular diseases including ischemic heart disease [17]. The main effector of nitrooxidative stress is peroxynitrite $\left(\mathrm{ONOO}^{-}\right)$, which is able to form different radicals and contribute to many radical reactions (see details in Fig. 3 d-f-g arrows) [17]. Moreover, $\mathrm{ONOO}^{-}$may activate several enzymes including MMPs via S-nitrosylation/S-glutathiolation of their tyrosine and/or cysteine residues [17, 18] (Fig. 3 b arrow) [17]. Furthermore, peroxynitrite forms nitrotyrosine with free tyrosine residues, which is a widely used marker for peroxynitrite generation [19].

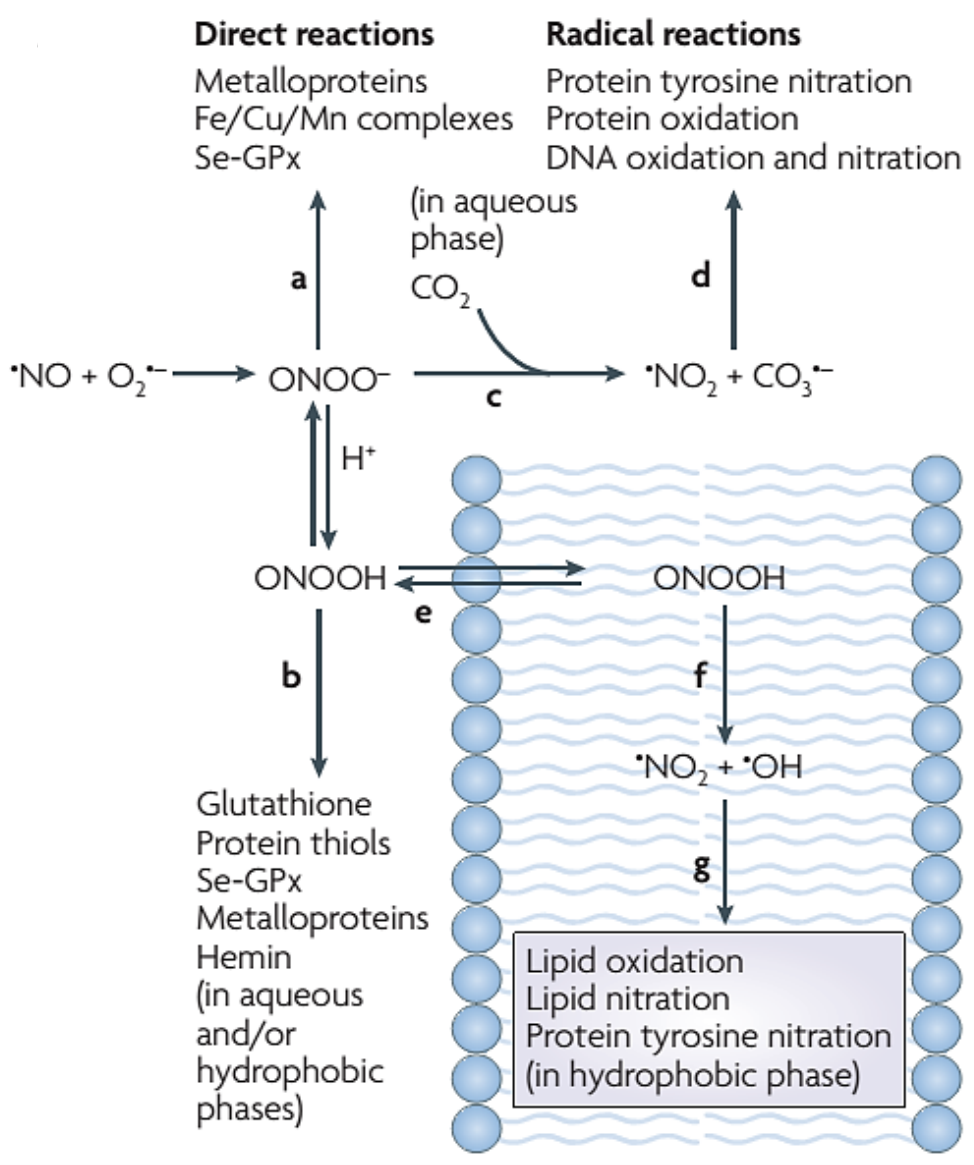

Figure 3. Biochemistry of peroxynitrite: reaction targets and fate. Peroxynitrite anion $\left(\mathrm{ONOO}^{-}\right)$is in equilibrium with peroxynitrous acid $(\mathrm{ONOOH})$ and both of them can undergo direct reactions with biomolecules $(\mathrm{a} ; \mathrm{b})$. $\mathrm{ONOO}^{-}$with carbon dioxide forms carbonate $\left(\mathrm{CO}_{3}{ }^{-}\right)$and nitrogen dioxide ( $\left.{ }^{\circ} \mathrm{NO}_{2}\right)$ radicals (c), which are good oxidants (d), that can readily oxidize amino acids such as cysteine and tyrosine in biological systems. As an alternative pathway, $\mathrm{ONOOH}$ can undergo homolytic fission to generate hydroxyl $\left({ }^{\circ} \mathrm{OH}\right)$ and ${ }^{\circ} \mathrm{NO}_{2}$ radicals (g). However, this reaction is slow in biological systems, and therefore is a modest component of the in vivo reactivity of peroxynitrite in aqueous compartments. However, $\mathrm{ONOOH}$ is able to cross lipid bilayers (f) and ${ }^{\circ} \mathrm{OH}$ and ${ }^{\circ} \mathrm{NO}_{2}$ radicals seems to become relevant in hydrophobic phases to initiate lipid peroxidation and lipid and protein nitration processes (g) [17]. 
1.6.2 Matrix metalloproteinases in CAD and myocardial ischemia

Matrix metalloproteinases are endopeptidases, which were discovered during the degradation of extracellular matrix protein in tadpole tail [20]. The family of MMPs contain approx. 30 members classified according to their major substrates (e.g. collagenases, gelatinases, stomelysins, etc.) [21]. MMPs play a crucial role in the physiology of embryogenesis or angiogenesis, but also have a potent role in the pathology of tumor metastasis or inflammation [see for review 22]. MMPs are major targets of drug and diagnostic development in several pathologies including cardiovascular diseases [21, 23].

The most abundant MMPs in the human myocardium are MMP-2 and MMP-9 (gelatinase A and B), which have been shown to play a crucial role in many cardiovascular diseases, (e.g. atherosclerosis, ischemic heart disease, stroke, or heart failure) [22], especially in myocardial ischemia/reperfusion injury in several animal models [24]. Furthermore, it has been shown that serum MMP-2 predicts infarct size and ventricular dysfunction in ST-segment elevation myocardial infarction (STEMI) patients [25].

The activation of MMP-2 and MMP-9 may occur not only by proteolysis but also due to nitro-oxidative stress, mediated by $\mathrm{ONOO}^{-}$as one of the most potent activator, via posttranslational modification of pro-MMPs and the formation of transcriptional complexes [26, 27] (Fig. 4 [22]).

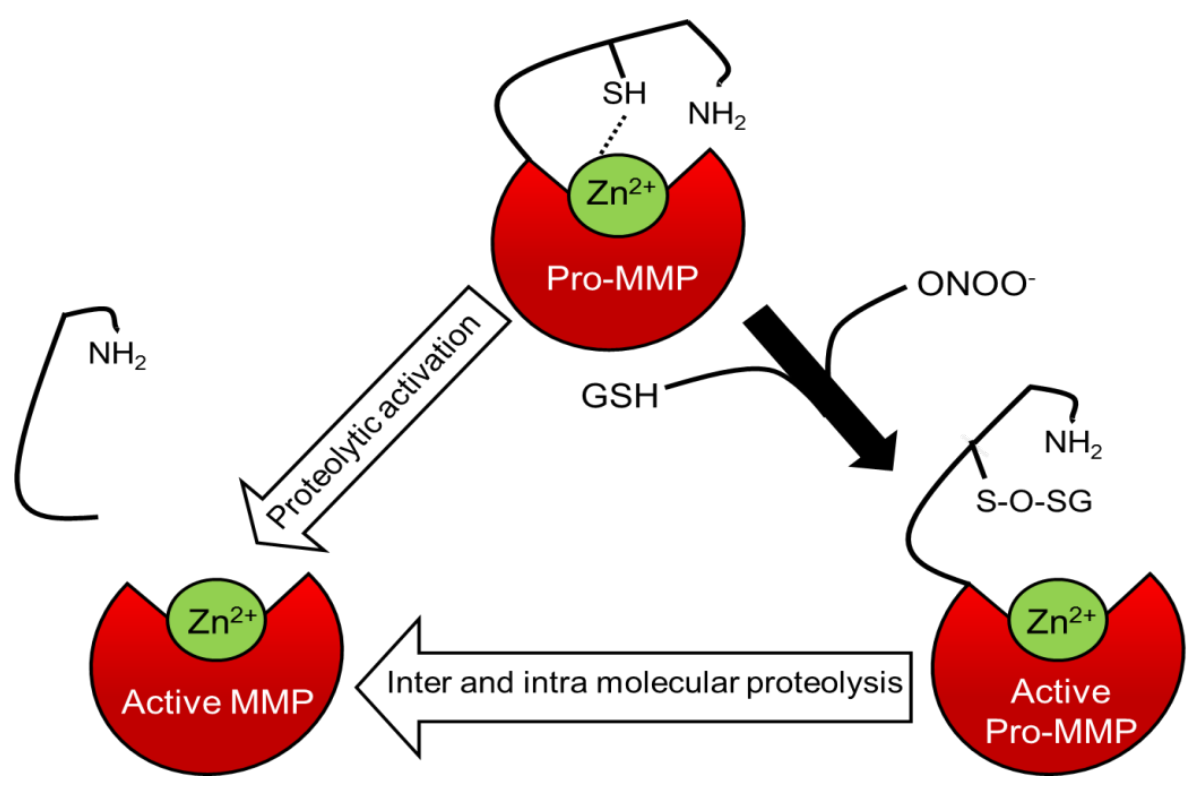

Figure 4. Activation mechanisms of MMPs. The full-length MMP can be activated in two ways. Proteolytic activation of MMP occurs by removal of the autoinhibitory propeptide domain (left arrow) resulting in an active truncated MMP. The simultaneous presence of oxidative stress $\left(\mathrm{ONOO}^{-}\right)$and cellular glutathione $(\mathrm{GSH})$ may lead to S-glutathiolation of the critical cysteine residue in the propeptide domain, disrupting its binding to the catalytic $\mathrm{Zn}^{2+}$ ion, resulting in an active full-length enzyme [22]. 
1.6.3 Erythropoietin induced protective pathways in CAD and myocardial ischemia

Erythropoietin (EPO) and its analogue with prolonged half-life, darbepoetin alpha (Dpa) are the main components of anemia treatment in chronic kidney disease and in cancer patients with anemia [28]. However, EPO is a pleiotropic cytokine, as EPO receptors (EpoR) are expressed in several different tissues (e.g. bone marrow, skeletal muscle, kidney, pancreas, heart, etc. [for review see 29]). It is well known that EPO receptors are present in rat cardiomyocytes [30], and also in human atrial and ventricular cardiomyocytes, as well as in cardiac endothelial cells [31].

Oxidative stress (namely hypoxia via hypoxia-inducible factor family) induces externalization or enhanced expression of EPO receptors and beta-common receptors ( $\mathrm{BcR}$; also known as CD131, which provides increased ligand-binding affinity to the receptor complex) to form the heterocomplex, EpoR-ßcR [32-35]. Via this complex, EPO is able to stimulate protective signaling pathways and reduce apoptosis, inflammation, and thus contributes to tissue repair [32, 34] (Fig. 5).

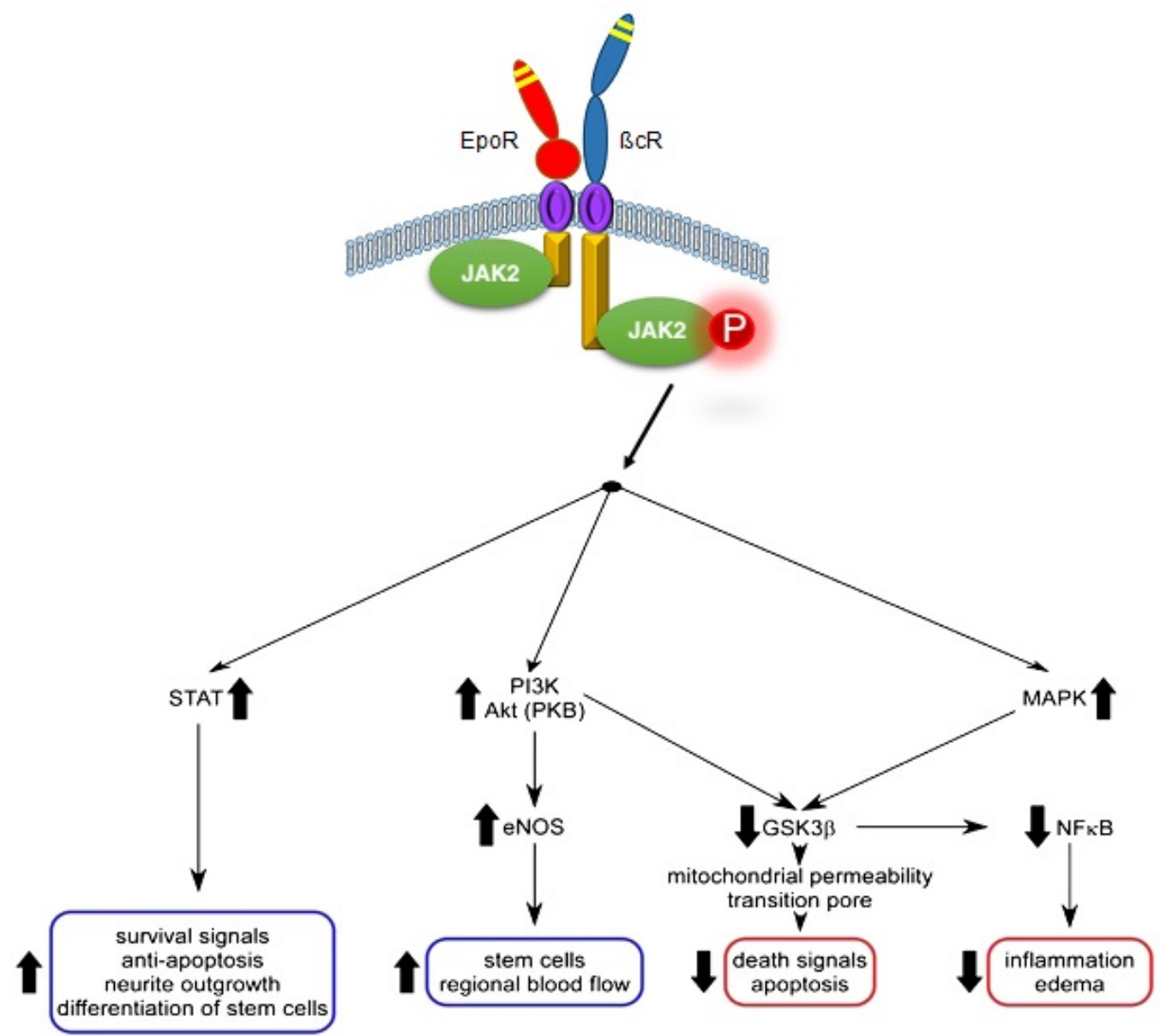

Figure 5. Intracellular signaling pathways in the biological activity of EpoR-ßcR heterocomplex. EpoR-ßcR complex phosphorylate and activate Janus kinase-2 (JAK2). Subsequently, signal transducers and transcription factors, including STAT, Akt, AMPK, 
NFkB and the mitogen-activated protein kinase systems are variably activated depending upon the tissue. Downstream sustained activation in survival, tissue reparative, and antiinflammatory pathways leads to tissue protection and repair [34.]

Therefore, it is highly plausible that EPO or Dpa has the capacity to reduce the effect of the nitro-oxidative stress in the myocardium and protect the heart against acute or chronic myocardial ischemia [29, 36, and 37]. Moreover, EPO reduces the expression of MMP-2 and -9 and simultaneously increases the tissue inhibitors of MMP (TIMPs) level, therefore ameliorates the shifted imbalance of MMP-2/TIMP-2 ratio during ischemia/reperfusion injury [38, 39, and 40]. Thus, EPO is able to attenuate collagen and extracellular matrix degradation in the ischemic heart [38, 39, and 40].

\subsubsection{Non-erythropoietic EPO analogues against myocardial ischemia}

EPO and Dpa were previously shown to decrease myocardial infarct size, prevent myocyte loss and hypertrophy, improve cardiac contractility and ejection fraction, and increase capillary density after transient or permanent coronary artery occlusion in different animal models [41, 42].

Based on the promising results of preclinical experiments with EPO and Dpa for cardioprotection, they were clinically tested against AMI or heart failure. Although, EPO improved left ventricular ejection fraction and New York Heart Association (NYHA) functional class in patients heart failure combined with anemia, Dpa had no effect on myocardial function in this population [43]. In most clinical trials, EPO or Dpa administered before or after percutaneous coronary intervention have failed to reduce infarct size in STEMI patients [29, 44]. This lack of clinical effectiveness likely arises from the immediate hematopoietic activity of EPO analogues. Hematopoiesis is activated by association with homodimeric (i.e. erythropoietic) receptors before erythropoietic EPO analogues would exert their tissue-protective effects via EpoR-ßcR heterocomplex receptors [29]. Thereby, due to enhanced erythropoiesis, high-dose or long-term EPO or Dpa treatments may lead to thrombotic and/or thromboembolic adverse events (e.g. stent thrombosis, stroke, etc.) [29], and increased mortality in ischemic heart disease patients [44-46]. Another synthetic erythropoiesis-stimulating agent, peginesatide is a dimeric peptide without sequence homology to EPO [47]. Peginesatide binds selectively and with high affinity to the EPO receptor [47]. 
Therefore, it is feasible that non-hematopoietic EPO analogues, such as asialoerythropoietin (asialoEpo) or carbamylated EPO (CEPO), may provide EpoR-mediated cardioprotection without concurrent hematopoietic safety issues [29]. These analogues bind to EpoR-ßcR heteroreceptors, but not to the "classical" homodimeric form of EpoR, thereby maintaining their protective effects without stimulating hematopoiesis [29]. In preclinical studies, asialoEpo or CEPO were shown to protect different tissues including myocardium by reducing apoptosis or inducing cardiac neovascularization with less adverse effects on procoagulant/haemopoetic activity [48-51]. However, since the structure of asialoEpo and CEPO mimics the three dimensional structure of EPO, clinical evaluation of potential immunogenicity and long-term stability is warranted [34, 52]. In contrast, a small peptide ligand may attenuate the aforementioned disadvantages (i.e. via reduction in the number of possible epitopes) and may serve as a suitable alternative compound to evoke cardioprotection by binding to EPO receptors. 


\section{Aims}

Therefore, the aims of our present studies were

1) to characterize the correlations of the markers of $\mathrm{ONOO}^{-}-\mathrm{MMP}^{-}$pathway in patients with single-vessel CAD subjected to elective percutaneous coronary intervention via the determination of

- the correlation between serum nitrotyrosine and MMP-2 and MMP-9 activities;

- the correlation of serum lipids (total, LDL and HDL cholesterol; triglyceride) with serum nitrotyrosine as well as with serum MMP-2 and MMP-9 activities, respectively;

- the correlation between serum nitrotyrosine, MMP-2, MMP-9 activities and left ventricular ejection fractions (LVEF) as a marker of cardiac function;

- the difference in serum nitrotyrosine, MMP-2 and MMP-9 activities in statin-naive and statin-treated patients;

- the difference in serum nitrotyrosine, MMP-2 and MMP-9 activities in non-smoker and smoker patients

- further correlations between renal function and nitrotyrosine levels and/or MMP activities.

2) to investigate the EpoR-mediated cardioprotection by testing two novel, selective EPO receptor ligand dimeric peptides (AF41676 and AF43136) in a rat model of AMI by investigating

- the cell-protective effects of EPO in isolated neonatal rat cardiomyocytes

- the infarct size reducing effects of EPO and Dpa in vivo

- the infarct size reducing effects of AF41676 and AF43136 compounds, which are structurally related to the peptide portion of peginesatide, but lacking erythropoietic activity in vivo. 


\section{Materials and methods}

3.1 Characterization of the correlations of $\mathrm{ONOO}^{-}$and MMPs in patients with CAD

\subsubsection{Study design}

Patients with single-vessel CAD subjected to elective PCI were selected. Echocardiographic examinations were performed prior the PCI to measure cardiac function. Blood samples were collected from patients 5 min before PCI to determine routine laboratory parameters, NTyr level and MMPs activities.

\subsubsection{Patients and blood sampling}

The study was approved by the Ethics Committee of the University of Szeged. A written informed consent was obtained from all patients enrolled in the study. The investigations were carried out in consecutive patients with single-vessel coronary disease elected for PCI.

Inclusion criteria were as follows:

1) Class II or III stable angina pectoris by the Canadian Cardiovascular Society grading system.

2) Single-vessel coronary artery disease defined as $\geq 70 \%$ diameter stenosis by visual assessment of the coronary angiogram.

In order to collect a homogenous population, patients with previous myocardial ischemic events, with some remedies or with certain comorbidities had to been exclude from this study. Exclusion criteria were as follows:

1) Angina pectoris or other signs of myocardial ischemia within 1 week before intervention.

2) History of myocardial infarction or baseline ST-segment abnormalities.

3) Severe left ventricular dysfunction (<35\% LVEF or NYHA functional circulatory stages III-IV).

4) Lown 3-4 ventricular arrhythmias before the intervention.

5) Angiographically visible collateral vessels interfering with the treated coronary artery.

6) Treatment with ATP-sensitive potassium channel inhibitors.

7) Serum electrolytes out of the physiologic range.

8) Serum creatinine level $>150 \mu \mathrm{mol} / \mathrm{L}$. 
9) Hypothyroidism.

According to inclusion and exclusion criteria, 36 patients were enrolled into this study. PCI was performed using the standard femoral approach in all patients after premedication with $100 \mathrm{mg}$ of aspirin and $75 \mathrm{mg}$ of clopidogrel once a day for 2 days prior to PCI.

Blood samples were collected from patients 5 min before the percutaneous coronary intervention from femoral artery. Blood samples were used immediately to determine the routine laboratory parameters. Additional blood samples were centrifuged at $1000 \mathrm{~g}$ for 15 min, at $4^{\circ} \mathrm{C}$, and then, serum samples were collected into polypropylene microcentrifuge tubes and stored at $-20^{\circ} \mathrm{C}$ until the performance of nitrotyrosine and MMP-2, MMP-9 activity measurements.

\subsubsection{Biochemical analyses}

\subsubsection{Determination of routine laboratory parameters}

Serum levels of total, LDL and HDL cholesterol, triglyceride, and creatinine and urea nitrogen (BUN) were quantitated by enzymatic methods (Institute of Laboratory Medicine, University of Szeged, Szeged, Hungary) on a Roche Hitachi Modular P800 automated analyzers (Roche Diagnostics, Indianapolis, IN, USA).

\subsubsection{Measurement of MMP-2 and MMP-9 activity by gelatin zymography}

To measure circulatory MMP-2 and MMP-9 activities, gelatin zymography was performed from serum samples (for a representative zymogram see Fig. 6). Gelatinolytic activities of MMPs were examined as previously described [53]. 8\% polyacrylamide gels were copolymerized with gelatin ( $2 \mathrm{mg} / \mathrm{mL}$, type A from porcine skin; Sigma-Aldrich, Budapest, Hungary), and $40 \mu \mathrm{g}$ of protein per lane was loaded. An internal standard (American Type Culture Collection, Manassas, VA, USA) was loaded into each gel to normalize activities between gels. After electrophoresis $(150 \mathrm{~V}, 1.5 \mathrm{~h})$, gels were washed with $2.5 \%$ Triton $\mathrm{X}-100$ for $3 \times 15 \mathrm{~min}$ and incubated for $20 \mathrm{~h}$ at $37^{\circ} \mathrm{C}$ in incubation buffer $(50 \mathrm{mM}$ Tris-HCl, $150 \mathrm{mM} \mathrm{NaCl}, 5 \mathrm{mM} \mathrm{CaCl} 2$ and $0.05 \% \mathrm{NaN}_{3}, \mathrm{pH}$ 7.4). Gels were then stained with $0.05 \%$ Coomassie brilliant blue (G-250; Sigma-Aldrich) in a mixture of methanol-acetic acid-water [2.5:1:6.5 ( $\mathrm{vol} / \mathrm{vol})]$ and destained in aqueous $4 \%$ methanol- $8 \%$ acetic acid (vol/vol). For positive controls, gelatinase zymography standard containing human MMP-2 and MMP-9 (Cat. No.: CC73, Chemicon Europe Ltd., South-ampton, UK) and MMP-2 
standard (Cat. No.: CC071; Chemicon Europe Ltd.) were used. For negative control, lanes containing serum samples were cut off after renaturation of the gel and were separately incubated for $20 \mathrm{~h}$ at $37^{\circ} \mathrm{C}$ in development buffer in the presence of the calcium chelator EGTA (ethylene glycol-bis (2-aminoethylether)-N, N, N', N'-tetraacetic acid; $10 \mathrm{mM}$ ). Gelatinolytic activities were detected as transparent bands against the dark-blue background. Band intensities were quantified, expressed as the ratio to the internal standard and presented in arbitrary units.

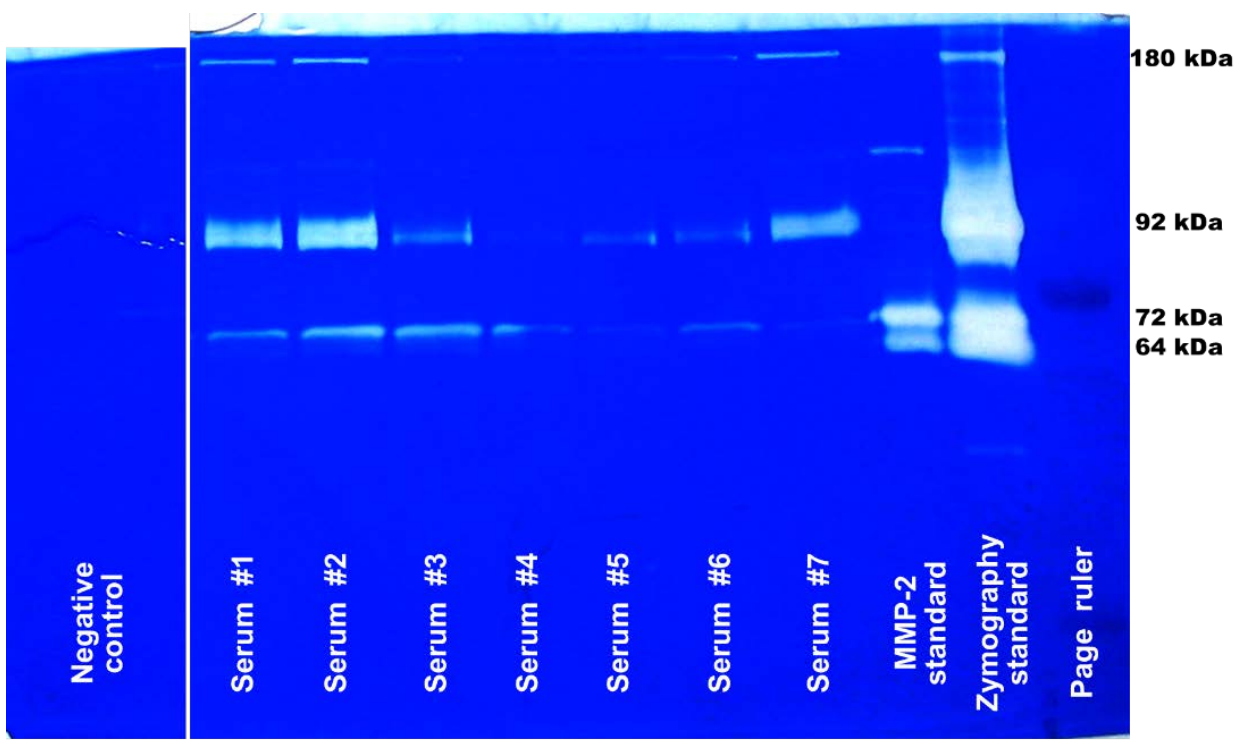

Figure 6. Representative gelatin zymogram from serum samples of CAD patients.

\subsubsection{Measurement of nitrotyrosine in the serum by ELISA}

To estimate systemic peroxynitrite formation, we have measured free nitrotyrosine by ELISA in serum samples as previously described $[54,55]$. Serum samples were deproteinized by addition of four volumes of ice-cold ethanol. After centrifugation, supernatants were separated and evaporated under nitrogen flow, and then, they were dissolved in phosphate buffer. Deproteinized sera were incubated overnight with anti-nitrotyrosine rabbit IgG and nitrotyrosine acetylcholinesterase tracer in precoated (mouse anti-rabbit IgG) microplates followed by development with Ellman's reagent. Serum nitrotyrosine levels were expressed in $\mathrm{ng} / \mathrm{mL}$. 


\subsubsection{Measurement of cardiac function}

Prior to PCI, echocardiographic examinations were performed on a GE Vivid 3 cardiac ultrasound device (GE Healthcare, Milwaukee, WI, USA), and data were digitally recorded. Images were acquired using a 3.5-MHz transducer. Images and video records were obtained in standard apical and parasternal two- and four-chamber views. To assess LVEF, calculations were performed according to recommendations for chamber quantification in consensus. LVEF was calculated using Simpson's method (LVEF= (end diastolic volume - end systolic volume)/ end diastolic volume×100).

\subsection{Investigation of EpoR-mediated cardioprotection}

The investigation conforms to the Guide for the care and use of laboratory animals published by the US National Institutes of Health (NIH publication No. 85-23, revised 1996) and was approved by the Ethics Committee at the University of Szeged and, when necessary, the Affymax Institutional Animal Care and Use Committee.

\subsubsection{Animals and test compounds}

Male Wistar rats (225-370 g) (purchased from Toxi-Coop Toxicological Research Center Zrt., Dunakeszi, Hungary and Charles-River, Budapest, Hungary) were housed in a room maintained at $12 \mathrm{~h}$ light-dark cycles and at a constant temperature of $22 \pm 2{ }^{\circ} \mathrm{C}$. The animals had free access to standard laboratory chow and drinking water.

Test compounds (including acetate vehicle) were synthetized and provided by Affymax Inc. except for Erythropoietin (Procrit ${ }^{\circledR}$, Amgen, Inc., Thousand Oaks, CA), Darbepoetin alpha (Aranesp ${ }^{\circledR}$, Amgen Europe b.v., ZK Breda, The Netherlands), B-type natriuretic peptide (BNP; Sigma-Aldrich, Budapest, Hungary) and cyclosporine A (CsA; Sandimmun $\operatorname{Neoral}{ }^{\circledR}$, Novartis Hungária Budapest, Hungary). Acetate vehicle consisted of $40 \mathrm{mM}$ acetate and $4.3 \%$ sorbitol, $\mathrm{pH} 5.0$.

\subsubsection{Characterization of non-erythropoietic EPO receptor ligands}

Two selective EPO receptor ligand dimeric peptides, AF41676 and AF43136 were developed and analyzed in preliminary experiments by Affymax Inc. The analysis of the two test compounds consisted of the determination of amino acid sequence, receptor binding assay and erythroid colony assay in vitro, and investigation of the erythropoietic activity in vivo. 


\subsubsection{Structure of non-erythropoietic EPO receptor ligands}

AF41676 and AF43136 were synthetized by Affymax Inc. as their acetate salts using a combination of solid phase peptide techniques to prepare the individual peptide chains followed by solution phase conjugation to the bifunctional linkers. The peptides were purified by reverse-phase preparative chromatography and characterized by mass spectrometry. Their erythropoietic activity has been significantly reduced by key amino acid substitutions. The amino acid sequence of AF41676 is (AcYACHYGPITNalVCQPPK) 2 -IDA (SS: C3-C12) and the amino acid sequence of AF43136 is (AcLYLCRYGRVHNalECQPLRK)2-DIG (SS:C4C13). Nal is 1-naphthylamine. Peptide dimer linkers are iminodiacetic acid (IDA) and 1,1'[oxybis[(1-oxo-2,1-ethanediyl)oxy]]bis-2,5-pyrrolidinedione (DIG), and the parentheses indicate two cyclic peptide chains linked to their respective linkers via the epsilon amine on the side chain of lysine.

\subsubsection{Investigation of erythropoietic activity of test compounds}

To investigate EPO receptor binding ability of EPO, Dpa, AF41676 and AF43136, competition binding assay was carried out by Affymax Inc. by incubating 100 pg of HuEpoRFc (R\&D Systems) with serial dilutions of competitor and 20,000 cpm ${ }^{125}$ I EPO, followed by incubation, addition of Protein G beads, washing, and counting, using conditions based on a method for the detection of anti-EPO antibodies [56]. The specificity of the binding properties of EPO, Dpa, AF41676, and AF43136 were evaluated by MDS Pharma Services (Taipei, Taiwan) in a screen of 66 diverse receptors, including both homo- and heterodimeric EPO receptors (LeadProfilingScreen).

To investigate the erythroid colony formation ability of EPO, Dpa, AF41676 and AF43136, erythroid colony assay was performed as described previously [57]. Human CD34 ${ }^{+}$ cells (Cambrex, Walkersville, MD, USA) were resuspended at 15,000 cells/mL in Iscove's Modified Dulbecco's Medium (IMDM) with 10\% FBS. EPO, Dpa, AF41676 and AF43136 were added to a methylcellulose-based colony assay media (MethoCult GF H4534, StemCell Technologies, and Vancouver, BC, Canada) supplemented with rhSCF, rhGM-CSF, and rhIL3. Cells were added to the methylcellulose and plated with subsequent incubation at $37^{\circ} \mathrm{C}$, in a $5 \% \mathrm{CO}_{2}$ incubator for 12-14 days. Colonies containing over 50 cells were counted by phase-contrast microscopy.

To evaluate erythropoiesis stimulating effect, EPO, Dpa, AF41676 and AF43136 were examined for their potential to induce reticulocytosis in normocythemic male Sprague- 
Dawley rats $(n=4)$. Colleagues at Affymax Inc. administered a single intravenous (iv.) dose of EPO at $5000 \mathrm{U} / \mathrm{kg}$, Dpa at $10 \mu \mathrm{g} / \mathrm{kg}, \mathrm{AF} 41676$ at $10 \mathrm{mg} / \mathrm{kg}$, and AF43136 at $10 \mathrm{mg} / \mathrm{kg}$ and acetate vehicle $(5 \mathrm{~mL} / \mathrm{kg})$ via the tail vein, respectively. Blood $(0.5 \mathrm{~mL})$ was collected for determination of reticulocyte number by retroorbital puncture of metoxyflurane-anesthetized rats into EDTA-containing tubes at baseline (pre-dose) and 5 days following administration as described previously [57].

\subsubsection{Study design}

We investigated the cell-protective effect of EPO on isolated neonatal rat cardiomyocytes subjected to simulated ischemia/ reperfusion injury (SI/R) (Table 1). Then, in 4 separate studies, we tested the infarct size reducing effect of EPO, Dpa and EPO-analogues (AF41676 and AF43136 compounds) in an in vivo rat model of AMI (Table 1).

\subsubsection{Investigation of direct cardio-cytoprotective effect by EPO}

To determine the direct, non-erythropoietic effect of EPO on cardiomyocytes, we tested different doses of $\operatorname{EPO}(1,10,100,500 \mathrm{U} / \mathrm{mL})$ on neonatal rat cardiomyocyte cell culture subjected to 150 min simulated ischemia followed by 120 min simulated reperfusion. BNP at $10^{-8} \mathrm{M}$ was used as the positive control. Cell death was compared to acetate vehicle-treated cells (Table 1). 


\begin{tabular}{|c|c|c|c|c|c|c|c|c|}
\hline \multicolumn{2}{|c|}{ Model } & Protocol & $\mathrm{n}$ & \multicolumn{4}{|c|}{ Experimental groups } & $\begin{array}{l}\text { End } \\
\text { points }\end{array}$ \\
\hline \multirow{2}{*}{\multicolumn{2}{|c|}{$\begin{array}{l}\text { In vitro } \\
\mathrm{SI} / \mathrm{R}\end{array}$}} & \multirow{2}{*}{$\begin{array}{l}150 \mathrm{~min} \\
\mathrm{SI} / \\
120 \mathrm{~min} \\
\mathrm{R}\end{array}$} & \multirow[b]{2}{*}{$7-8$} & \multirow{2}{*}{$\begin{array}{c}\text { negative } \\
\text { controls } \\
\\
\text { acetate } \\
\text { vehicle }\end{array}$} & \multirow{2}{*}{$\begin{array}{c}\text { positive } \\
\text { controls } \\
\text { BNP 10-8 M }\end{array}$} & \multicolumn{2}{|c|}{$\begin{array}{l}\text { test compounds \& } \\
\text { applied doses }\end{array}$} & \multirow[b]{2}{*}{$\begin{array}{c}\text { cell } \\
\text { viability }\end{array}$} \\
\hline & & & & & & $\begin{array}{c}\text { EPO } \\
(\mathrm{U} / \mathrm{mL})\end{array}$ & $\begin{array}{r}1 \\
10 \\
100\end{array}$ & \\
\hline \multirow{4}{*}{ 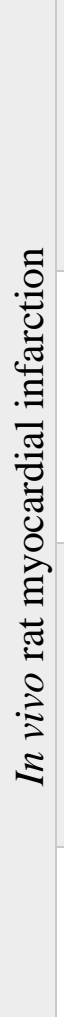 } & $\begin{array}{c}\text { Study } \\
1\end{array}$ & \multirow{4}{*}{ 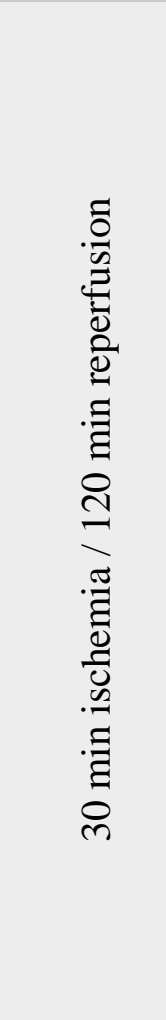 } & $\begin{array}{l}9- \\
11\end{array}$ & $\begin{array}{l}\text { acetate } \\
\text { vehicle }\end{array}$ & $\begin{array}{c}\text { BNP } \\
10 \mathrm{nmol} / \mathrm{kg} \\
\text { bolus } \\
+2 \\
\mathrm{nmol} / \mathrm{kg} / \mathrm{min}\end{array}$ & $\begin{array}{c}\text { EPO } \\
(\mathrm{U} / \mathrm{kg})\end{array}$ & $\begin{array}{l}5000 \\
\text { ip } \\
\text { iv }\end{array}$ & \multirow{4}{*}{ 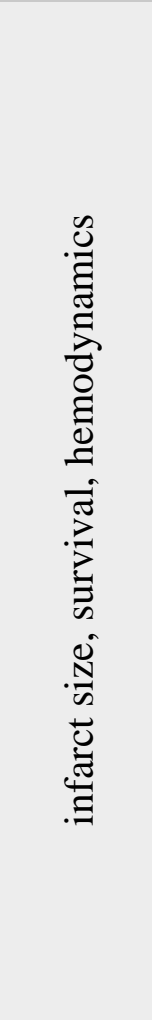 } \\
\hline & $\begin{array}{c}\text { Study } \\
2\end{array}$ & & $\begin{array}{l}8- \\
11\end{array}$ & $\begin{array}{l}\text { acetate } \\
\text { vehicle }\end{array}$ & $\begin{array}{c}\text { BNP } \\
10 \mathrm{nmol} / \mathrm{kg} \\
\text { bolus } \\
+2 \\
\mathrm{nmol} / \mathrm{kg} / \mathrm{min}\end{array}$ & $\begin{array}{c}\text { Dpa } \\
(\mu g / k g)\end{array}$ & $\begin{array}{l}2.5 \\
5 \\
15 \\
25\end{array}$ & \\
\hline & $\begin{array}{c}\text { Study } \\
3\end{array}$ & & $\begin{array}{l}8- \\
13\end{array}$ & $\begin{array}{l}\text { acetate } \\
\text { vehicle }\end{array}$ & $\begin{array}{c}\text { BNP } \\
10 \mathrm{nmol} / \mathrm{kg} \\
\text { bolus } \\
+2 \\
\mathrm{nmol} / \mathrm{kg} / \mathrm{min}\end{array}$ & $\begin{array}{c}\text { AF41676 } \\
(\mathrm{mg} / \mathrm{kg})\end{array}$ & $\begin{array}{l}0.3 \\
1 \\
3 \\
10 \\
30\end{array}$ & \\
\hline & $\begin{array}{c}\text { Study } \\
\quad 4\end{array}$ & & $\begin{array}{l}8- \\
10\end{array}$ & $\begin{array}{l}\text { saline, } \\
\text { acetate } \\
\text { vehicle }\end{array}$ & $\begin{array}{c}\text { CsA } \\
10 \mathrm{mg} / \mathrm{kg}\end{array}$ & $\begin{array}{c}\text { AF43136 } \\
\text { (mg/kg) }\end{array}$ & $\begin{array}{l}10 \\
30\end{array}$ & \\
\hline
\end{tabular}

Table 1. Study design. n: sample size/ group; SI/R: simulated ischemia/ simulated reperfusion; BNP: B-type natriuretic peptide; EPO: Erythropoietin; Dpa: darbepoetin alpha; CsA: cyclosporine A; iv: intravenous; ip: intraperitoneal

3.2.3.2 Investigation of myocardial infarct size limiting effect of EPO, Dpa and EPO analogues

In a further series of in vivo studies (studies 1-4, see below), animals were randomly assigned to the different experimental groups with a total number of 8-13 animals per group. Each test compound was administered before the onset of reperfusion (Table 1). During the individual studies, all-cause mortality was registered to compare the survival among the controls and the drug-treated groups.

Study 1: We have administered EPO at $5000 \mathrm{U} / \mathrm{kg}$ [used successfully for cardioprotection several times in the literature; for review see [58] bolus injection 5 min before the onset of 
reperfusion intraperitoneally (ip) or intravenously (iv) to compare different ways of administration. Positive control BNP was administered iv. at $10 \mathrm{nmol} / \mathrm{kg}$ bolus +2 $\mathrm{nmol} / \mathrm{kg} / \mathrm{min}$ infusions for $15 \mathrm{~min}$ starting at the $25^{\text {th }}$ min of ischemia. This dose was derived from a previous publication where $10 \mathrm{nM}$ BNP was cardioprotective ex vivo [59], and due to its short half-life [60] a maintenance infusion (2 nmol/ $\mathrm{kg} / \mathrm{min})$ was applied in our in vivo model. The vehicle was used as the negative control and comprised $40 \mathrm{mM}$ acetate with $4.3 \%$ sorbitol, pH 5.0 and was administered iv. 5 min before the onset of reperfusion.

Study 2: To investigate the dose dependence of the EPO analogue, darbepoetin (Dpa) was administered at the $15^{\text {th }}$ min of ischemia, in 2.5, 5, 15 and $25 \mu \mathrm{g} / \mathrm{kg}$ boluses administered iv. The positive control BNP and the negative control acetate vehicle were administered identically to Study 1 . The reason for Dpa administration 10 min earlier than EPO (i.e. at the $15^{\text {th }}$ min of ischemia) was its prolonged half-life.

Study 3: Dose dependence of AF41676 was tested at 0.3, 1, 3, 10 and $20 \mathrm{mg} / \mathrm{kg}$ doses administered as iv. bolus injection 5 min before the onset of reperfusion. Negative control acetate vehicle was administered accordingly to Study 1.

Study 4: In an exploratory study, we tested AF43136, a slightly modified version of AF41676 (see above for structural differences) in two doses in order to monitor potential hypotensive effects, which have occurred previously with EPO analogues. AF43136 was administered at 10 and $30 \mathrm{mg} / \mathrm{kg}$ doses iv. as a bolus infusion for 5 min starting at the $25^{\text {th }}$ min of ischemia at a final volume load of $6 \mathrm{~mL} / \mathrm{kg}$ due to the high concentration being administered (30 mg/kg). Saline and the positive control CsA (10 mg/kg, diluted in saline) were administered iv. as a bolus infusion for 5 min starting at the $25^{\text {th }}$ min of ischemia at a final volume load of $1 \mathrm{~mL} / \mathrm{kg}$. Acetate vehicle was administered same as test compounds at a final volume load of $6 \mathrm{~mL} / \mathrm{kg}$.

\subsubsection{Simulated ischemia/reperfusion in cultured neonatal cardiomyocytes}

Neonatal cardiomyocyte isolation and culture method was described previously [61, 62]. Newborn Wistar rats were disinfected with $70 \%$ ethanol and sacrificed by cervical dislocation. Hearts were excised and transferred to cold, sterile phosphate buffered saline (PBS) $\mathrm{pH}$ 7.2. Ventricles were separated from atria, minced gently with sterile forceps and collected in $0.25 \%$ trypsin solution (Invitrogen, Life Technologies Hungary Ltd., Budapest, Hungary). At the end of digestion, cell suspension was centrifuged for $15 \mathrm{~min}$ at $2000 \mathrm{rpm}$ at $4^{\circ} \mathrm{C}$, supernatant was removed gently and the pellet was re-suspended in complete growth 
medium and plated onto 6-well plates to eliminate fibroblasts (pre-plating). Supernatants were collected in fresh Falcon tubes and cells were counted manually in a Burker chamber. Then cells of the supernatant were re-plated into 24-well fresh plates: $10^{5}$ cells/well supplemented with $1 \mathrm{~mL}$ growth medium and incubated under normoxic conditions $\left(37^{\circ} \mathrm{C}\right.$, in $95 \%$ air and $5 \% \mathrm{CO}_{2}$ gas mixture) in a standard $\mathrm{CO}_{2}$ incubator. Growth medium was changed the following day. Cultures were used for treatment at the 3-day-old stage. The simulated ischemic group was treated during the experimental protocol using a combination of hypoxic chamber and hypoxic solution [62] to simulate tissue ischemia. In treated groups, EPO $(1,10$, $100,500 \mathrm{U} / \mathrm{mL})$ and BNP $\left(10^{-8} \mathrm{M}\right)$ or acetate vehicle were administered into the hypoxic solution and plates were kept in a hypoxic chamber (gassed with $95 \% \mathrm{~N}_{2}$ and $5 \% \mathrm{CO}_{2}$ at $37^{\circ} \mathrm{C}$ ) for $150 \mathrm{~min}$. Following treatments, $120 \mathrm{~min}$ of simulated reperfusion was applied in growing medium (mixed with treating compounds) and the plates were kept in a normoxic incubator.

\subsubsection{Cell viability measurement}

At the end of the experiments, viability tests were performed in all groups with trypan blue staining after simulated reperfusion. Treating solutions were removed and cells were detached with trypsin. Single cell suspensions were collected into Eppendorf tubes and centrifuged at $2000 \mathrm{rpm}$ for $15 \mathrm{~min}$ at $4^{\circ} \mathrm{C}$. Supernatants were removed and the pellets were re-suspended in $50 \mu \mathrm{L}$ PBS solution and mixed with $50 \mu \mathrm{L} 0.4 \%$ trypan blue and incubated for $5 \mathrm{~min}$. Cells were counted in a Burker chamber and the ratio of dead (blue) cells to total cell count was calculated and plotted.

\subsubsection{In vivo rat model of acute myocardial infarction}

Myocardial infarction in rats was described previously [63]. Rats were anesthetized by intraperitoneal injection of pentobarbital (Euthasol, Produlab Pharma b.v., Raamsdonksveer, The Netherlands; $60 \mathrm{mg} / \mathrm{kg}$ bolus dose followed by $15-20 \mathrm{mg} / \mathrm{kg}$ when required during the experiment). The rats were weighed and stomach and chest area shaved. Body temperature was maintained using a constant-temperature heating pad. The trachea was intubated with a cannula connected to a rodent ventilator. The animals were ventilated with room air (6.2 $\mathrm{mL} / \mathrm{kg}, 70 \pm 5$ breath/min). Blood pressure, surface-lead ECG, and body core temperature were monitored throughout the experiments to ensure the stability of the preparation (Haemosys data acquisition system, Experimetria, Budapest, Hungary), while hemodynamic 
data were collected at baseline, $29^{\text {th }}$ min of ischemia and $120^{\text {th }}$ min of reperfusion. The right carotid artery was cannulated for measurement of blood pressure and the right femoral vein was cannulated for the administration of the test compounds. A thoracotomy was performed at the $5^{\text {th }}$ inter-costal space and the heart was exposed through the fifth intercostal space. The pericardium was incised and a 5-0 Prolene suture was placed around the left descending coronary artery. The coronary artery was then occluded for $30 \mathrm{~min}$ by placing the ligature through a small piece of plastic tubing and pulling the snare tightly in place using a hemostat. After 30 min of coronary occlusion, reperfusion was initiated by releasing the snare and then continued for $120 \mathrm{~min}$. All-cause mortality was monitored throughout the entire study, i.e. from the anesthesia to the end of reperfusion. The cause of death was determined as follows: irreversible ventricular arrhythmias or hypotension.

\subsubsection{Infarct size measurement}

At the end of the 120 min reperfusion, the heart was excised and infarct size was determined [64]. The left anterior descending coronary artery was re-occluded and the heart was perfused with $4 \mathrm{~mL}$ of $0.3 \%$ (w/v) Evans-blue dye (Sigma-Aldrich, Budapest, Hungary) with a constant $100 \mathrm{cmH}_{2} \mathrm{O}$ pressure into the aorta to delineate the area at risk zone. Stained hearts were rapidly frozen (at $-20^{\circ} \mathrm{C}$ for at least $30 \mathrm{~min}$ ), cut into $2 \mathrm{~mm}$ thick slices, and each slice was incubated at $37^{\circ} \mathrm{C}$ in $1.5 \mathrm{~mL}$ of $1 \%$ (w/v) 2,3,5-triphenyltetrazolium-chloride (TTC, Merck Biosciences, Budapest, Hungary) dissolved in $50 \mathrm{mM}$ phosphate buffer (pH 7.4) for 10 min. Slices were then transferred into 10\% formalin solution for 5-10 min, rinsed, and then scanned between glass plates. The differently stained areas of the images were quantified by digital planimetry (InfarctsizeTM2.5, Pharmahungary, Szeged, Hungary). Evaluation of all images was carried out in a blinded manner by an experienced investigator throughout the study. Area at risk zone (AAR) was expressed as the percentage of total ventricular area (LV), and infarct size (IS) was expressed as a percentage of the AAR.

\subsection{Statistical analysis}

Data are expressed as mean \pm standard deviation (SD) or mean \pm standard error of the mean (SEM). Statistical significance was accepted at $\mathrm{p}<0.05$.

Univariate correlations between lipid parameters and MMP activities as well as nitrotyrosine were analyzed using the Pearson correlation coefficient. Because of the relatively small sample sizes in the current study, bootstrapped confidence intervals were 
calculated, using 1000 samples with replacement, to make robust estimates of the correlation coefficients as described elsewhere $[65,66]$. Linear regression analysis was used to estimate the prediction of the selected variables. The effects of statin treatment on variables were analyzed by unpaired two-tailed Student's t-test.

Differences among means of the ratio of dead cells in cell-culture experiments, and among means of IS/AAR (\%) in in vivo experiments were analyzed by One-way analysis of variance (ANOVA) followed by Fisher LSD post hoc test to compare each group to the control when appropriate. To analyze the reticulocyte stimulation test, One-way ANOVA was used followed by Tukey post hoc test, where means of reticulocyte number/L of EPO and Dpa were compared to the vehicle, while means of the AF test compounds were compared to EPO. Mortality was analyzed with Chi-square test followed by Fisher's exact test. CsA group was compared to the saline control group by Student's t-test. 


\section{Results}

4.1 Characterization of the correlations of $\mathrm{ONOO}^{-}$and MMPs in patients with CAD

Baseline characteristics of the 36 patients with coronary artery disease are summarized in Table 2.

\begin{tabular}{|c|c|}
\hline $\begin{array}{c}\text { Biographic and anamnestic } \\
\text { variables }\end{array}$ & $\begin{array}{l}\text { Mean } \pm \text { SD or Occurrence } \\
\text { (number of individuals) }\end{array}$ \\
\hline Age (years) & $67.4 \pm 10.5$ \\
\hline Gender, m/f & $19 / 17$ \\
\hline Type 1 diabetes & $0 / 36$ \\
\hline Type 2 diabetes & $5 / 36$ \\
\hline Statin treatment & $15 / 36$ \\
\hline ACE inhibitor treatment & $31 / 36$ \\
\hline ARB treatment & $1 / 36$ \\
\hline Nitrate treatment & $18 / 36$ \\
\hline \multicolumn{2}{|c|}{ Hemodynamic variables } \\
\hline Systolic blood pressure (mmHg) & $141.7 \pm 11.1$ \\
\hline Diastolic blood pressure (mmHg) & $89.8 \pm 21.4$ \\
\hline Heart rate (beats/min) & $70.4 \pm 12.1$ \\
\hline LVEF (\%) & $56.0 \pm 10.5$ \\
\hline Coronary stenosis (\%) & $63.5 \pm 8.0$ \\
\hline Occurrence of hypertension & 29/36 \\
\hline \multicolumn{2}{|c|}{ Serum variables } \\
\hline Total cholesterol (mmol/L) & $4.6 \pm 0.9$ \\
\hline LDL cholesterol (mmol/L) & $2.5 \pm 0.8$ \\
\hline HDL cholesterol (mmol/L) & $1.3 \pm 0.4$ \\
\hline Triglycerides (mmol/L) & $1.8 \pm 0.8$ \\
\hline 3-nitrotyrosine (ng/mL) & $17.4 \pm 11.3$ \\
\hline Urea nitrogen (mmol/l) & $5.9 \pm 2.4$ \\
\hline Creatinine $(\mu \mathrm{mol} / \mathrm{l})$ & $86.3 \pm 27.5$ \\
\hline
\end{tabular}

Table 2. Baseline characteristics of the $\mathbf{3 6}$ coronary artery disease patients. 
4.1.1 Correlation between serum nitrotyrosine and MMP-2 or MMP-9 activities

We have determined whether serum nitrotyrosine correlates with MMP-2 and MMP-9 activities in patients with CAD. Nitrotyrosine correlated positively with MMP-9 activity (Fig. 7A; $r=0.535, p=0.010$ ); however, there was no significant correlation between serum nitrotyrosine and MMP-2 activity (Fig. 7B).
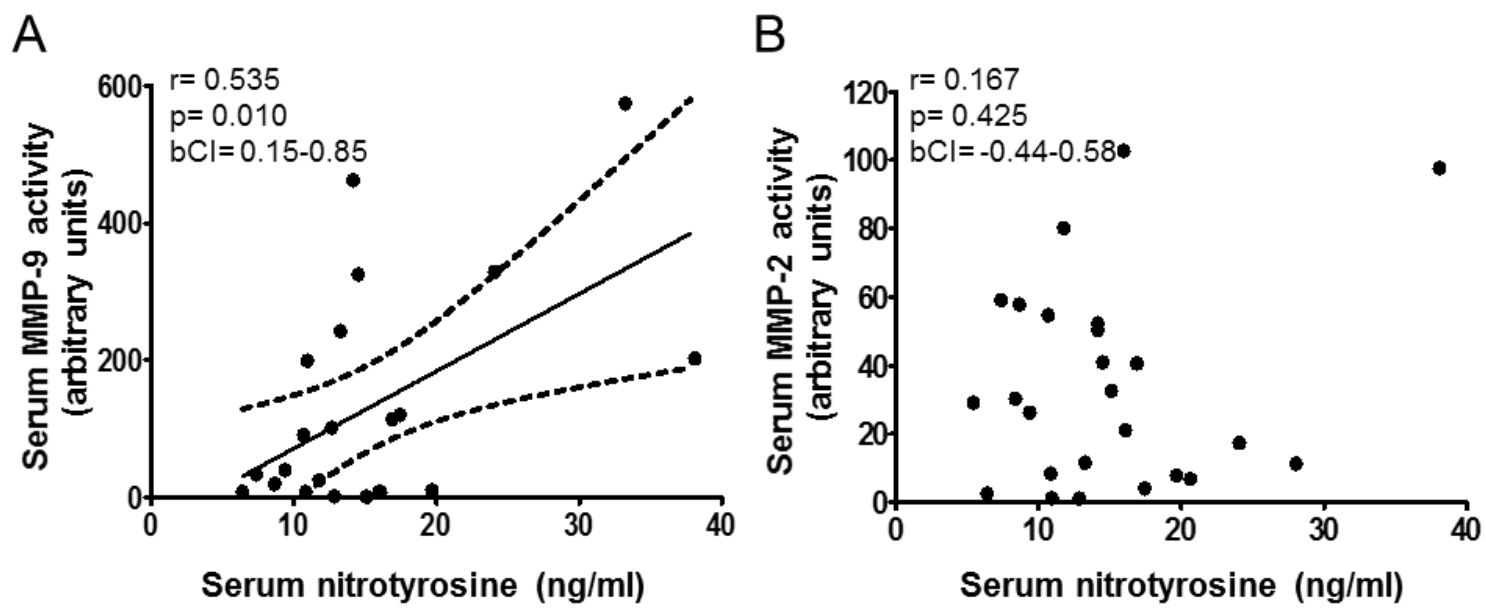

Figure 7. Correlation of serum nitrotyrosine content with MMP-2 and MMP-9 activities. Serum MMP-9 activity correlated positively with serum nitrotyrosine (A). Serum MMP-2 activity (B) did not correlate with serum nitrotyrosine. Continuous line: linear regression of data; dotted line: 95\% confidence interval. r: Pearson's correlation coefficient, p: significance, bCI: bootstrapped confidence interval of correlation coefficient.

\subsubsection{Correlation between serum lipids and nitrotyrosine or MMPs activity}

In patients with CAD, serum total cholesterol (Fig. 8A), LDL cholesterol (Fig. 8B) and triglyceride (Fig. 8C) levels correlated positively $(r=0.582, p=0.003 ; r=0.552, p=0.008 ; r=$ 0.471, $\mathrm{p}=0.023$, respectively), while HDL cholesterol negatively (Fig. 8D; $r=-0.455, p=$ 0.033) with serum nitrotyrosine. Serum MMP-2 activity correlated positively with serum total cholesterol (Fig. 8E, r= 0.550, p= 0.015) and LDL cholesterol levels (Fig. 8F, r= 0.448, p= 0.028, respectively); however, neither serum triglyceride (Fig. 8G) nor HDL cholesterol (Fig. 8H) showed a significant correlation with MMP-2 activity. None of the serum lipid parameters correlated with MMP-9 activity in patients with CAD (Table 3). 
A

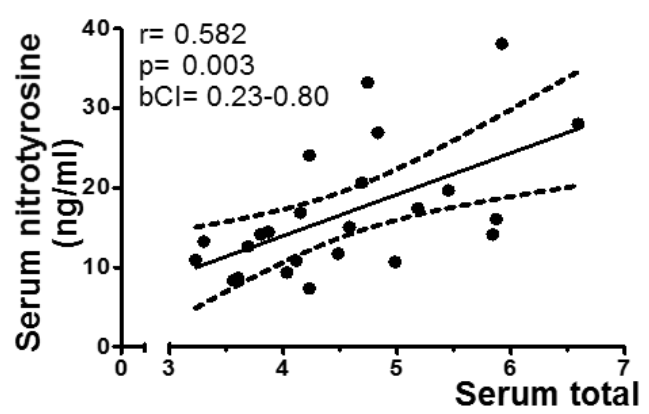

B

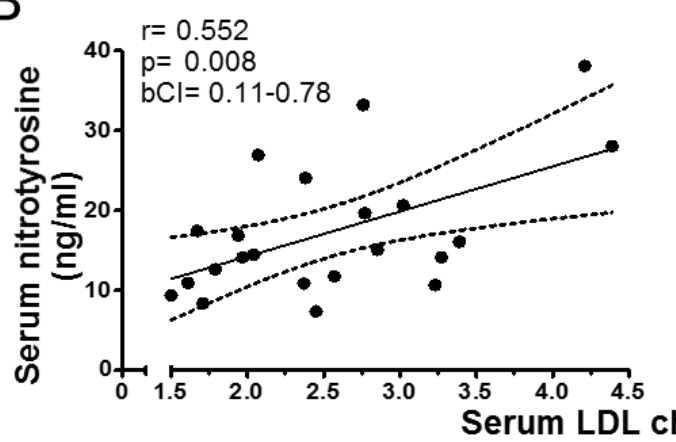

C

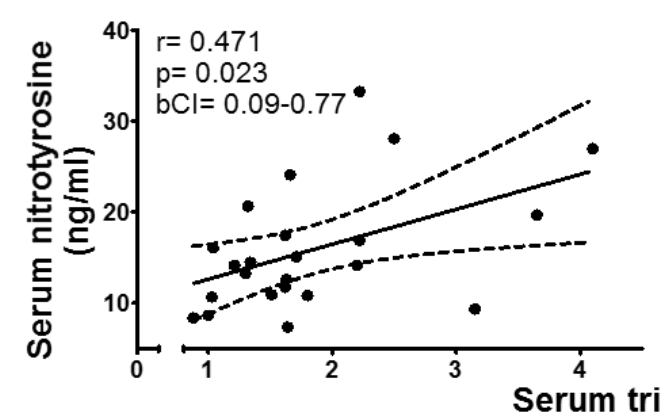

D

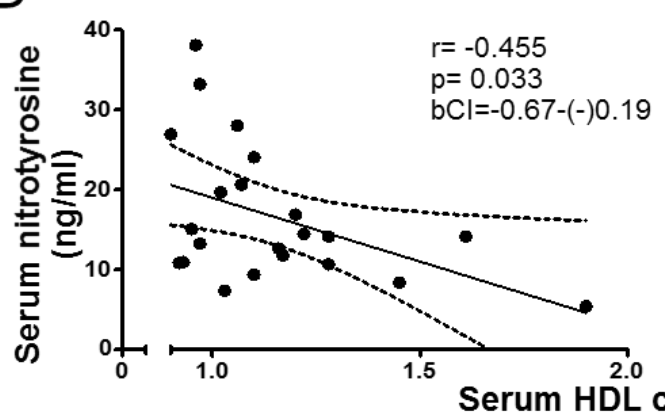

$E$

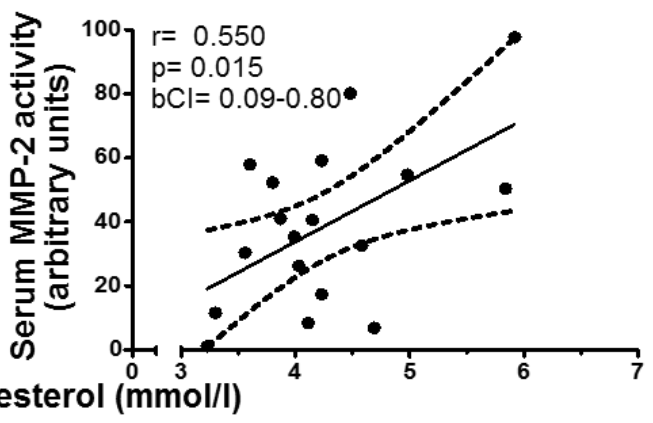

$\mathrm{F}$

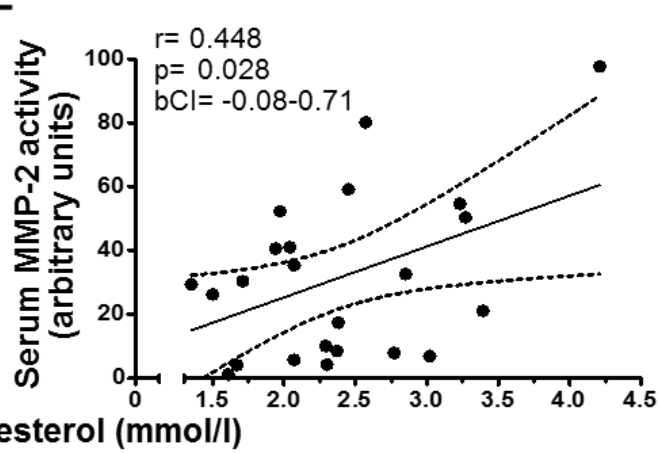

G

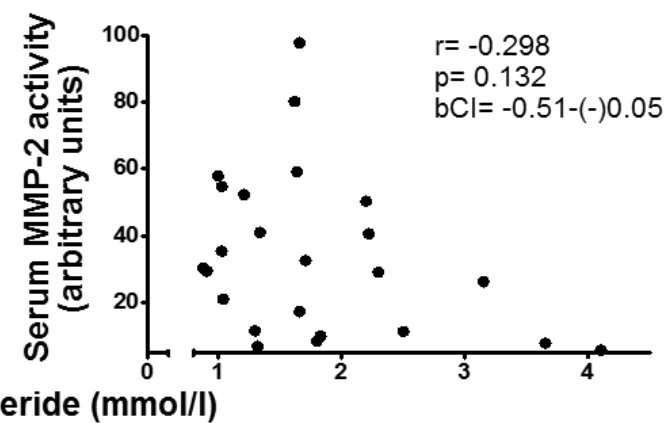

$\mathrm{H}$

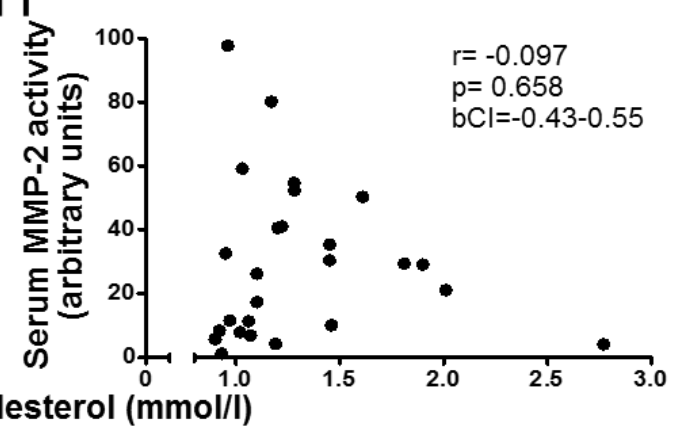

Figure 8. Correlation of serum nitrotyrosine and MMP-2 activities with serum lipids. Serum nitrotyrosine level correlated positively with total (A) and LDL cholesterol (B) as well as with triglyceride (C) and correlated negatively with HDL cholesterol (D). Serum MMP-2 activity correlated positively with serum total (E) and LDL cholesterol levels (F). Neither serum triglyceride $(G)$ nor HDL cholesterol $(\mathrm{H})$ showed a significant correlation with serum MMP-2 activity. Continuous line: linear regression of data; dotted line: 95\% confidence interval. r: Pearson's correlation coefficient, p: significance, bCI: bootstrapped confidence interval of correlation coefficient. 


\begin{tabular}{|l|c|c|c|c|}
\hline & Variables & $\begin{array}{c}\text { Pearson } \\
\text { correlation } \\
\text { coefficient }\end{array}$ & $\begin{array}{c}\text { Bootstrapped confidence } \\
\text { intervals of correlation } \\
\text { coefficient }\end{array}$ & $\mathrm{p}$ \\
\hline MMP-9 / & total cholesterol & 0.171 & $-0.27-0.49$ & 0.436 \\
\hline MMP-9 / & LDL cholesterol & 0.020 & $-0.38-0.30$ & 0.939 \\
\hline MMP-9 / & HDL cholesterol & 0.050 & $-0.31-0.59$ & 0.840 \\
\hline MMP-9 / & triglyceride & 0.024 & $-0.34-0.40$ & 0.913 \\
\hline
\end{tabular}

Table 3. Correlations between serum MMP-9 activity and lipid parameters.

4.1.3 Correlation between myocardial function and serum nitrotyrosine or MMPs activity

Serum nitrotyrosine level correlated negatively with LVEF (Fig. 9A, r= -0.548, p= 0.010). MMP-2 activity did not correlate with LVEF (Fig. 9B), however, MMP-9 activity also showed a negative correlation with LVEF (Fig. 9C, r= -0.732, $\mathrm{p}=0.0002$, similarly to the nitrotyrosine level), in patients with CAD. The negative correlation indicates that deteriorated cardiac function associates with elevated nitrotyrosine level and MMP-9 activity.
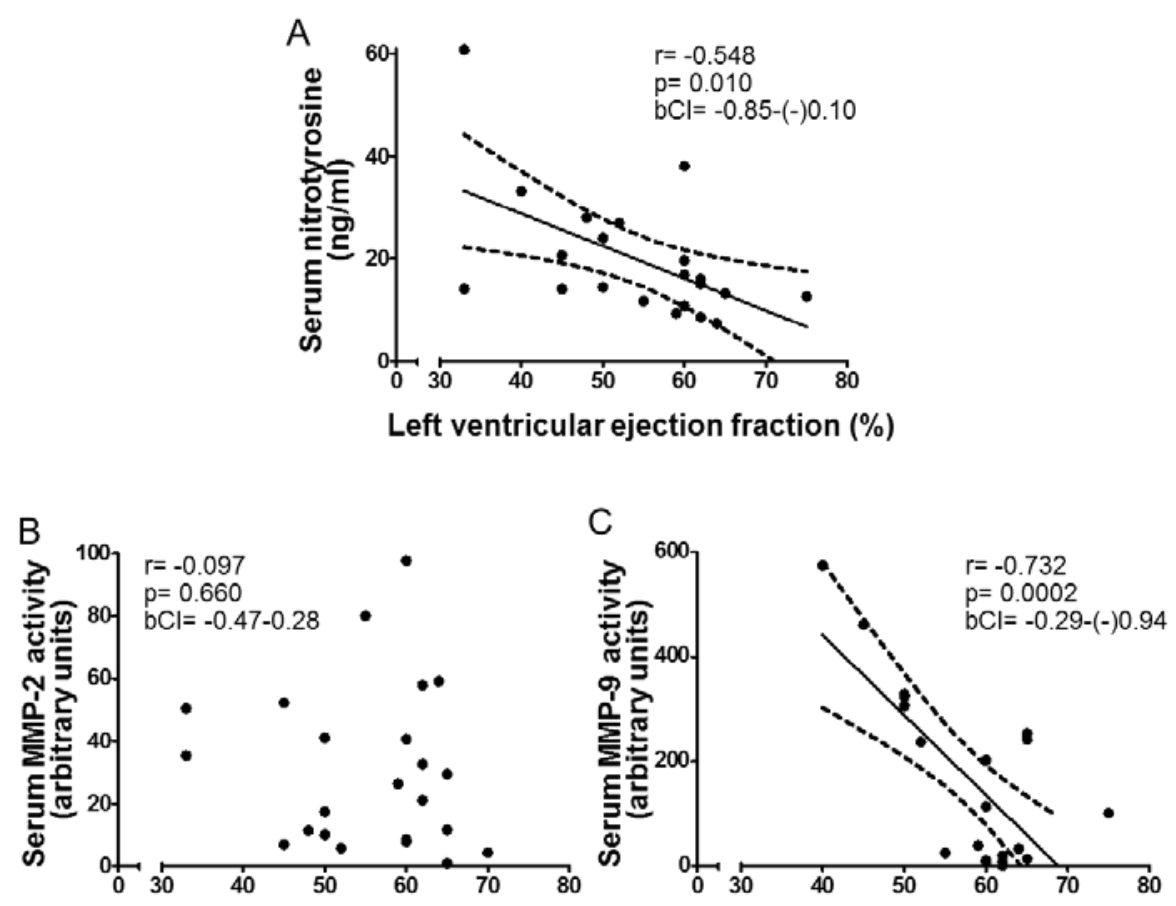

Left ventricular ejection fraction (\%)

Left ventricular ejection fraction (\%)

Figure 9. Correlation of left ventricular ejection fraction (LVEF) with serum nitrotyrosine, and serum MMP-2 and MMP-9 activities. Serum nitrotyrosine (A) and MMP-9 (C) activity correlated negatively with LVEF. Serum MMP-2 activity did not correlate with LVEF (B). Continuous line: linear regression of data; dotted line: 95\% confidence interval. r: Pearson's correlation coefficient, p: significance, bCI: bootstrapped confidence interval of correlation coefficient. 
4.1.4 Serum nitrotyrosine or MMPs activity in statin-treated patients

Fifteen of the 36 patients with CAD involved in this study were treated with different types of statins. In statin-treated patients, a significantly reduced serum nitrotyrosine level was found as compared to statin-naive patients (Fig. 10A, $23.5 \pm 4.5 \mathrm{ng} / \mathrm{mL}$ vs. $13.6 \pm 5.1$ ng/mL; $\mathrm{p}<0.05$ ). MMP-2 and MMP-9 activities did not show any difference between statintreated and statin-naive patients (Fig. 10B, C).
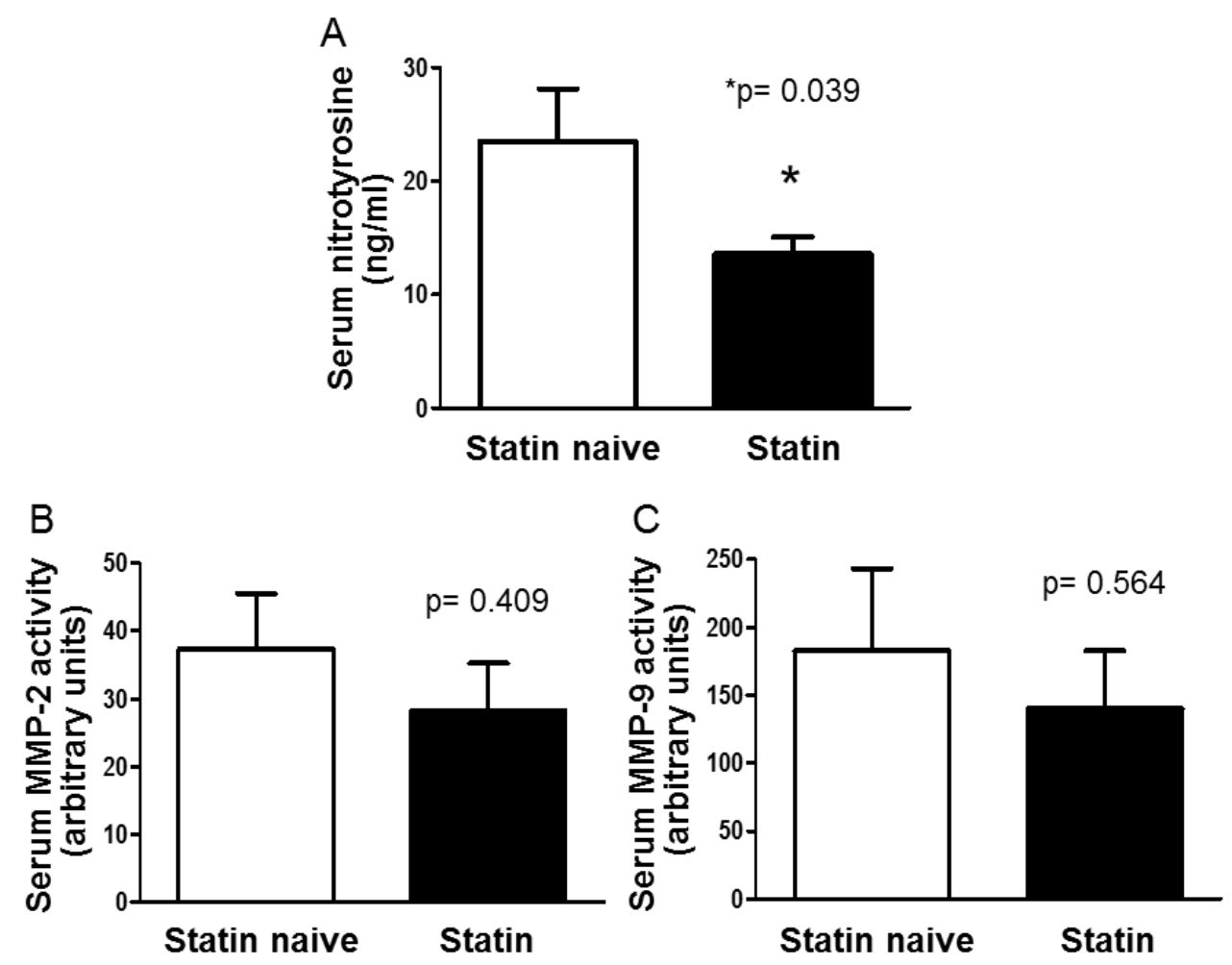

Figure 10. Serum nitrotyrosine levels (A) and serum MMP-2 (B) and MMP-9 (C) activities in statin-treated and statin-naive patients with CAD. Serum nitrotyrosine was significantly reduced in statin-treated patients with CAD as compared to statin-naive patients $\left({ }^{*} \mathrm{p}<0.05\right)$. MMP-2 and MMP-9 activities were not changed in statin-treated patients with CAD as compared to statin-naive ones. Data are shown as mean \pm SEM

\subsubsection{Serum nitrotyrosine or MMPs activity in smoking patients}

Eleven of the 36 patients with CAD were active smoker during the study and seventeen patients did not smoke (we got no information about smoking in case of eight patients). Serum nitrotyrosine level did not show any difference between non-smoker and smoker patients (Fig. 11A, $16.0 \pm 1.7 \mathrm{ng} / \mathrm{mL}$ vs. $16.7 \pm 3.3 \mathrm{ng} / \mathrm{mL}$; p=0.7). MMP-2 activity was significantly increased in smoker patients as compared to the non-smokers (Fig. 11B, $45.5 \pm$ 8.5 vs. $22.4 \pm 4.6$ arbitrary unit; $\mathrm{p}<0.05$ ). MMP-9 activity did not show any difference 
between non-smokers and smokers (Fig. 11C, $123.0 \pm 31.6$ vs. $130.0 \pm 45.2$ arbitrary unit, p= $0.9)$.
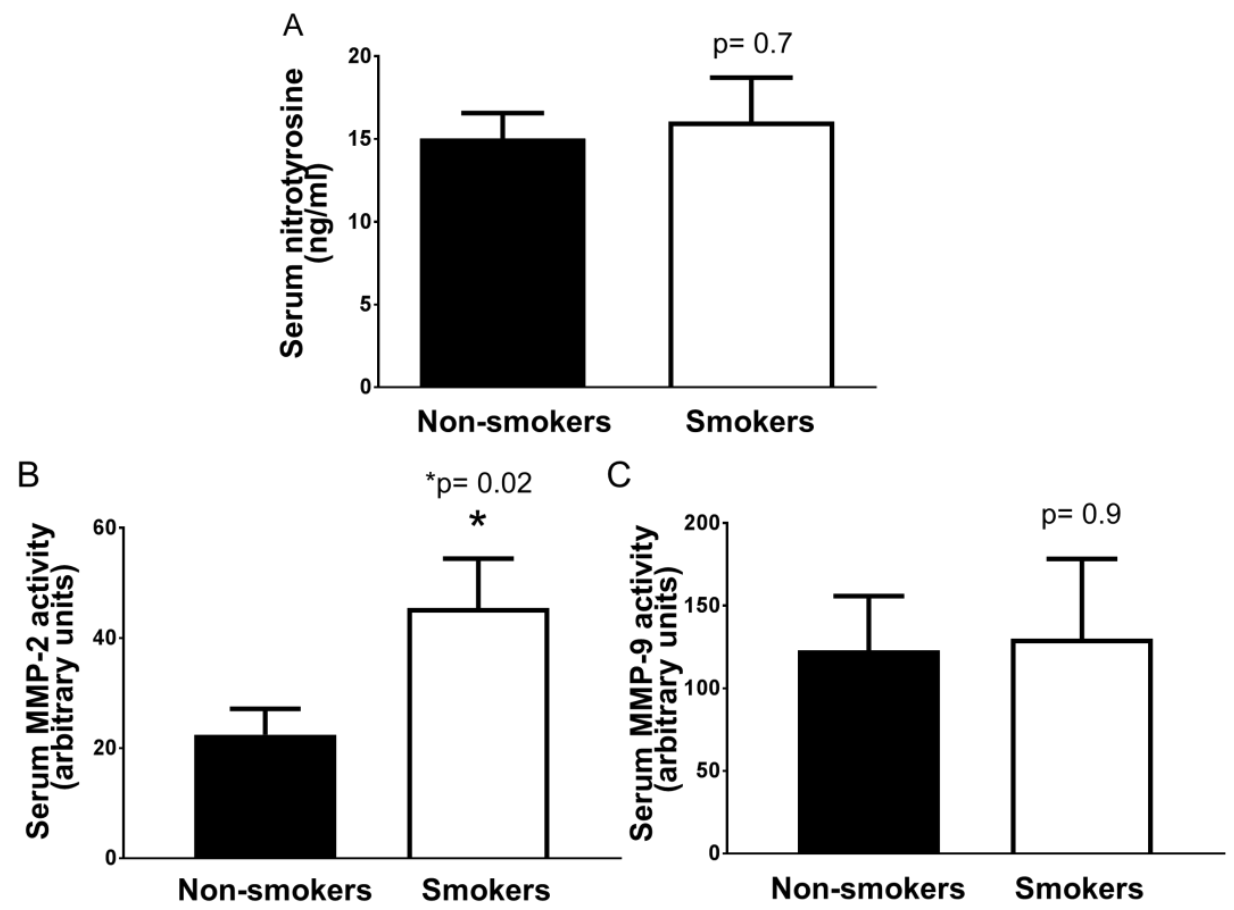

Figure 11. Serum nitrotyrosine levels (A) and serum MMP-2 (B) and MMP-9 (C) activities in non-smoker and smoker patients with CAD. Serum MMP-2 was significantly increased in smoker patients with CAD as compared to non-smoker patients ( $\left.{ }^{*} \mathrm{p}<0.05\right)$. NTyr and MMP-9 activities were not changed in non-smoker patients with CAD as compared to smoker ones. Data are shown as mean \pm SEM, $n=11-17$.

\subsubsection{Correlation between renal function and serum nitrotyrosine or MMPs activity}

In addition, we tested the correlation of renal function parameters with markers of peroxynitrite-MMP pathway and also with LVEF, since renal dysfunction may be a severe complication in CAD. Serum creatinine correlated positively with nitrotyrosine $(r=0.422, p=$ 0.036; Fig. 12A), but not with MMP-2 and MMP-9 activities (Table 4). Urea nitrogen level correlated positively with MMP-9 activity ( $r=0.423, \mathrm{p}=0.035$; Fig. 12B), but not with nitrotyrosine or MMP-2 activity (Table 4). Serum creatinine correlated negatively with LVEF $(\mathrm{r}=-0.503, \mathrm{p}=0.009$; Fig. 12C); however, urea nitrogen did not correlate with LVEF (Table 4). 

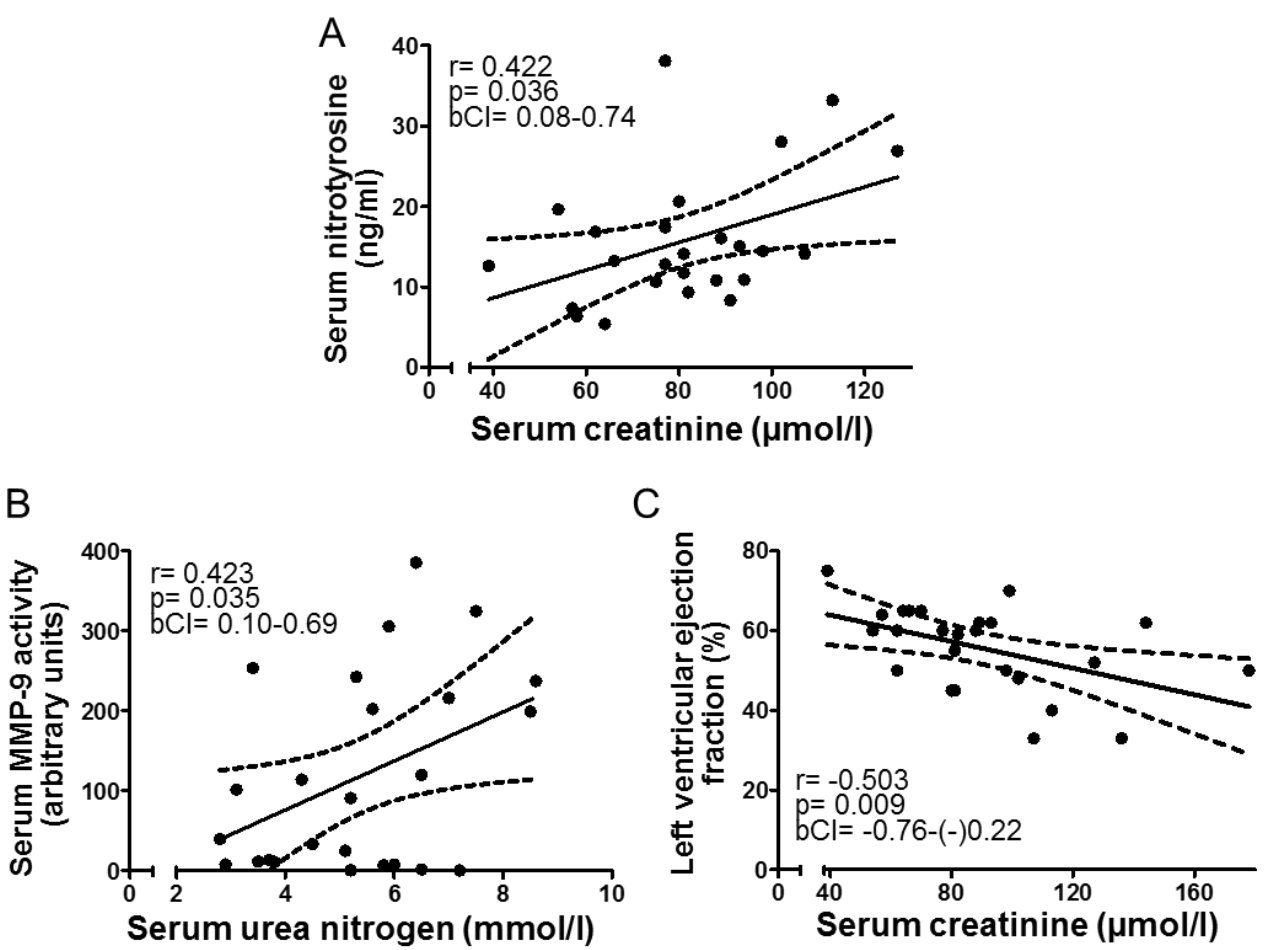

Figure 12. Correlation of renal function with serum nitrotyrosine, MMP activities and myocardial function. Serum nitrotyrosine correlated positively with serum creatinine (A). Serum MMP-9 activity correlated positively with urea nitrogen level (B). Continuous line: linear regression of data; dotted line: 95\% confidence interval, r: Pearson's correlation coefficient, p: significance, bCI: bootstrapped confidence interval of correlation coefficient.

\begin{tabular}{|c|c|c|c|c|}
\hline \multicolumn{2}{|c|}{ Variables } & $\begin{array}{c}\text { Pearson } \\
\text { correlation } \\
\text { coefficient }\end{array}$ & $\begin{array}{c}\text { Bootstrapped confidence } \\
\text { intervals of correlation } \\
\text { coefficient }\end{array}$ & $\mathrm{p}$ \\
\hline MMP-2 / & creatinine & 0.125 & $-0.20-0.45$ & 0.504 \\
\hline MMP-9 / & creatinine & 0.118 & $-0.30-0.48$ & 0.550 \\
\hline NTyr/ & BUN & 0.105 & $-0.22-0.39$ & 0.602 \\
\hline MMP-2 / & BUN & 0.071 & $-0.20-0.42$ & 0.700 \\
\hline LVEF/ & BUN & -0.250 & $-0.57-0.00$ & 0.217 \\
\hline
\end{tabular}

Table 4. Correlations between serum nitrotyrosine level, MMPs activities, or LVEF and renal function parameters. MMP: matrix metalloproteinase, NTyr: nitrotyrosine, BUN: blood urea nitrogen, LVEF: left ventricular ejection fraction. 
4.2 Investigation of EpoR-mediated cardioprotection

\subsubsection{Erythropoietic activity of test compounds}

As described previously, erythropoietic activity of test compounds was analyzed by Affymax Inc.

EPO, Dpa and AF43136 bound to the EPO receptor with high affinity (AF41676 exhibiting with modest affinity), AF41676 and AF43136 did not show in vitro erythropoietic activity (Table 5A).

EPO and Dpa differentiated CD34 ${ }^{+}$cells into erythroid precursors with high efficiency $\left(\mathrm{EC}_{50}=2\right.$ to $\left.14 \mathrm{pM}\right)$, whereas AF41676 and AF43136 required vastly greater amounts (approx. 3-4 orders of magnitude, Table 5A).

Reticulocytosis, a predictive marker of erythropoiesis, was significantly stimulated 5 days following administration of EPO at $5000 \mathrm{U} / \mathrm{kg}$ and Dpa at $10 \mu \mathrm{g} / \mathrm{kg}$, but not by administration of AF41676 and AF43136 compared to acetate vehicle (Table 5B, Fig. 13).

\begin{tabular}{|c|c|c|c|c|c|}
\hline \multirow[t]{5}{*}{ A } & Test compounds & $\begin{array}{c}\text { Binding } \\
\left(\mathrm{EC}_{50},\right. \\
\mathrm{pM})\end{array}$ & $\begin{array}{c}\text { BFU-E } \\
(\mathrm{pM})\end{array}$ & Test compounds & $\begin{array}{c}\text { Reticulocytes } \\
\left(10^{9} / \mathrm{L}\right)\end{array}$ \\
\hline & EPO & 7 & 2 & Acetate vehicle & $373 \pm 24$ \\
\hline & Dpa & 12 & 14 & EPO (5,000 U/kg) & $762 \pm 146^{*}$ \\
\hline & AF41676 & 1240 & 34680 & Dpa (10 g/kg) & $1056 \pm 104^{*}$ \\
\hline & AF43136 & 27 & 2623 & AF41676 (10 mg/kg) & $284 \pm 51^{\#}$ \\
\hline & & & & AF43136 (10 mg/kg) & $286 \pm 57^{\#}$ \\
\hline
\end{tabular}

Table 5. Data for erythroid colony assay and EPO receptor binding assay of the test compounds (A). Data for reticulocyte stimulation test measured 5 days after administration of the test compounds (B). Data are expressed as mean \pm SD. AF41676 and AF43136 did not induce reticulocytosis while EPO and Dpa produced a robust erythropoietic response. ${ }^{*} \mathrm{p}<0.05$ vs. acetate vehicle, ${ }^{\#} \mathrm{p}<0.05$ vs. EPO. BFU-E: Erythroid blood forming unit; $\mathrm{EC}_{50}$ : Half maximal effective concentration; EPO: Erythropoietin; Dpa: darbepoetin alpha. 


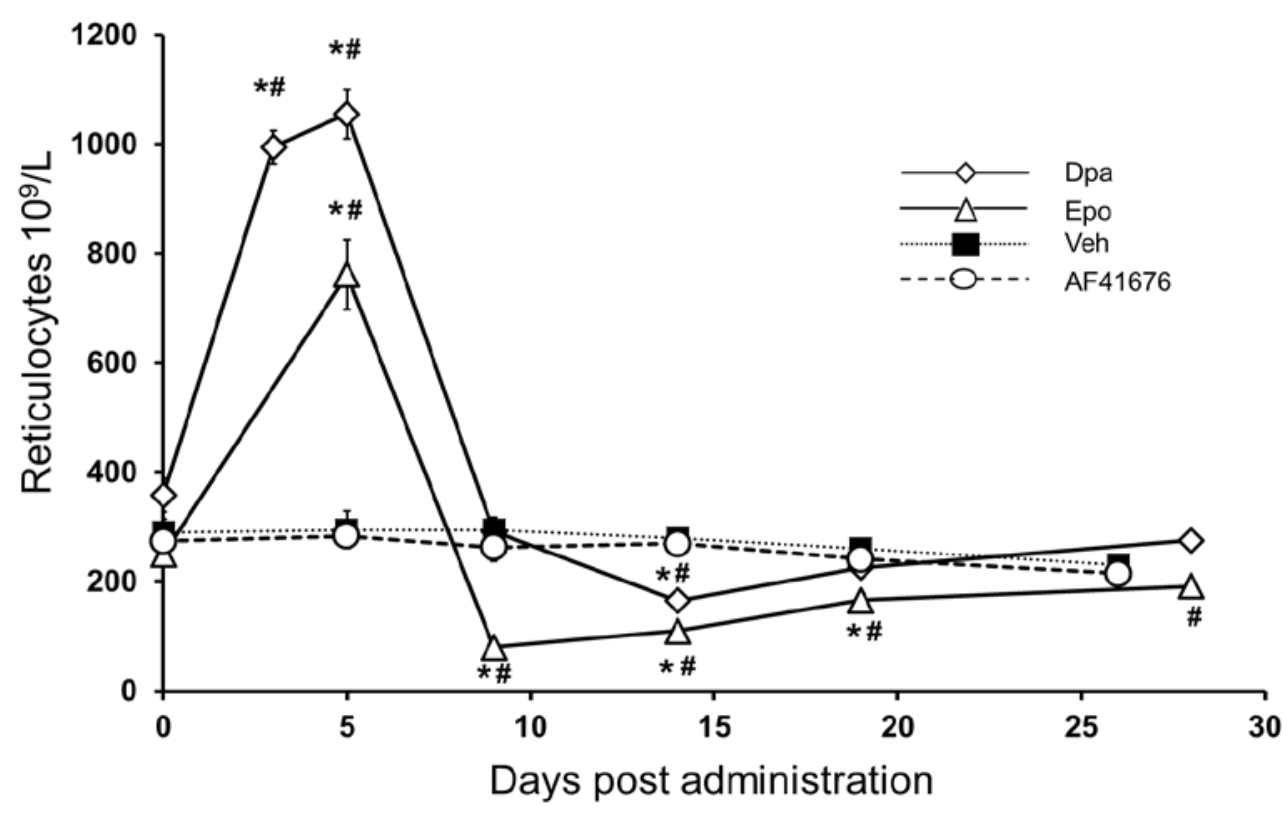

Figure 13. The effects of 5,000 Units/kg EPO, $10 \mu \mathrm{g} / \mathrm{kg}$ Dpa, $10 \mathrm{mg} / \mathrm{kg}$ AF41676, and acetate vehicle on reticulocytes number following administration of single iv. boluses. Data are expressed as mean $\pm \mathrm{SD},{ }^{*} \mathrm{p}<0.05$ vs. vehicle, ${ }^{*} \mathrm{p}<0.05$ vs. baseline analyzed by repeated measures ANOVA, $n=4$ rats per time point/ group.

\subsubsection{The effects of EPO on cell death}

Erythropoietin showed a U-shaped response curve on cell viability in cultured neonatal rat cardiomyocytes subjected to simulated ischemia/reperfusion (Fig. 14B). EPO at $100 \mathrm{U} / \mathrm{mL}$ significantly decreased the ratio of dead cells (by approx. 16\%) compared to the vehicle control group. Similarly to lower doses (1 or $10 \mathrm{U} / \mathrm{mL}$ ), highest tested dose (500 U/mL) of EPO did not reduce cell death as compared to the vehicle-treated cells. The positive control BNP reduced cell death compared to the vehicle by approx. 30\% (Fig. 14B). 

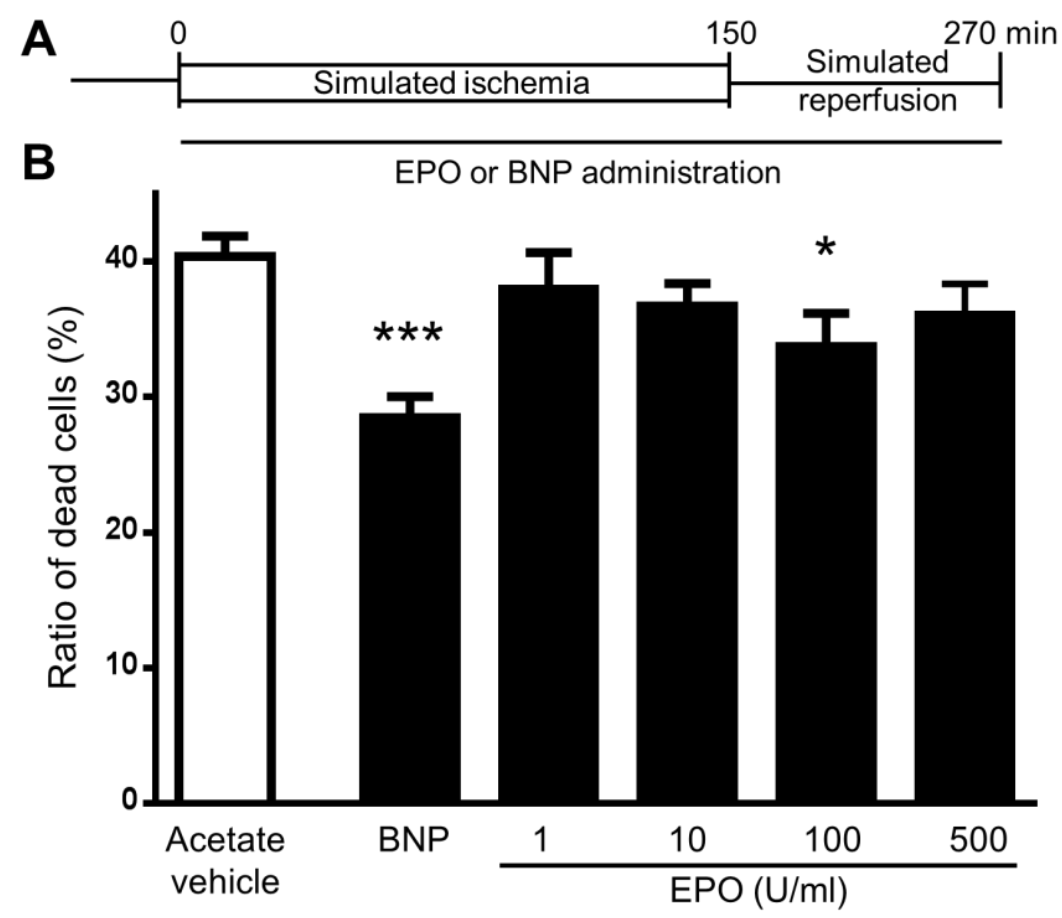

Figure 14. Panel A: Experimental protocol for the pilot study. Panel B: Dose-response relationships for EPO and the effect of BNP on cell death in cultured neonatal rat cardiomyocytes subjected to simulated ischemia/reperfusion. Data are expressed as mean \pm $\mathrm{SEM},{ }^{*} \mathrm{p}<0.05,{ }^{* * *} \mathrm{p}<0.001$ vs. simulated ischemia/reperfusion (SI/R) control; $\mathrm{n}=7-8$ wells.

\subsubsection{The effects of EPO on infarct size and hemodynamics (Study1)}

Different EPO dosing regimens were evaluated. EPO at $5000 \mathrm{U} / \mathrm{kg}$ administered intravenously, before the onset of reperfusion decreased infarct size significantly compared to the vehicle by approx. 24\%, while intraperitoneal administration was less effective (approx. 11\% decrease, non-significant) (Fig. 15B, Table 6). The positive control BNP (10 nmol/kg + $2 \mathrm{nmol} / \mathrm{kg}$ infusion for $15 \mathrm{~min}$ ) decreased infarct size significantly compared to the vehicle by approx. 47\% (Fig. 15B, Table 6). There was no difference in area at risks among the groups (Table 6). BNP reduced mean arterial blood pressure (MABP) significantly during ischemia compared to the vehicle, whereas EPO did not show any significant effect on MABP or heart rate (HR) (Table 6). There was no significant difference in survival among the groups (Table $6)$. 


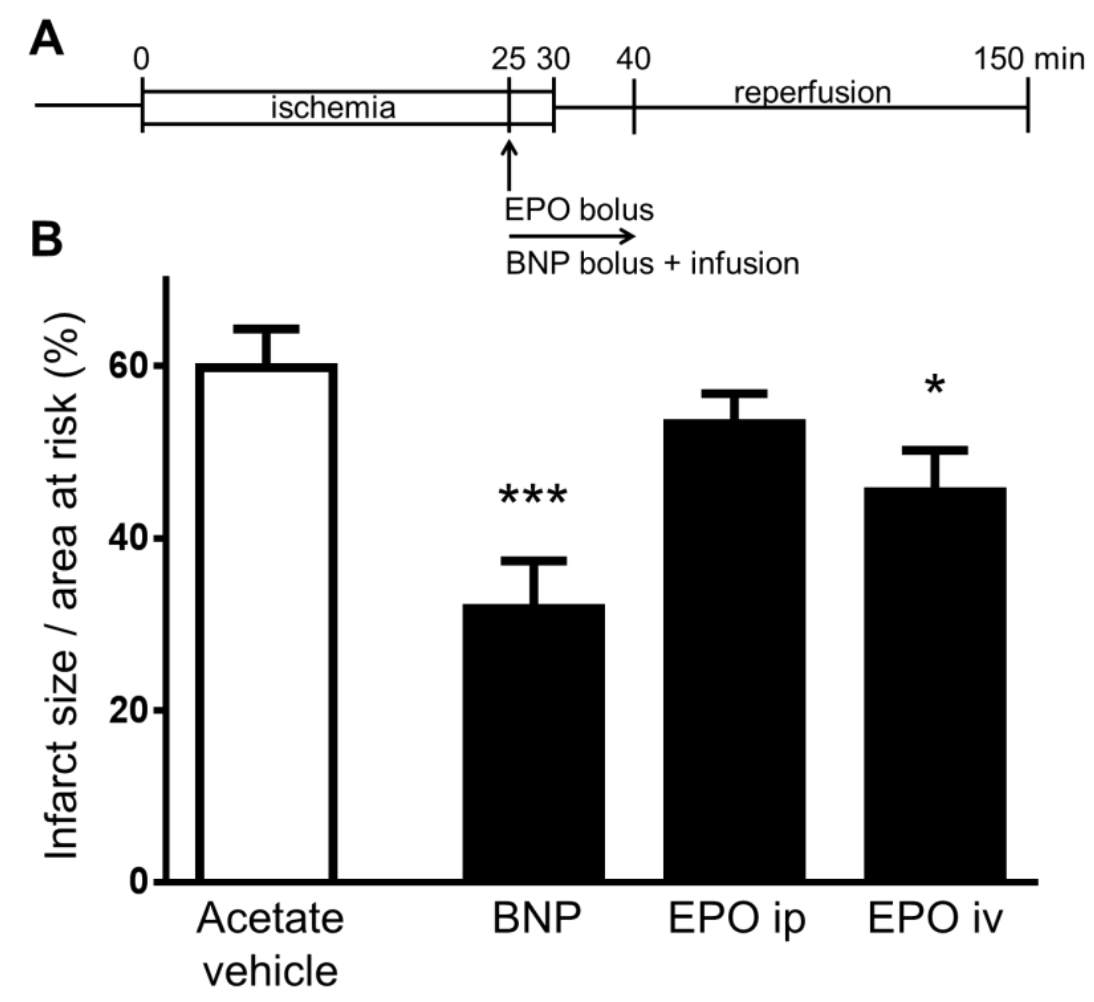

Figure 15. Panel A: Experimental protocol for Study 1. Panel B: The effects of BNP and EPO on infarct size in rats subjected to in vivo 30-min coronary occlusion followed by $120 \mathrm{~min}$ reperfusion. EPO was administered either intraperitoneally (EPO ip) or intravenously (EPO iv) for rats. Data are expressed as means \pm S.E.M., ${ }^{*} \mathrm{p}<0.05,{ }^{* * *} \mathrm{p}<0.001$ vs. vehicle control; $\mathrm{n}=8-9$.

\begin{tabular}{|c|c|c|c|c|c|c|c|c|c|}
\hline $\begin{array}{c}\text { Exp. } \\
\text { Group }\end{array}$ & $\mathrm{n}$ & $\begin{array}{c}\text { AAR/LV } \\
(\%)\end{array}$ & \multicolumn{3}{|c|}{$\begin{array}{c}\text { mean arterial blood } \\
\text { pressure (mmHg) }\end{array}$} & \multicolumn{3}{|c|}{$\begin{array}{c}\text { heart rate } \\
\text { (beats/min) }\end{array}$} & $\begin{array}{c}\text { SR } \\
\text { (\%) }\end{array}$ \\
\hline $\begin{array}{c}\text { Vehicle } \\
\text { acetate }\end{array}$ & 9 & $34.3 \pm 2.7$ & $142 \pm 7$ & $119 \pm 7$ & $107 \pm 6$ & $404 \pm 10$ & $399 \pm 14$ & $400 \pm 14$ & 82 \\
\hline BNP & 8 & $38.8 \pm 5.5$ & $124 \pm 10$ & $89 \pm 5 *$ & $91 \pm 6$ & $401 \pm 14$ & $405 \pm 6$ & $413 \pm 11$ & 89 \\
\hline Epo ip & 8 & $33.9 \pm 2.2$ & $151 \pm 7$ & $118 \pm 5$ & $108 \pm 9$ & $418 \pm 20$ & $410 \pm 18$ & $399 \pm 15$ & 89 \\
\hline Epo iv & 8 & $37.3 \pm 3.7$ & $126 \pm 11$ & $115 \pm 8$ & $111 \pm 9$ & $427 \pm 6$ & $396 \pm 13$ & $403 \pm 12$ & 80 \\
\hline
\end{tabular}

Table 6. Hemodynamic parameters, area at risk and survival ratio for study 1 . Data are expressed as means \pm S.E.M, ${ }^{*} \mathrm{p}<0.05,{ }^{* * *} \mathrm{p}<0.001$ vs. vehicle. BNP: B-type natriuretic peptide; Epo: Erythropoietin; ip: intraperitoneal; iv: intravenous; AAR/LV: area at risk/ left ventricle; BL: baseline; ISCH: $29^{\text {th }}$ min of ischemia; REP: $120^{\text {th }}$ min of reperfusion; SR: survival rate 


\subsubsection{The effects of darbepoetin on infarct size and hemodynamics (Study 2)}

Different doses of darbepoetin were administered iv. at the $15^{\text {th }}$ min of ischemia. Doseresponse relationship of darbepoetin showed maximal infarct size limiting effect at $5 \mu \mathrm{g} / \mathrm{kg}$ compared to the vehicle (Fig. 16B, Table 7). The infarct size-limiting effect of darbepoetin was comparable to that of the positive control BNP (approx. 33\% for both, Fig. 16B, Table 7). There was no significant difference in the infarct-size limiting effect of the other Dpa doses (2.5, 5 or $25 \mu \mathrm{g} / \mathrm{kg}$, respectively). There was no significant difference in the area at risks among groups (Table 7). BNP and Dpa at $5 \mu \mathrm{g} / \mathrm{kg}$ reduced MABP significantly during ischemia, while Dpa at $15 \mu \mathrm{g} / \mathrm{kg}$ significantly improved MABP at the end of reperfusion compared to the vehicle. Neither Dpa nor BNP had any effect on HR (Table 7). There was no significant difference in survival among the groups (Table 7).

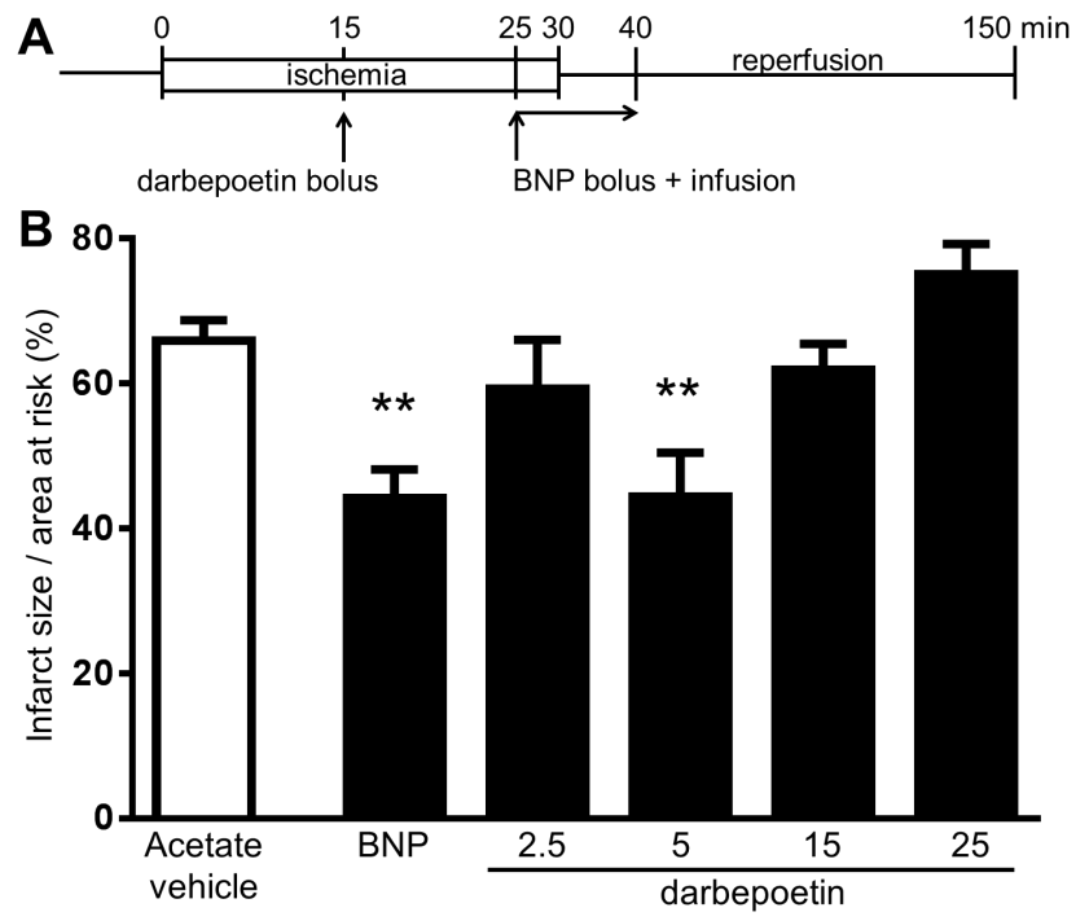

Figure 16. Panel A: Experimental protocol for Study 2. Panel B: Dose-response relationships for darbepoetin (doses are given in $\mu \mathrm{g} / \mathrm{kg}$ ) and the effect of BNP on infarct size in rats subjected to in vivo 30-min coronary occlusion followed by 120 min reperfusion. Data are expressed as means $\pm \mathrm{SEM},{ }^{* *} \mathrm{p}<0.01$ vs. vehicle control; $\mathrm{n}=7-8$. 


\begin{tabular}{|c|c|c|c|c|c|c|c|c|c|}
\hline \multirow[t]{2}{*}{$\begin{array}{l}\text { Exp. } \\
\text { Group }\end{array}$} & \multirow[t]{2}{*}{$\mathrm{n}$} & \multirow[t]{2}{*}{$\begin{array}{c}\text { AAR/LV } \\
(\%)\end{array}$} & \multicolumn{3}{|c|}{$\begin{array}{l}\text { mean arterial blood } \\
\text { pressure }(\mathrm{mmHg})\end{array}$} & \multicolumn{3}{|c|}{$\begin{array}{l}\text { heart rate } \\
\text { (beats/min) }\end{array}$} & \multirow[t]{2}{*}{$\begin{array}{l}\text { SR } \\
(\%)\end{array}$} \\
\hline & & & BL & ISCH & REP & BL & ISCH & REP & \\
\hline $\begin{array}{l}\text { Vehicle } \\
\text { acetate }\end{array}$ & 8 & $41.5 \pm 3.3$ & $115 \pm 4$ & $95 \pm 7$ & $75 \pm 3$ & $411 \pm 11$ & $422 \pm 13$ & $389 \pm 10$ & 90 \\
\hline BNP & 7 & $51.6 \pm 1.5$ & $107 \pm 5$ & $71 \pm 4^{*}$ & $75 \pm 4$ & $386 \pm 15$ & $389 \pm 18$ & $386 \pm 14$ & 100 \\
\hline $\begin{array}{c}\text { Dpa } \\
2.5 \mu g / k g\end{array}$ & 8 & $51.5 \pm 3.0$ & $112 \pm 3$ & $91 \pm 5$ & $80 \pm 4$ & $408 \pm 13$ & $437 \pm 11$ & $387 \pm 17$ & 100 \\
\hline $\begin{array}{c}\text { Dpa } \\
5 \mu g / k g\end{array}$ & 8 & $43.3 \pm 5.3$ & $123 \pm 2$ & $62 \pm 4^{*}$ & $76 \pm 6$ & $430 \pm 3$ & $378 \pm 9$ & $398 \pm 16$ & 100 \\
\hline $\begin{array}{c}\text { Dpa } \\
15 \mu g / k g\end{array}$ & 7 & $41.3 \pm 4.1$ & $126 \pm 11$ & $80 \pm 5$ & $91 \pm 4 *$ & $368 \pm 14^{*}$ & $418 \pm 8$ & $416 \pm 8$ & 88 \\
\hline $\begin{array}{c}\text { Dpa } \\
25 \mu \mathrm{g} / \mathrm{kg}\end{array}$ & 7 & $49.9 \pm 2.5$ & $127 \pm 1$ & $104 \pm 4$ & $74 \pm 4$ & $396 \pm 14$ & $420 \pm 11$ & $406 \pm 14$ & 88 \\
\hline
\end{tabular}

Table 7. Hemodynamic parameters, area at risk and survival ratio for study 2. Data are expressed as means \pm SEM, ${ }^{*} \mathrm{p}<0.05$ vs. vehicle. BNP: B-type natriuretic peptide; Dpa: darbepoetin alpha; AAR/LV: area at risk/left ventricle; BL: baseline; $\mathrm{ISCH}$ : $29^{\text {th }}$ min of ischemia; REP: $120^{\text {th }}$ min of reperfusion; SR: survival rate

\subsubsection{The effects of AF41676 on infarct size and hemodynamics (Study 3)}

Dose-dependent efficacy of AF41676 was investigated by five different intravenouslyadministered doses in a bolus injection 5 min before the onset of reperfusion. On the doseeffect curve, AF41676 at 0.3, 1, 3 and $10 \mathrm{mg} / \mathrm{kg}$ decreased infarct size significantly, of which the $3 \mathrm{mg} / \mathrm{kg}$ dose showing the most potent infarct size limiting effect compared to the vehicle (approx. 46\% reduction, Fig. 17B, Table 8). BNP also reduced infarct size significantly compared to the vehicle (approx. 25\% reduction; Fig. 17B, Table 8). There was no significant difference in the area at risks among the groups (Table 8). BNP as well as 10 and $20 \mathrm{mg} / \mathrm{kg}$ AF41676 reduced MABP during ischemia compared to the vehicle (Table 8). AF41676 at 20 $\mathrm{mg} / \mathrm{kg}$ reduced $\mathrm{HR}$ at the $29^{\text {th }} \mathrm{min}$ of ischemia and at $10 \mathrm{mg} / \mathrm{kg}$ reduced MABP at the end of reperfusion (Table 8). In spite of the transient hypotensive effect of the 10 and $20 \mathrm{mg} / \mathrm{kg}$ dose of AF41676, there was no significant difference in survival among the groups (Table 8). 


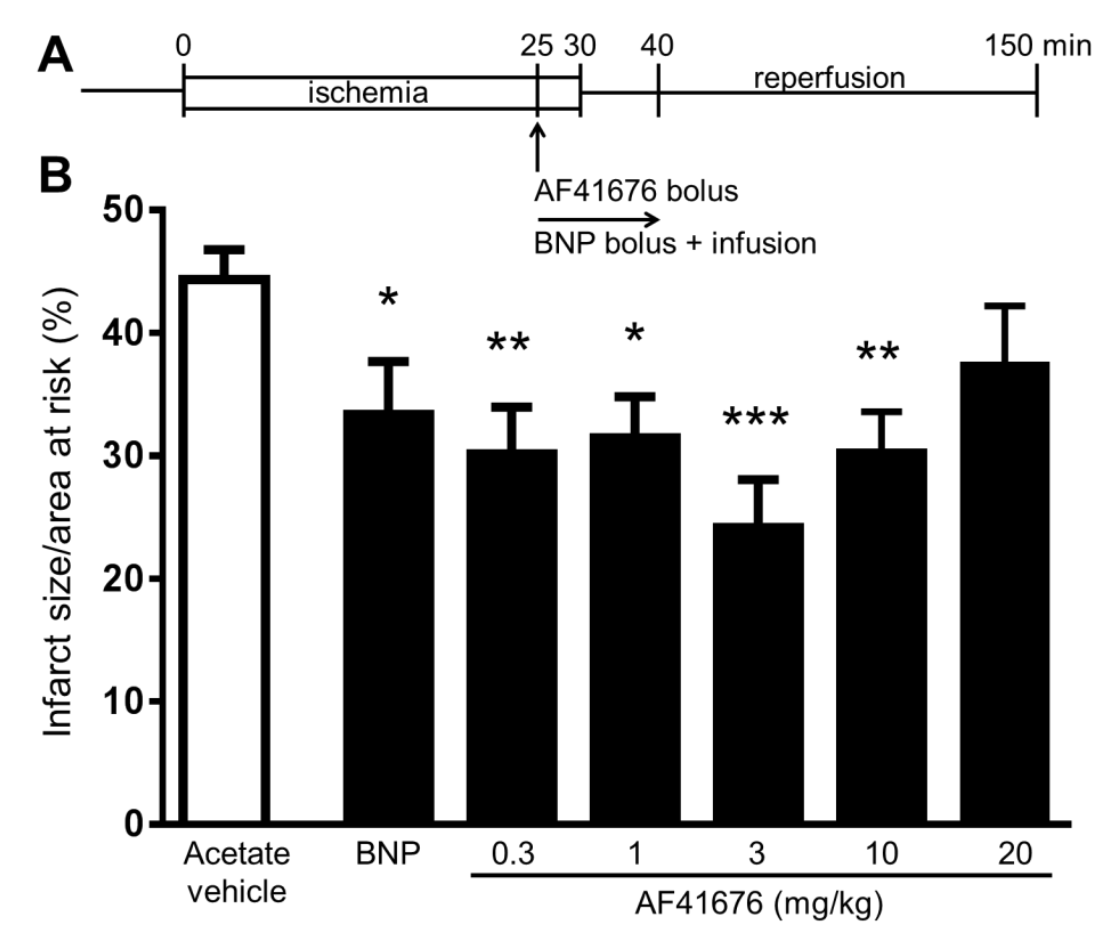

Figure 17. Panel A: Experimental protocol for Study 3. Panel B: Dose-response curve for AF41676 on infarct size in rats subjected to in vivo 30-min coronary occlusion followed by 120 min reperfusion. Data are expressed as means $\pm \mathrm{SEM},{ }^{*} \mathrm{p}<0.05,{ }^{* *} \mathrm{p}<0.01,{ }^{* * *} \mathrm{p}<0.001$ vs. vehicle control; $n=7-8$

\begin{tabular}{|c|c|c|c|c|c|c|c|c|c|}
\hline \multirow[t]{2}{*}{$\begin{array}{l}\text { Exp. } \\
\text { Group }\end{array}$} & \multirow[t]{2}{*}{$\mathrm{n}$} & \multirow[t]{2}{*}{$\begin{array}{c}\mathrm{AAR} / \mathrm{LV} \\
(\%)\end{array}$} & \multicolumn{3}{|c|}{$\begin{array}{l}\text { mean arterial blood } \\
\text { pressure }(\mathrm{mmHg})\end{array}$} & \multicolumn{3}{|c|}{$\begin{array}{l}\text { heart rate } \\
\text { (beats/min) }\end{array}$} & \multirow[t]{2}{*}{$\begin{array}{l}\text { SR } \\
(\%)\end{array}$} \\
\hline & & & BL & ISCH & REP & $\mathrm{BL}$ & ISCH & REP & \\
\hline $\begin{array}{l}\text { Vehicle } \\
\text { (acetate) }\end{array}$ & 8 & $33.0 \pm 3.4$ & $118 \pm 9$ & $116 \pm 11$ & $100 \pm 9$ & $418 \pm 14$ & $427 \pm 16$ & $402 \pm 10$ & 100 \\
\hline BNP & 8 & $34.9 \pm 2.4$ & $103 \pm 9$ & $73 \pm 6^{*}$ & $98 \pm 6$ & $396 \pm 16$ & $405 \pm 10$ & $490 \pm 18 *$ & 89 \\
\hline $\begin{array}{l}\text { AF41676 } \\
0.3 \mathrm{mg} / \mathrm{kg}\end{array}$ & 8 & $43.3 \pm 4.0$ & $109 \pm 6$ & $111 \pm 4$ & $94 \pm 3$ & $429 \pm 5$ & $450 \pm 4$ & $423 \pm 8$ & 100 \\
\hline $\begin{array}{l}\text { AF41676 } \\
1 \mathrm{mg} / \mathrm{kg}\end{array}$ & 8 & $36.7 \pm 4.0$ & $114 \pm 9$ & $104 \pm 6$ & $80 \pm 8$ & $427 \pm 8$ & $433 \pm 11$ & $410 \pm 9$ & 100 \\
\hline $\begin{array}{l}\text { AF41676 } \\
3 \mathrm{mg} / \mathrm{kg}\end{array}$ & 8 & $44.5 \pm 2.6$ & $125 \pm 5$ & $116 \pm 10$ & $104 \pm 5$ & $408 \pm 17$ & $418 \pm 11$ & $411 \pm 4$ & 77 \\
\hline $\begin{array}{l}\text { AF41676 } \\
10 \mathrm{mg} / \mathrm{kg}\end{array}$ & 8 & $34.1 \pm 3.5$ & $122 \pm 5$ & $75 \pm 8^{*}$ & $75 \pm 8^{*}$ & $443 \pm 6$ & $393 \pm 17$ & $413 \pm 17$ & 90 \\
\hline $\begin{array}{l}\text { AF41676 } \\
20 \mathrm{mg} / \mathrm{kg}\end{array}$ & 7 & $40.9 \pm 2.4$ & $125 \pm 8$ & $84 \pm 1^{*}$ & $83 \pm 9$ & $413 \pm 11$ & $361 \pm 26 *$ & $438 \pm 16$ & 80 \\
\hline
\end{tabular}

Table 8. Hemodynamic parameters, area at risk and survival ratio for study 3 . Data are expressed as means $\pm \mathrm{SEM},{ }^{*} \mathrm{p}<0.05,{ }^{* *} \mathrm{p}<0.01,{ }^{* * *} \mathrm{p}<0.001$ vs. vehicle. BNP: B-type natriuretic peptide; AAR/LV: area at risk/left ventricle; BL: baseline; $\mathrm{ISCH}: 29^{\text {th }}$ min of ischemia; REP: $120^{\text {th }}$ min of reperfusion; SR: survival rate 


\subsubsection{The effects of AF43136 on blood pressure, survival and infarct size (Study 4)}

AF43136 was administered in 10 and $30 \mathrm{mg} / \mathrm{kg}$ doses iv. as a bolus infusion for $5 \mathrm{~min}$ starting at the $25^{\text {th }}$ min of ischemia at a final volume load of $6 \mathrm{~mL} / \mathrm{kg}$. AF43136 at $10 \mathrm{mg} / \mathrm{kg}$ dose reduced infarct size significantly by approx. 30\% compared to the acetate vehicle control, however, infarct size data of $30 \mathrm{mg} / \mathrm{kg}$ AF43136 is equivocal due to the high mortality ratio and the consequent small sample size at the end of the experiments ( $n=2$; Fig. 18B, Table 9). The positive control CsA used in study 4 decreased infarct size significantly by approx. 23\% compared to the saline control (Fig. 18B, Table 9). There was no difference in the area at risks among the groups (Table 9). AF43136 at $30 \mathrm{mg} / \mathrm{kg}$ decreased mean arterial blood pressure significantly during ischemia compared to the acetate vehicle, but it did not reduce blood pressure at $10 \mathrm{mg} / \mathrm{kg}$ (Table 9). In addition, AF43136 at $10 \mathrm{mg} / \mathrm{kg}$ increased mean arterial blood pressure at the end of 120 min reperfusion compared to the acetate vehicle (Table 9). AF43136 at $30 \mathrm{mg} / \mathrm{kg}$ reduced survival rate significantly compared to acetate vehicle (Fig. 18C).

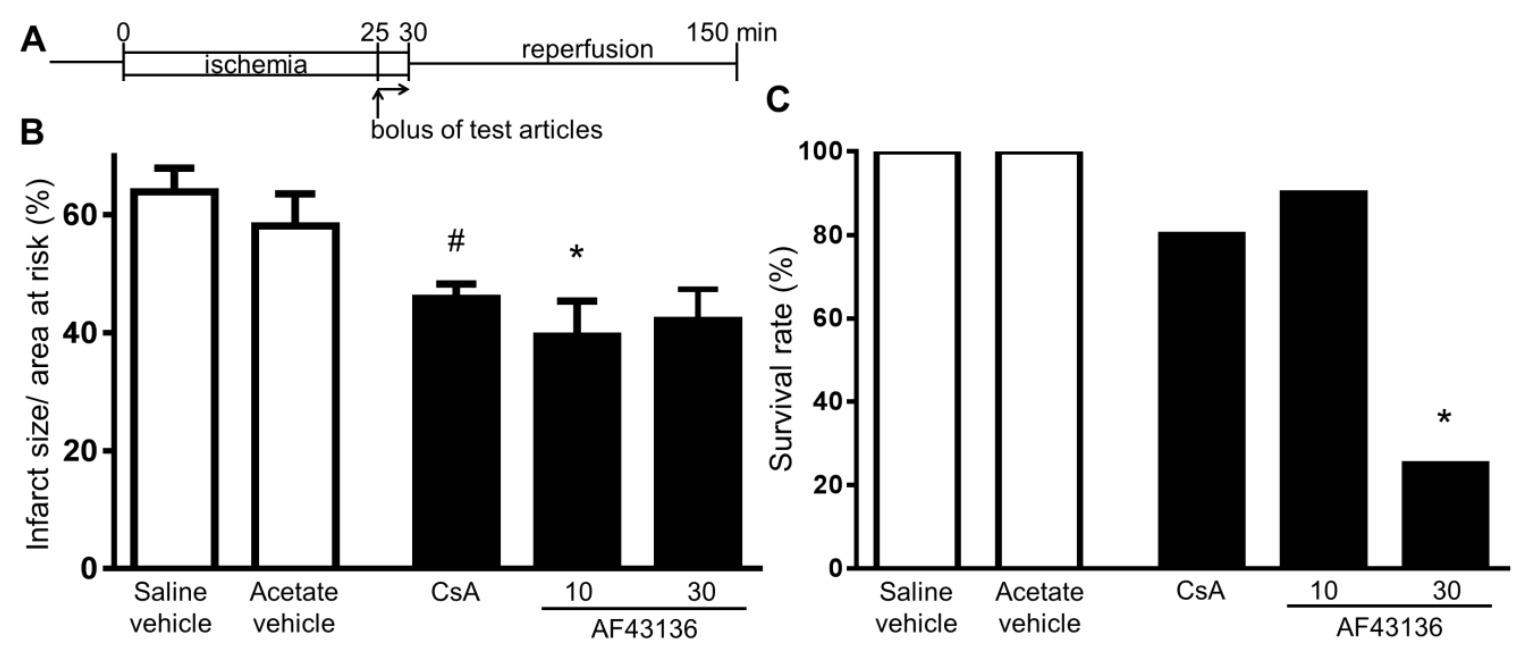

Figure 18. Panel A: Experimental protocol for Study 4. Panel B: The effect of 2 doses of AF43136 and cyclosporine A (CsA) on infarct size in rats subjected to in vivo 30-min coronary occlusion followed by 120 min reperfusion. Data are expressed as means \pm SEM, ${ }^{*} \mathrm{p}<0.05$ vs. vehicle control, ${ }^{\#} \mathrm{p}<0.05$ vs. saline control; $\mathrm{n}=7-8$. Infarct size data of $30 \mathrm{mg} / \mathrm{kg}$ AF43136 contains only 2 samples because of high mortality rate (see in Panel C). Panel C: The effect of 2 doses of AF43136 and cyclosporine A (CsA) on survival. Data are expressed as means $\pm \mathrm{SEM},{ }^{*} \mathrm{p}<0.01$ vs. vehicle control. 


\begin{tabular}{|c|c|c|c|c|c|c|c|c|}
\hline $\begin{array}{c}\text { Exp. } \\
\text { Group }\end{array}$ & $\mathrm{n}$ & $\begin{array}{c}\text { AAR/LV } \\
(\%)\end{array}$ & \multicolumn{2}{|c|}{$\begin{array}{r}\text { mean arterial blood } \\
\text { pressure (mmHg) }\end{array}$} & \multicolumn{4}{|c|}{$\begin{array}{c}\text { heart rate } \\
\text { (beats/min) }\end{array}$} \\
\hline $\begin{array}{c}\text { Vehicle } \\
\text { (saline) }\end{array}$ & 8 & $27.9 \pm 2.6$ & $110 \pm 5$ & $91 \pm 4$ & $72 \pm 3$ & $416 \pm 9$ & $432 \pm 23$ & $440 \pm 21$ \\
\hline $\begin{array}{c}\text { Vehicle } \\
\text { (acetate) }\end{array}$ & 8 & $30.6 \pm 3.1$ & $106 \pm 4$ & $90 \pm 6$ & $67 \pm 4$ & $433 \pm 15$ & $427 \pm 20$ & $415 \pm 17$ \\
\hline CsA & 7 & $34.5 \pm 2.5$ & $99 \pm 6$ & $82 \pm 6$ & $76 \pm 5$ & $445 \pm 12$ & $425 \pm 22$ & $434 \pm 12$ \\
\hline $\begin{array}{l}\text { AF43136 } \\
10 \text { mg/kg }\end{array}$ & 8 & $28.2 \pm 5.5$ & $111 \pm 6$ & $105 \pm 3$ & $88 \pm 5^{*}$ & $394 \pm 11$ & $413 \pm 12$ & $426 \pm 13$ \\
\hline $\begin{array}{l}\text { AF43136 } \\
30 \text { mg/kg }\end{array}$ & 8 & $20.3 \pm 4.8^{\$}$ & $96 \pm 6$ & $47 \pm 9 *$ & $54 \pm 18^{\$}$ & $438 \pm 15$ & $383 \pm 19$ & $437 \pm 15^{\$}$ \\
\hline
\end{tabular}

Table 9. Hemodynamic parameters, area at risk for study 4. Data are expressed as means \pm SEM, ${ }^{*} \mathrm{p}<0.05$ vs. vehicle; ${ }^{\$} \mathrm{n}=2$ due to high mortality. CsA: cyclosporine A; AAR/LV: area at risk/left ventricle; BL: baseline; ISCH: $29^{\text {th }}$ min of ischemia; REP: $120^{\text {th }}$ min of reperfusion. 


\section{Discussion}

The aims of the present experiments were to analyze further the $\mathrm{ONOO}^{-}-\mathrm{MMP}^{-}$and $\mathrm{EPO}$ receptor-mediated signaling pathways in ischemic heart diseases by investigating: i) the correlations of the markers of $\mathrm{ONOO}^{-}-\mathrm{MMP}$ signaling with hyperlipidemia as well as cardiac function in patients with significant coronary stenosis and ii) EpoR-mediated cardioprotective effects of two novel selective non-erythropoietic EPO receptor ligand dimeric peptides (AF41676 and AF43136) in an in vivo rat model of AMI.

\subsection{Summary of major findings of our studies}

\subsubsection{Characterization of $\mathrm{ONOO}^{-}-\mathrm{MMP}^{-1}$ signaling}

We found that serum nitrotyrosine positively correlated with MMP-9 activity, but did not correlate with MMP-2. We performed a comprehensive investigation to establish the correlation between serum nitrotyrosine, MMP-2, MMP-9 and the individual components of the lipid panel, respectively. Here we found, that serum nitrotyrosine correlated positively with serum total- and LDL- cholesterol as well as with triglyceride levels, while it correlated negatively with HDL cholesterol. MMP-2 activity showed a significant positive correlation with total- and LDL cholesterol as well, but did not correlate with triglyceride or HDL cholesterol. MMP-9 activity showed no correlation with any components of the lipid panel.

Besides the lipid panel, we used the left ventricular ejection fraction to examine the correlation between serum nitrotyrosine, MMPs and cardiac function. The nitrotyrosine level and the activity of MMP-9 correlated negatively with LVEF, respectively, while MMP-2 activity showed no correlation with this parameter.

In patients treated with statin, the nitrotyrosine level was significantly lower, than in statin-naive patients. There was no significant difference in MMP-2 and MMP-9 activity in the statin-treated population. In smoker patients, MMP-2 activity was significantly higher than in non-smoker patients. There was no significant difference in serum nitrotyrosine level and MMP-9 activity between smoker and non-smoker CAD patients.

Finally, we investigated the connection among serum nitrotyrosine levels, the activity of MMPs or the cardiac function and parameters of renal function. We found that serum nitrotyrosine correlates positively with serum creatinine, and MMP-9 activity correlates positively with serum urea nitrogen, while LVEF correlates negatively with serum creatinine. 
5.1.2 Cardioprotection by two selective non-erythropoietic EPO receptor ligand dimeric peptides (AF41676 and AF43136)

During the preliminary in vitro experiments, the receptor binding ability and nonerythropoietic effect of AF41676 and AF43136 compounds were confirmed. AF43136 bound with high affinity and AF41676 bound with modest activity to the EPO receptor. Moreover, AF41676 and AF43136 did not stimulate erythropoiesis either in vitro or in vivo.

We confirmed that EPO was able to induce cardio-cytoprotection independently from its erythropoietic activity in cultured neonatal cardiomyocytes subjected to simulated ischemia/reperfusion injury, furthermore EPO as well as its well-known derivative, Dpa were shown to decrease infarct size in an in vivo rat model of AMI.

The main novelty of this study was that AF41676 reduced infarct size in a dosedependent manner in a rat model of AMI, and AF43136 was also able to evoke cardioprotection, however, its higher dose could have potential adverse effects.

\subsection{Serum nitrotyrosine correlates with MMP activity}

We found a positive correlation of serum nitrotyrosine with MMP-9 activity, but not with MMP-2 activity. This may suggest that peroxynitrite can activate MMPs in humans as well. Previously, a positive correlation between nitrotyrosine content and MMP-9 expression was found in instable atherosclerotic plaques derived from patients with ischemic heart disease, which supports our present results [67]. However, the reason why we have not found a significant correlation between peroxynitrite and MMP-2 activity is not known. A plausible explanation is that MMP-2 activation and release can be less sensitively detected in the serum than that of MMP-9. While MMP-9 is an abundant enzyme in different cells and tissues including macrophages and leukocytes, MMP-2 is an intracellular enzyme occurring mainly in contractile tissues that can be activated and released; for example, due to acute myocardial ischemia/reperfusion and infarction [18, 68-71]. However, our CAD patient population did not have severe ischemia at the time of tissue sampling.

\subsection{Serum lipids correlate with nitrotyrosine and MMPs activity}

Hyperlipidemia is a well-characterized risk factor for cardiovascular diseases, and it has been also demonstrated that it contributes to elevated nitro-oxidative stress in humans [13, 72]. We have previously shown in rats and in apoB-100 transgenic mice that hypercholesterolemia increases nitro-oxidative stress, which leads to myocardial functional 
deterioration [73, 74]. Here, we have also examined the correlation pattern of serum lipids with nitrotyrosine in patients with $\mathrm{CAD}$ and shown that nitrotyrosine correlated positively with triglyceride, total and LDL cholesterol levels, and negatively with HDL cholesterol. In a previous study, an increased serum nitrotyrosine level was reported in hypercholesterolemic patients, wherein only LDL cholesterol showed significant positive correlation with nitrotyrosine [75]. In patients with CAD, a minor correlation was found between only serum protein bound nitrotyrosine and triglyceride [13]. A similar correlation was shown by others in patients with metabolic syndrome [76]. Here, we have found that serum MMP-2 activity correlated positively with total and LDL cholesterol levels. However, neither HDL cholesterol, nor triglyceride levels correlated with MMP-2 activity. According to our best knowledge, MMP-2 activity has been investigated by only one previous study in patients with CAD, in which a negative correlation between serum MMP-2 activity and HDL cholesterol was found; however, other correlations were not assessed [77]. In another study, plasma MMP-2 protein level was shown to correlate negatively with HDL in patients with CAD [78]. Noji et al. measured plasma MMP-2 in patients with CAD several days before coronary intervention and interestingly found a positive correlation between MMP-2 protein level and HDL cholesterol; however, they did not assess MMP-2 activity [79]. In our present study, serum MMP-9 activity did not show correlation with any of the serum lipids. Nilsson et al. found negative correlation between MMP-9 level and serum HDL in hypercholesterolemia patients [80]. Two independent studies in patients with CAD and acute coronary syndrome showed that MMP-9 protein level positively correlated with LDL cholesterol [78, 79]. Furthermore, correlation of plasma MMP-9 protein content with triglyceride level has been also shown [78]. However, in these studies, the authors did not measure MMP-9 activities, only MMP-9 protein immune reactivity.

\subsection{Myocardial function correlates with serum nitrotyrosine and MMPs activity}

Here, we have demonstrated first time in the literature in patients with CAD that cardiac function characterized by LVEF showed a significant negative correlation with serum nitrotyrosine. This may suggest that nitro-oxidative stress is detrimental to cardiac function in humans, which is in accordance with preclinical studies. Furthermore, we have found here that LVEF correlated negatively with MMP-9 activity; however, there was no correlation with MMP-2 activity. This is partly in accordance with previous findings showing that MMP-2 and MMP-9 protein levels correlate with LVEF or left ventricular end diastolic volume index in cardiac patients with acute myocardial infarction or heart failure [81-83]. We have also 
examined here the correlation of serum cholesterol and triglyceride levels with LVEF, however, we did not observe any significant correlation among these data. In contrast, Wang et al. described a positive correlation of LVEF with serum HDL cholesterol and a negative correlation with serum triglyceride in patients with angina [84].

\subsection{Decreased serum nitrotyrosine in statin-treated patients}

Most CAD patients are treated with various statins. Statins are well-characterized inhibitors of endogenous cholesterol synthesis, and it has been also described that they attenuate nitro-oxidative stress [85] as assessed by plasma nitrotyrosine level in patients with CAD [13]. Accordingly, we found here a reduced serum nitrotyrosine level in statin-related CAD patients as compared to statin naive ones. Here, we have found that MMP-2 and MMP9 activities were not significantly different in statin-treated patients with CAD as compared to statin naives, although a tendency of decrease was found. In contrast, it has been shown in 48 patients with CAD undergone coronary artery bypass surgery that protein levels and activities of MMP-2 and MMP-9 measured both in plasma and in pericardial fluid were reduced after 2month pravastatin therapy as compared to untreated patients [86]. Other authors have also reported a reduction in plasma MMP-2 and/or MMP-9 protein levels after statin treatment of cardiac patients; however, in these studies, only MMP protein levels were measured [81-83, 87].

\subsection{Increased MMP-2 activity in smoker patients}

Here we found that MMP-2 but not MMP-9 activity was significantly higher in the serum samples of smoker patients compared to the non-smokers. Previously, significant increase in proMMP-9 and modest increase in proMMP-2 activity was found in rat aortic vascular smooth muscle cells treated with cigarette-smoke extracts [88]. In clinical studies, increased gene expression of MMP-2 and MMP-9 was found in venous [89] and aortic wall samples [90] of smoker patients. In human serum samples, the amount of proMMP-2 and proMMP-9 was higher in smokers, however the active forms of MMPs were not detectable in those samples [91]. Although cigarette smoke contains peroxynitrite and peroxynitrite-generating species suggesting that it contributes to the pathogenesis of atherosclerosis via increased nitro-oxidative stress [92, 93], we could not demonstrate any difference of serum $\mathrm{ONOO}^{-}$ level between smokers and non-smokers. 
5.7 Renal function correlates with serum nitrotyrosine and MMPs activity

It has been previously described that renal dysfunction may develop and contribute to mortality in patients with myocardial infarction [94]. It is also well known that ischemic coronary disease is a leading cause of death in uremic patients [95]. Although uremic patients and patients with severe left ventricular dysfunction were not enrolled into the present study, we have shown a significant negative correlation between serum creatinine level and LVEF for the first time in the literature in patients with CAD. Moreover, we have found a positive correlation between serum creatinine and nitrotyrosine as well as between urea nitrogen and MMP-9 activity in patients with CAD. These results suggest that both increased nitrotyrosine level and MMP-9 activity may indicate an incipient renal dysfunction before myocardial infarction even when the patients have creatinine and/or urea nitrogen levels near or within the normal range.

\subsection{Cardioprotective effects of EPO}

In the present study, we demonstrated that EPO, independently from its erythropoietic activity, protected cultured neonatal cardiomyocytes against simulated ischemia/reperfusion. Our findings confirm previous studies that EPO has cytoprotective- [96] and anti-apoptotic effects on cardiomyocytes [97]. In in vivo coronary occlusion/reperfusion experiments, we found that iv., but not ip. administration of the same dose of EPO before the onset of reperfusion decreased infarct size in rats, although it has been previously demonstrated that EPO reduces infarct size by both ip. [97, 98] or iv. [99] administration. This discrepancy could be due to pharmacokinetic differences or different duration of treatments [100].

\subsection{Dose-response effect of Dpa in AMI}

Here, we also reported first time in the literature about the dose-response relationship of Dpa administered before the onset of reperfusion. Although, the infarct size-limiting dose of Dpa administered before reperfusion varies in a wide range in the literature (from 2.5 [101] to $30 \mu \mathrm{g} / \mathrm{kg}$ [102]), our results point out that $5 \mu \mathrm{g} / \mathrm{kg}$ dose of Dpa is sufficient to reduce infarct size in a rat model of AMI. 


\subsection{Cardioprotective effect of AF41676 and AF43136}

One of the major novelty of our present study is that two novel selective nonerythropoietic EPO receptor ligand dimeric peptides, AF41676 and AF43136, reduce infarct size significantly when administered before reperfusion in an in vivo rat model of AMI. AF41676 was effective in reducing infarct size at a wide dose-range $(0.3-10 \mathrm{mg} / \mathrm{kg})$. Although, high doses (10 and $20 \mathrm{mg} / \mathrm{kg}$ ) of AF41676 decreased mean arterial blood pressure, they did not influence survival, and we did not register any severe side effects during the experiments. In contrast, AF43136 reduced infarct size, but it was lethal in higher doses due to a rapid decline in mean arterial blood pressure during its administration. As analogs of the peptide portion of peginesatide, AF41676 and AF43136 were initially prepared as an attempt to define non-erythropoietic agents. These analogs exhibit reliable binding to the extracellular portion of the EPO receptor, however, do not stimulate erythropoiesis suggesting that they may act via the EpoR-mediated cytoprotective pathways.

It has been previously demonstrated that the modified EPO analogues, CEPO and asialoEpo, preserve the tissue protective effects of EPO, such as infarct size reduction, prevention of cardiac hypertrophy and improvement of cardiac function [35,48-51], without any erythropoietic safety problems [29]. However, these EPO analogues are unfavorable due to their potential for high antigenicity, inadequate long-term stability and relatively high costs of production [34, 52]. Therefore, previously, a small EPO analogue, pyroglutamate helix B surface peptide (pHBSP or ARA 290) consisting of 11 amino acids of the beta-chain of EPO, was generated to substitute EPO or its large peptide analogues to achieve cardioprotection without inducing erythropoiesis [103]. PHBSP is a small fragment of EPO, and one would assume that when excised out of the cytokine, it would only randomly adopt the appropriate conformation and thus be a very poor binder to the receptor. So far, only one study has demonstrated that pHBSP reduces infarct size in acute coronary ligation in rats [104]. In contrast, AF peptides were structured via the linker and disulfide bonds to wrap around each other, and present a surface that is highly complementary to the EPO receptor. The two AF peptides are structurally related to the peptide portion of peginesatide and therefore expected to bind EpoR tightly. These features support our findings, that non-erythropoietic EPO analogue dimeric peptides may be promising cardioprotective agents against acute myocardial infarction. 


\subsection{Study limitations}

In the present human study the number of the enrolled patients was relatively low. However, bootstrap analysis of the correlation coefficients was performed, which is a widely accepted statistical method of making robust estimates of the coefficients in case of small sample sizes. The correlations we found were relatively weak, but statistically significant. This may show that there might be several other players in the interactions between the parameters we correlated in the present study.

Direct translational conclusion to human cardioprotection cannot be drawn from the preclinical results of EPO analogues. However, modulation of EPO receptor stimulation by novel receptor ligands should be a target of continued investigations as a promising cardioprotective strategy. 


\section{Conclusion}

6.1 Novel findings

Here, we investigated the correlations of the $\mathrm{ONOO}^{-}-\mathrm{MMP}$ pathway and analyzed EpoR-mediated cardioprotective signaling in ischemic heart disease.

We have demonstrated for the first time in the literature that (i) serum nitrotyrosine correlates with MMP-9 activity, (ii) serum lipid parameters correlate with nitrotyrosine level and MMP-2 activity, (iii) myocardial function correlates with nitrotyrosine, MMP-9 activity as well as with creatinine, and (iv) creatinine correlates with nitrotyrosine and urea nitrogen correlates with MMP-9 activity in patients with CAD.

Here, we have shown that two novel selective non-erythropoietic EPO receptor ligand dimeric peptides, AF41676 and AF43136, reduce infarct size in a rat model of acute myocardial infarction. This is the first demonstration that these EPO receptor ligand peptides are cardioprotective in a rat model of AMI, and their effects are comparable with that of EPO and Dpa.

\subsection{Future perspectives}

These findings suggest that nitrotyrosine and MMP-2 and MMP-9 activities may have predictive or diagnostic values in cardiac and renal function of patients with CAD, and attenuation of nitrooxidative stress and MMP activities may provide therapeutic benefits in this patient population. Thus, to study markers of peroxynitrite-MMP pathway in large prospective studies may reveal their diagnostic avails.

Moreover, non-erythropoietic EPO receptor ligands may be potential cardioprotective agents in acute myocardial infarction. Further translational studies will be needed to ensure the safety and efficacy of these agents as potential alternative clinical treatments. 


\section{Acknowledgment}

This project was supported by the following grants: Hungarian Ministry of Health [ETT 476/2009], the National Office for Research and Technology [NKFP_06_A1-MMP_2006, HURO/ 0901/137/2.2.2 - HU-RO TRANS-MED, TAMOP-4.2.1/B-09/ 1/KONV-2010-0005, TAMOP-4.2.2/B-10/1-2010-0012, TAMOP-4.2.2.A-11/1/KONV-2012-0035 and BAROSSDA07-DA-TECH-07-2008-0041], and János Bolyai Research Scholarship of the Hungarian Academy of Sciences (PB) as well as by direct financing from Pharmahungary Group partially via partnership with Affimax Inc.

I would like to greatly acknowledge Professor László Dux for the opportunity to work at the Department of Biochemistry.

I am especially grateful to my supervisors Péter Bencsik and Tamás Csont for their lots of work in my guiding.

I am very thankful to Professor Péter Ferdinandy for the possibility to work in his Cardiovascular Research Group.

I would like to say special thanks to Imre Ungi and Viktor Sasi for the clinical examinations and for providing human blood samples as well as to Imre Földesi for the laboratory measurements.

I would like to express my sincere gratitude to Kathryn W. Woodburn, Mehrdad Shamloo and Christopher P. Holmes, colleagues of the Affymax Inc., for their kind partnership with Pharmahungary Group, for providing the AF test compounds and for their great help in the compilation of the manuscript.

Many thanks to all co-authors, who contributed with their work to the two studies and the scientific papers, which provided the basis of my $\mathrm{PhD}$ thesis.

I would like to give my special thanks to all of my present and past colleagues and friends, who supported me during the years.

Finally, I take this opportunity to acknowledge my family for their support. 


\section{References}

[1] http://ipscience.thomsonreuters.com/product/journal-citation-reports

[2] N. Townsend, L. Wilson, P. Bhatnagar, et al., Cardiovascular disease in Europe: epidemiological update 2016, Eur. Heart J. 0 (2016) 1-14

[3] M. Nichols, N. Townsend, P. Scarborough, et al., European Cardiovascular Disease Statistics 2012 edition, (2012) ISBN 978-2-9537898-1-2

[4] P. Libby, P. Theroux, Pathophysiology of Coronary Artery Disease, Circulation 111 (2005) 3481-8

[5] E. Bronze-da-Rocha, MicroRNAs Expression Profiles in Cardiovascular Diseases, Biomed. Res. Int. (2014) Article ID: 985408

[6] S. Sayols-Baixeras, C. Lluís-Ganella, G. Lucas, et al., Pathogenesis of coronary artery disease: focus on genetic risk factors and identification of genetic variants, Appl. Clin. Genet. 7 (2014) 15-32

[7] T. S. Han, M. E. Lean, A clinical perspective of obesity, metabolic syndrome and cardiovascular disease, JRSM. Cardiovasc. Dis. 5 (2016) 1-13

[8] L. F. Van Gaal, I. L. Mertens, C. E. De Block, Mechanisms linking obesity with cardiovascular disease, Nature 444 (2006) 875-80

[9] V. H. Nguyen, M. A. McLaughlin, Coronary artery disease in women: a review of emerging cardiovascular risk factors, Mt. Sinai. J. Med. 69 (2002) 338-49

[10] A. Warnholtz, H. Mollnau, M. Oelze, et al., Antioxidants and endothelial dysfunction in hyperlipidemia, Curr. Hypertens. Rep. 3 (2001) 53-60

[11] P. Ferdinandy, R. Schulz, G.F. Baxter, Interaction of cardiovascular risk factors with myocardial ischemia/reperfusion injury, preconditioning, and postconditioning, Pharmacol. Rev. 59 (2007) 418-58

[12] I. Ungi, T. Ungi, Z. Ruzsa, et al., Hypercholesterolemia attenuates the anti-ischemic effect of preconditioning during coronary angioplasty, Chest 128 (2005) 1623-8

[13] M. H. Shishehbor, R. J. Aviles, M. L. Brennan, et al., Association of nitrotyrosine levels with cardiovascular disease and modulation by statin therapy, JAMA 289 (2003) 1675-80

[14] R. S. Vasan, Biomarkers of cardiovascular disease: molecular basis and practical considerations, Circulation 113 (2006) 2335-62

[15] P. T. O’Gara, F. G. Kushner, D. D. Ascheim, et al., 2013 ACCF/AHA guideline for the management of ST-elevation myocardial infarction: a report of the American College of Cardiology Foundation/American Heart Association Task Force on Practice Guidelines, J. Am. Coll. Cardiol. 61 (2013) 78-140

[16] R. Khan, V. Spagnoli, J. Tardif, et al., Novel anti-inflammatory therapies for the treatment of atherosclerosis, Atherosclerosis 240 (2015) 497-509

[17] C. Szabo, H. Ischiropoulos, R. Radi, Peroxynitrite: biochemistry, pathophysiology and development of therapeutics, Nat. Rev. Drug. Discov. 6 (2007) 662-80

[18] P. Bencsik, K. Kupai, Z. Giricz, et al., Cardiac capsaicin-sensitive sensory nerves regulate myocardial relaxation via S-nitrosylation of SERCA: role of peroxynitrite, $\mathrm{Br}$. J. Pharmacol. 153 (2008) 488-96

[19] P. Ferdinandy, Peroxynitrite: just an oxidative/nitrosative stressor or a physiological regulator as well? Br. J. Pharmacol. 148 (2006) 1-3 
[20] J. Gross, C. M. Lapiere, Collagenolytic activity in amphibian tissues: a tissue culture assay, Proc. Natl. Acad. Sci. 48 (1962) 1014-22

[21] G. Dorman, S. Cseh, I. Hajdu, et al., Matrix metalloproteinase inhibitors: a critical appraisal of design principles and proposed therapeutic utility, Drugs 70 (2010) 94964

[22] A. K. Chow, J. Cena, R. Schulz, Acute actions and novel targets of matrix metalloproteinases in the heart and vasculature, Br. J. Pharmacol. 152 (2007) 189-205

[23] G. Dorman, K. Kocsis-Szommer, C. Spadoni, et al., MMP inhibitors in cardiac diseases: an update, Recent. Pat. Cardiovasc. Drug. Discov. 2 (2007) 186-94

[24] R. Schulz, Intracellular targets of matrix metalloproteinase-2 in cardiac disease: rationale and therapeutic approaches, Annu. Rev. Pharmacol. Toxicol. 47 (2007) 21142

[25] L. Nilsson, J. Hallen, D. Atar, et al., Early measurements of plasma matrix metalloproteinase-2 predict infarct size and ventricular dysfunction in ST-elevation myocardial infarction, Heart 98 (2012) 31-6

[26] M. A. Ali, R. Schulz, Activation of MMP-2 as a key event in oxidative stress injury to the heart, Front. Biosci. 14 (2009) 699-716

[27] F. G. Spinale, Myocardial matrix remodeling and the matrix metalloproteinases: influence on cardiac form and function, Physiol. Rev. 87 (2007) 1285-342

[28] C. Bokemeyer, M. S. Aapro, A. Courdi, et al., EORTC guidelines for the use of erythropoietic proteins in anaemic patients with cancer: 2006 update, Eur. J. Cancer 43 (2007) 258-270

[29] F. Sanchis-Gomar, J. L. Garcia-Gimenez, H. Pareja-Galeano, et al., Erythropoietin and the heart: physiological effects and the therapeutic perspective, Int. J. Cardiol. 171 (2014) 116-125

[30] G. L. Wright, P. Hanlon, K. Amin, et al., Erythropoietin receptor expression in adult rat cardiomyocytes is associated with an acute cardioprotective effect for recombinant erythropoietin during ischemia-reperfusion injury, FASEB J. 18 (2004) 1031-1033

[31] R. Depping, K. Kawakami, H. Ocker, et al., Expression of the erythropoietin receptor in human heart, J. Thorac. Cardiovasc. Surg. 130 (2005) 877-878

[32] K. Maiese, Z. Z. Chong, J. Hou, Erythropoietin and oxidative stress, Curr. Neurovasc. Res. 5 (2008) 125-42

[33] M. Brines, G. Grasso, F. Fiordaliso, et al., Erythropoietin mediates tissue protection through an erythropoietin and common beta-subunit heteroreceptor, Proc. Natl. Acad. Sci. U. S. A. 101 (2004) 14907-14912

[34] M. Collino, C. Thiemermann, A. Cerami, M. Brines, Flipping the molecular switch for innate protection and repair of tissues: long-lasting effects of a non-erythropoietic small peptide engineered from erythropoietin, Pharmacol. Ther. 151 (2015) 32-40

[35] K. Xu, I. George, S. Klotz, et al., Erythropoietin derivate improves left ventricular systolic performance and attenuates left ventricular remodeling in rats with myocardial infarct-induced heart failure, J. Cardiovasc. Pharmacol. 56 (2010) 506-512

[36] J. T. Parissis, K. Kourea, I. Andreadou, et al., Effects of Darbepoetin Alfa on plasma mediators of oxidative and nitrosative stress in anemic patients with chronic heart failure secondary to ischemic or idiopathic dilated cardiomyopathy, Am. J. Cardiol. 103 (2009) 1134-8

[37] Q. Wang, F. Pfister, A. Dorn-Beineke, et al., Low-dose erythropoietin inhibits oxidative stress and early vascular changes in the experimental diabetic retina, Diabetologia 53 (2010) 1227-38 
[38] C. Y. Chan, Y. S. Chen, H. H. Lee, et al., Erythropoietin protects post-ischemic hearts by preventing extracellular matrix degradation: role of Jak2-ERK pathway, Life Sci. 81 (2007) 717-23

[39] X. Chen, Z. Guo, P. Wang et al., Erythropoietin modulates imbalance of matrix metalloproteinase-2 and tissue inhibitor of metalloproteinase-2 in doxorubicin-induced cardiotoxicity, Heart Lung Circ. 23 (2014) 772-7

[40] H. Wu, G. Dong, H. Liu, et al., Erythropoietin attenuates ischemia-reperfusion induced lung injury by inhibiting tumor necrosis factor-alpha and matrix metalloproteinase-9 expression, Eur. J. Pharmacol. 602 (2009) 406-12

[41] R. Latini, M. Brines, F. Fiordaliso, Do non-hemopoietic effects of erythropoietin play a beneficial role in heart failure, Heart Fail. Rev. 13 (2008) 415-423

[42] E. Lipsic, R.G. Schoemaker, P. van der Meer, et al., Protective effects of erythropoietin in cardiac ischemia: from bench to bedside, J. Am. Coll. Cardiol. 48 (2006) 2161-2167

[43] A. Palazzuoli, G. Ruocco, M. Pellegrini, et al., The role of erythropoietin stimulating agents in anemic patients with heart failure: solved and unresolved questions, Ther. Clin. Risk. Manag. 10 (2014) 641-650

[44] S.S. Najjar, S.V. Rao, C. Melloni, et al., Intravenous erythropoietin in patients with ST-segment elevation myocardial infarction: REVEAL: a randomized controlled trial, JAMA 305 (2011) 1863-1872

[45] A. Besarab, W.K. Bolton, J.K. Browne, et al., The effects of normal as compared with low hematocrit values in patients with cardiac disease who are receiving hemodialysis and epoetin, N. Engl. J. Med. 339 (1998) 584-590

[46] I. Ott, S. Schulz, J. Mehilli, et al., Erythropoietin in patients with acute ST-segment elevation myocardial infarction undergoing primary percutaneous coronary intervention: a randomized, double-blind trial, Circ. Cardiovasc. Interv. 3 (2010) 408413

[47] Q. Fan, K. K. Leuther, C.P. Holmes, et al., Preclinical evaluation of Hematide, a novel erythropoiesis stimulating agent, for the treatment of anemia, Exp. Hematol. 34 (2006) 1303-1311

[48] F. Fiordaliso, S. Chimenti, L. Staszewsky, et al., A nonerythropoietic derivative of erythropoietin protects the myocardium from ischemia-reperfusion injury, Proc. Natl. Acad. Sci. U. S. A. 102 (2005) 2046-2051

[49] C. Moon, M. Krawczyk, D. Paik, et al., Erythropoietin, modified to not stimulate red blood cell production, retains its cardioprotective properties, J. Pharmacol. Exp. Ther. 316 (2006) 999-1005

[50] T. Takeyama, G. Takemura, H. Kanamori, et al., Asialoerythropoietin, a nonerythropoietic derivative of erythropoietin, displays broad anti-heart failure activity, Circ. Heart Fail. 5 (2012) 274-285

[51] X. Xu, Z. Cao, B. Cao, et al., Carbamylated erythropoietin protects the myocardium from acute ischemia/reperfusion injury through a PI3K/Akt-dependent mechanism, Surgery 146 (2009) 506-514

[52] M. Brines, A. Cerami, Erythropoietin-mediated tissue protection: reducing collateral damage from the primary injury response, J. Intern. Med. 264 (2008) 405-432

[53] K. Kupai, G. Szucs, S. Cseh, et al., Matrix metalloproteinase activity assays: importance of zymography, J. Pharmacol. Toxicol. Methods 61 (2010) 205-9

[54] Z. Radak, H. Ogonovszky, J. Dubecz, et al., Super-marathon race increases serum and urinary nitrotyrosine and carbonyl levels, Eur. J. Clin. Invest. 33 (2003) 726-30 
[55] T. Csont, C. Csonka, A. Onody, et al., Nitrate tolerance does not increase production of peroxynitrite in the heart, Am. J. Physiol. Heart. Circ. Physiol. 283 (2002) H69-76

[56] N. Casadevall, J. Nataf, B. Viron, et al., Pure red-cell aplasia and antierythropoietin antibodies in patients treated with recombinant erythropoietin, N. Engl. J. Med. 346 (2002) 469-475

[57] Q. Fan, K. K. Leuther, C. P. Holmes, et al., Preclinical evaluation of Hematide, a novel erythropoiesis stimulating agent, for the treatment of anemia, Exp. Hematol. 34 (2006) 1303-1311

[58] D. Burger, A. Xenocostas, Q. P. Feng, Molecular basis of cardioprotection by erythropoietin, Curr. Mol. Pharmacol. 2 (2009) 56-69

[59] D. S. Burley, G. F. Baxter, B-type natriuretic peptide at early reperfusion limits infarct size in the rat isolated heart, Basic Res. Cardiol. 102 (2007) 529-541

[60] H. Kemperman, M. van den Berg, H. Kirkels, et al., B-type natriuretic peptide (BNP) and N-terminal proBNP in patients with end-stage heart failure supported by a left ventricular assist device, Clin. Chem. 50 (2004) 1670-1672

[61] T. Csont, A. Gorbe, E. Bereczki, et al., Biglycan protects cardiomyocytes against hypoxia/reoxygenation injury: role of nitric oxide, J. Mol. Cell. Cardiol. 48 (2010) 649-652

[62] A. Görbe, Z. Giricz, A. Szunyog, et al., Role of cGMP-PKG signaling in the protection of neonatal rat cardiac myocytes subjected to simulated ischemia/reoxygenation, Basic Res. Cardiol. 105 (2010) 643-650

[63] P. Bencsik, J. Paloczi, G. F. Kocsis, et al., Moderate inhibition of myocardial matrix metalloproteinase-2 by ilomastat is cardioprotective, Pharmacol. Res. 80 (2014) 36-42

[64] C. Csonka, K. Kupai, G. F. Kocsis, et al., Measurement of myocardial infarct size in preclinical studies, J. Pharmacol. Toxicol. Methods 61 (2010) 163-170

[65] C. M. Campos, K. D. Van, V. Farooq, et al., Long-term forecasting and comparison of mortality in the evaluation of the xience everolimus eluting stent vs. Coronary Artery Bypass Surgery for Effectiveness of Left Main Revascularization (EXCEL) trial: prospective validation of the SYNTAX Score II, Eur. Heart. J. 36 (2015) 1231-41

[66] R. Yotti, J. Bermejo, Y. Benito, et al., Noninvasive estimation of the rate of relaxation by the analysis of intraventricular pressure gradients, Circ. Cardiovasc. Imaging 4 (2011) 94-104

[67] F. Sigala, A. Kotsinas, P. Savari, et al., Oxidized LDL in human carotid plaques is related to symptomatic carotid disease and lesion instability, J. Vasc. Surg. 52 (2010) 704-13

[68] C. Q. Gao, G. Sawicki, W. L. Suarez-Pinzon, et al., Matrix metalloproteinase-2 mediates cytokine induced myocardial contractile dysfunction, Cardiovasc. Res. 57 (2003) 426-33

[69] D. Polewicz, V. J. Cadete, A. Doroszko, et al., Ischemia induced peroxynitrite dependent modifications of cardiomyocyte MLC1 increases its degradation by MMP-2 leading to contractile dysfunction, J. Cell. Mol. Med. 15 (2011) 1136-47

[70] M. M. Sung, C. G. Shchulz, W. Wang, et al., Matrix metalloproteinase-2 degrades the cytoskeletal protein alpha-actinin in peroxynitrite mediated myocardial injury, J. Mol. Cell. Cardiol. 43 (2007) 429-36

[71] W. Wang, G. Sawicki, R. Schulz, Peroxynitrite-induced myocardial injury is mediated through matrix metalloproteinase-2, Cardiovasc. Res. 53 (2002) 165-74

[72] T. Munzel, T. Gori, R. M. Bruno, et al., Is oxidative stress a therapeutic target in cardiovascular disease? Eur. Heart. J. 31 (2010) 2741-8 
[73] A. Onody, C. Csonka, Z. Giricz, et al., Hyperlipidemia induced by a cholesterol-rich diet leads to enhanced peroxynitrite formation in rat hearts, Cardiovasc. Res. 58 (2003) 663-70

[74] T. Csont, E. Bereczki, P. Bencsik, et al., Hypercholesterolemia increases myocardial oxidative and nitrosative stress thereby leading to cardiac dysfunction in apoB-100 transgenic mice, Cardiovasc. Res. 76 (2007) 100-9

[75] M. Pirro, G. Schillaci, M. R. Mannarino, et al., Effects of rosuvastatin on 3nitrotyrosine and aortic stiffness in hypercholesterolemia, Nutr. Metab. Cardiovasc. Dis. 17 (2007) 436-41

[76] K. Esposito, M. Ciotola, B. Schisano, et al., Oxidative stress in the metabolic syndrome, J. Endocrinol. Invest. 29 (2006) 791-5

[77] M. L. Muzzio, V. Miksztowicz, F. Brites, et al., Metalloproteases 2 and 9, Lp-PLA(2) and lipoprotein profile in coronary patients, Arch. Med. Res. 40 (2009) 48-53

[78] G. Derosa, A. D’Angelo, F. Scalise, et al., Comparison between metalloproteinases-2 and -9 in healthy subjects, diabetics, and subjects with acute coronary syndrome, Heart Vessels 22 (2007) 361-70

[79] Y. Noji, K. Kajinami, M. A. Kawashiri, et al., Circulating matrix metalloproteinases and their inhibitors in premature coronary atherosclerosis, Clin. Chem. Lab. Med. 39 (2001) 380-4

[80] L. Nilsson, P. Eriksson, P. Cherfan, et al., Effects of simvastatin on proinflammatory cytokines and matrix metalloproteinases in hypercholesterolemic individuals, Inflammation 34 (2011) 225-30

[81] R. Nakaya, H. Uzui, H. Shimizu, et al., Pravastatin suppresses the increase in matrix metalloproteinase-2 levels after acute myocardial infarction, Int. J. Cardiol. 105 (2005) 67-73

[82] A. T. Yan, R. T. Yan, F. G. Spinale, et al., Plasma matrix metalloproteinase-9 level is correlated with left ventricular volumes and ejection fraction in patients with heart failure, J. Card. Fail. 12 (2006) 514-9

[83] S. Yasuda, S. Miyazaki, H. Kinoshita, et al., Enhanced cardiac production of matrix metalloproteinase-2 and -9 and its attenuation associated with pravastatin treatment in patients with acute myocardial infarction, Clin. Sci. 112 (2007) 43-9

[84] T. D. Wang, C. M. Lee, C. C. Wu, et al., The effects of dyslipidemia on left ventricular systolic function in patients with stable angina pectoris, Atherosclerosis 146 (1999) 117-24

[85] J. Davignon, R. F. Jacob, R. P. Mason, The antioxidant effects of statins, Coron. Artery. Dis. 15 (2004) 251-8

[86] T. Fujiwara, S. Saito, T. Osanai, et al., Decreased plasma and cardiac matrix metalloproteinase activities in patients with coronary artery disease and treated with pravastatin, Eur. J. Pharmacol. 594 (2008) 146-51

[87] K. K. Koh, J. W. Son, J. Y. Ahn, et al., Non-lipid effects of statin on hypercholesterolemic patients established to have coronary artery disease who remained hypercholesterolemic while eating a step-II die, Coron. Artery. Dis. 12 (2001) 305-11

[88] A. Ghosh, A. Pechota, D. Coleman, et al., Cigarette smoke-induced MMP2 and MMP9 secretion from aortic vascular smooth cells is mediated via the Jak/Stat pathway, Hum. Pathol. 46 (2015) 284-94

[89] Y. Sun, D. Wenjun, W. Qiang, et al., Heavy Smoking Before Coronary Surgical Procedures Affects the Native Matrix Metalloproteinase-2 and Matrix 
Metalloproteinase-9 Gene Expression in Saphenous Vein Conduits, Ann. Thorac. Surg. 95 (2013) 55-61

[90] J. F. Dilmé, S. Bellmunt, M. Camacho, et al., Influence of cardiovascular risk factors on levels of matrix metalloproteinases 2 and 9 in human abdominal aortic aneurysms, Eur. J. Vasc. Endovasc. Surg. 48 (2014) 374-81

[91] A. Raitio, H. Tuomas, N. Kokkonen, et al., Levels of matrix metalloproteinase-2, -9 and -8 in the skin, serum and saliva of smokers and non-smokers, Arch. Dermatol. Res. 297 (2005) 242-8

[92] A. Csiszar, A. Podlutsky, M. S. Wolin, et al., Oxidative stress and accelerated vascular aging: implications for cigarette smoking, Front. Biosci. (Landmark Ed) 14 (2009) 3128-44

[93] Y. Yamaguchi, S. Kagota, J. Haginaka, et al., Peroxynitrite-generating species: good candidate oxidants in aqueous extracts of cigarette smoke, Jpn. J. Pharmacol. 82 (2000) 78-81

[94] N. S. Anavekar, J. J. McMurray, E. J. Velazquez, et al., Relation between renal dysfunction and cardiovascular outcomes after myocardial infarction, N. Engl. J. Med. 351 (2004) 1285-95

[95] P. T. Vaitkus, Current status of prevention, diagnosis, and management of coronary artery disease in patients with kidney failure, Am. Heart. J. 139 (2000) 1000-8

[96] L. Calvillo, R. Latini, J. Kajstura, et al., Recombinant human erythropoietin protects the myocardium from ischemia-reperfusion injury and promotes beneficial remodeling, Proc. Natl. Acad. Sci. U. S. A. 100 (2003) 4802-4806

[97] E. Lipsic, P. van der Meer, R. H. Henning, et al., Timing of erythropoietin treatment for cardioprotection in ischemia/reperfusion, J. Cardiovasc. Pharmacol. 44 (2004) 473-479

[98] A. J. Bullard, P. Govewalla, D. M. Yellon, Erythropoietin protects the myocardium against reperfusion injury in vitro and in vivo, Basic Res. Cardiol. 100 (2005) 397-403

[99] M. Nishihara, T. Miura, T. Miki, et al., Erythropoietin affords additional cardioprotection to preconditioned hearts by enhanced phosphorylation of glycogen synthase kinase-3 beta, Am. J. Physiol. Heart Circ. Physiol. 291 (2006) H748-H755

[100] P. A. Statler, R. J. McPherson, L. A. Bauer, et al., Pharmacokinetics of high-dose recombinant erythropoietin in plasma and brain of neonatal rats, Pediatr. Res. 61 (2007) 671-675

[101] J. E. Baker, D. Kozik, A. K. Hsu, et al., Darbepoetin alfa protects the rat heart against infarction: dose-response, phase of action, and mechanisms, J. Cardiovasc. Pharmacol. 49 (2007) 337-345

[102] E. Gao, M. Boucher, J. K. Chuprun, et al., Darbepoetin alfa, a long-acting erythropoietin analog, offers novel and delayed cardioprotection for the ischemic heart, Am. J. Physiol. Heart Circ. Physiol. 293 (2007) H60-H68

[103] M. Brines, N. S. Patel, P. Villa, et al., Nonerythropoietic, tissue-protective peptides derived from the tertiary structure of erythropoietin, Proc. Natl. Acad. Sci. U. S. A. 105 (2008) 10925-10930

[104] I. Ahmet, H. J. Tae, M. Juhaszova, et al., A small nonerythropoietic helix B surface peptide based upon erythropoietin structure is cardioprotective against ischemic myocardial damage, Mol. Med. 17 (2011) 194-200 
Appendix

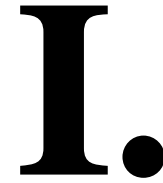




\title{
ORIGINAL ARTICLE
}

\section{Serum lipids and cardiac function correlate with nitrotyrosine and MMP activity in coronary artery disease patients}

\author{
Péter Bencsik ${ }^{*} \dagger$, Viktor Sasi ${ }^{\ddagger}$, Krisztina Kiss ${ }^{*}$, Krisztina Kupai $^{*}$, Márton Kolossváry ${ }^{\S}$, Pál Maurovich-Horvat ${ }^{\S}$, \\ Tamás Csont ${ }^{\ddagger}$, Imre Ungi ${ }^{\ddagger}$, Béla Merkely ${ }^{\S}$ and Péter Ferdinandy ${ }^{\dagger * * *}$ \\ ${ }^{*}$ Cardiovascular Research Group, Department of Biochemistry, University of Szeged, Szeged, Hungary, †Pharmahungary \\ Group, Szeged, Hungary, "Division of Invasive Cardiology, Second Department of Internal Medicine and Center of \\ Cardiology, University of Szeged, Szeged, Hungary, ${ }^{\S}$ MTA-SE Cardiovascular Imaging Research Group, Heart and Vascular \\ Center, Semmelweis University, Budapest, Hungary, "Metabolic Diseases and Cell Signaling Research Group, Department of \\ Biochemistry, University of Szeged, Budapest, Hungary, **Department of Pharmacology and Pharmacotherapy, \\ Semmelweis University, Budapest, Hungary
}

\begin{abstract}
Aims Peroxynitrite-matrix metalloproteinase (MMP) signalling has been shown to contribute to myocardial ischaemia/reperfusion injury and heart failure and to be influenced by hyperlipidaemia in preclinical models. Therefore, here we investigated the correlation between the markers of peroxynitrite-MMP signalling and hyperlipidaemia in patients with significant coronary stenosis.
\end{abstract}

Methods Five minutes before percutaneous coronary intervention (PCI), arterial blood samples were collected from 36 consecutive patients with coronary artery disease (CAD) selected for elective PCl.

Results Serum nitrotyrosine positively correlated with MMP-9 activity $(r=0.54, P=0.01)$, but not with MMP-2 activity. Nitrotyrosine positively correlated with total $(r=0.58 ; P<0.01)$ and LDL cholesterol $(r=0.55$; $P<0.01)$, serum triglyceride $(r=0.47 ; P<0.05)$, and creatinine $(r=0.42 ; P<0.05)$ and negatively correlated with HDL cholesterol $(r=-0.46 ; P<0.05)$ and with left ventricular ejection fraction (LVEF; $r=-0.55$; $P<0.05)$, respectively. MMP-2 activity correlated positively with total $(r=0.55 ; P<0.05)$ and LDL cholesterol $(r=0.45 ; P<0.05)$. In statin-treated patients, a significantly reduced serum nitrotyrosine was found as compared to statin naives; however, MMP activities and serum cholesterol levels were not different. MMP-9 activity correlated with urea nitrogen $(r=0.42 ; P<0.05)$ and LVEF $(r=-0.73 ; P<0.01)$. Serum creatinine correlated negatively with LVEF $(r=-0.50, P<0.01)$.

Conclusions This is the first demonstration that (i) serum nitrotyrosine correlates with MMP-9 activity, (ii) lipid parameters correlate with nitrotyrosine and MMP-2 activity, (iii) myocardial function correlates with creatinine, nitrotyrosine and MMP-9 activity, and (iv) creatinine correlates with nitrotyrosine and urea nitrogen with MMP-9 activity in patients with CAD. Studying the biomarkers of peroxynitrite-MMP pathway in large prospective trials may reveal their diagnostic avails.

Keywords Cardiac function, coronary artery disease, lipids, matrix metalloproteinase, nitro-oxidative stress, nitrotyrosine.

Eur J Clin Invest 2015; 45 (7): 692-701

\section{Introduction}

Matrix metalloproteinases (MMPs) are major targets of drug and diagnostic development in several pathologies including cardiovascular diseases $[1,2]$. The most abundant MMPs in the human myocardium are MMP-2 and MMP-9, which have been shown to play a crucial role in myocardial ischaemia/reperfu- sion injury in several animal models [3]. Furthermore, it has been shown that serum MMP-2 predicts infarct size and ventricular dysfunction in ST-elevation myocardial infarction patients [4]. The activation of MMP-2 and MMP-9 may occur not only by proteolysis but also due to nitro-oxidative stress via post-translational modification of pro-MMPs and the formation of transcriptional complexes [5,6]. 
Nitro-oxidative stress plays a pivotal role in the pathomechanism of several cardiovascular diseases including ischaemic heart disease [7]. The main effector of nitro-oxidative stress is peroxynitrite, which may activate several enzymes including MMPs via S-nitrosylation/S-glutathiolation of their tyrosine and/or cysteine residues $[7,8]$. Furthermore, peroxynitrite nitrates free tyrosine residues to form nitrotyrosine, which is a widely used marker for peroxynitrite generation [9].

The contribution of increased nitrotyrosine formation to the development of atherosclerosis and thus to coronary artery disease (CAD) has been described in patients with hypercholesterolaemia-combined CAD [10]. Hyperlipidaemia is well-characterized risk factor for cardiovascular diseases at least in part due to its nitro-oxidative stress-enhancing effect $[11,12]$ and deterioration of cardioprotective mechanisms $[13,14]$. Nevertheless, the correlation between serum nitrotyrosine and lipid levels is not consistent in the literature. Moreover, correlations between serum nitrotyrosine and MMP-2 and MMP-9 activities are still unknown in patients with CAD.

Therefore, we have conducted a pilot clinical study to determine the correlation between serum nitrotyrosine and MMP-2 and MMP-9 activities in patients with single-vessel CAD subjected to elective percutaneous coronary intervention. Furthermore, we have investigated the correlation of serum lipids (total, LDL and HDL cholesterol; triglyceride) with serum nitrotyrosine as well as with serum MMP-2 and MMP-9 activities, respectively. To investigate whether serum nitrotyrosine or MMP-2 and MMP-9 activities may correlate with cardiac function, we determined left ventricular ejection fractions (LVEF). Finally, we have examined whether there is a difference in serum MMP-2 and MMP-9 activities in statinnaive and statin-treated patients with CAD.

\section{Materials and methods}

\section{Patients and blood sampling}

The study was approved by the Ethics Committee of the University of Szeged. A written informed consent was obtained from all patients enrolled in the study. The investigations were carried out in consecutive patients with single-vessel coronary disease elected for percutaneous coronary intervention (PCI). Blood samples were collected from patients $5 \mathrm{~min}$ before the PCI.

Inclusion criteria were as follows:

1 Class II or III stable angina pectoris by the Canadian Cardiovascular Society grading system.

2 Single-vessel coronary artery disease defined as $\geq 70 \%$ diameter stenosis by visual assessment of the coronary angiogram.

Exclusion criteria were as follows:
1 Angina pectoris or other signs of myocardial ischaemia within 1 week before intervention.

2 Lown 3-4 ventricular arrhythmia before the intervention.

3 Severe left ventricular dysfunction ( $<35 \%$ LVEF or New York Heart Association functional circulatory stages III-IV).

4 Treatment with ATP-sensitive potassium channel inhibitors.

5 History of myocardial infarction or baseline ST-segment abnormalities.

6 Serum electrolytes out of the physiologic range.

7 Serum creatinine level $>150 \mu \mathrm{mol} / \mathrm{L}$.

8 Hypothyreosis.

9 Angiographically visible collateral vessels interfering with the treated coronary artery.

According to inclusion and exclusion criteria, 36 patients were enrolled into this study.

PCI was performed using the standard femoral approach in all patients after premedication with $100 \mathrm{mg}$ of aspirin and $75 \mathrm{mg}$ of clopidogrel once a day for 2 days prior to PCI. Serum levels of total, LDL and HDL cholesterol, triglyceride, creatinine and urea nitrogen were quantitated by enzymatic methods on a Roche Hitachi Modular P800 automated analysers (Roche Diagnostics, Indianapolis, IN, USA). Additional blood samples were collected from patients $5 \mathrm{~min}$ before the percutaneous coronary intervention from femoral artery.

Blood samples were centrifuged at $1000 \mathrm{~g}$ for $15 \mathrm{~min}$, at $4{ }^{\circ} \mathrm{C}$, and then, serum samples were collected into polypropylene microcentrifuge tubes and stored at $-20{ }^{\circ} \mathrm{C}$ until the performance of nitrotyrosine and MMP-2, MMP-9 activity measurements.

\section{Biochemical analyses}

To measure circulatory MMP-2 and MMP-9 activities, gelatin zymography was performed from serum samples (for a representative zymogram see Fig. 1). Gelatinolytic activities of MMPs were examined as previously described [15]. Briefly, $8 \%$ polyacrylamide gels were copolymerized with gelatin ( $2 \mathrm{mg} / \mathrm{mL}$, type A from porcine skin; Sigma-Aldrich, Budapest, Hungary), and $40 \mu \mathrm{g}$ of protein per lane was loaded. An internal standard (American Type Culture Collection, Manassas, VA, USA) was loaded into each gel to normalize activities between gels. After electrophoresis (150 V, $1.5 \mathrm{~h}$ ), gels were washed with $2.5 \%$ Triton X-100 for $3 \times 15$ min and incubated for $20 \mathrm{~h}$ at $37{ }^{\circ} \mathrm{C}$ in incubation buffer $(50 \mathrm{mM}$ Tris$\mathrm{HCl}, 150 \mathrm{mM} \mathrm{NaCl}, 5 \mathrm{mM} \mathrm{CaCl}_{2}$ and $0.05 \% \mathrm{NaN}_{3}, \mathrm{pH} \mathrm{7.4)}$. Gels were then stained with $0.05 \%$ Coomassie brilliant blue (G-250; Sigma-Aldrich) in a mixture of methanol-acetic acidwater [2.5:1:6.5 ( $\mathrm{vol} / \mathrm{vol})]$ and destained in aqueous $4 \%$ methanol-8\% acetic acid (vol/vol). For positive controls, gelatinase zymography standard containing human MMP-2 and MMP-9 (Cat. No.: CC73, Chemicon Europe Ltd., South- 


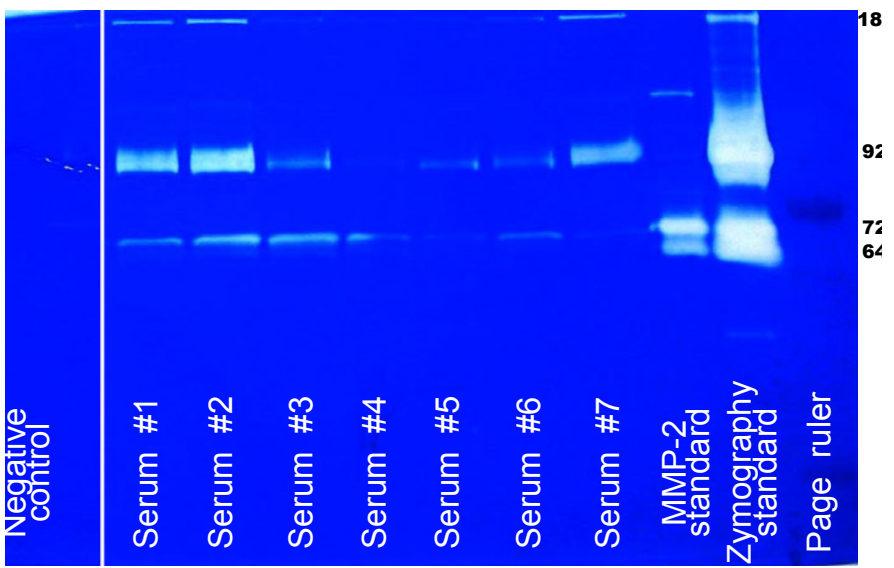

Figure 1 Representative gelatin zymogram from serum samples of patients with CAD.

ampton, UK) and MMP-2 standard (Cat. No.: CC071; Chemicon Europe Ltd.) was used. For negative control, lanes containing serum samples were cut off after renaturation of the gel and were separately incubated for $20 \mathrm{~h}$ at $37{ }^{\circ} \mathrm{C}$ in development buffer in the presence of the calcium chelator EGTA (ethylene glycol-bis(2-aminoethylether)- $N, N$, $N^{\prime}, N^{\prime}$-tetraacetic acid; $10 \mathrm{mM}$ ). Gelatinolytic activities were detected as transparent bands against the dark-blue background. Band intensities were quantified, expressed as the ratio to the internal standard and presented in arbitrary units.

To estimate systemic peroxynitrite formation, we have measured free nitrotyrosine by ELISA in serum samples as previously described [16,17]. Briefly, serum samples were deproteinized by addition of four volumes of ice-cold ethanol. After centrifugation, supernatants were separated and evaporated under nitrogen flow, and then, they were dissolved in phosphate buffer. Deproteinized sera were incubated overnight with antinitrotyrosine rabbit IgG and nitrotyrosine acetylcholinesterase tracer in precoated (mouse anti-rabbit IgG) microplates followed by development with Ellman's reagent. Serum nitrotyrosine levels were expressed in $\mathrm{ng} / \mathrm{mL}$.

\section{Measurement of cardiac function}

Prior to PCI, echocardiographic examinations were performed on a GE Vivid 3 cardiac ultrasound device (GE Healthcare, Milwaukee, WI, USA), and data were digitally recorded. Images were acquired using a $3 \cdot 5-\mathrm{MHz}$ transducer. Images and cines were obtained in standard apical and parasternal two- and four-chamber views. To assess LVEF, calculations were performed according to recommendations for chamber quantification in consensus. LVEF was calculated using the modified Simpson's method.

\section{Statistical analysis}

Data are expressed as mean \pm SEM. Univariate correlations between lipid parameters and MMP activities as well as nitrotyrosine were analysed using the Pearson correlation coefficient. Because of the relatively small sample sizes in the current pilot study, bootstrapped confidence intervals were calculated, using 1000 samples with replacement, to make robust estimates of the correlation coefficients as described elsewhere [18,19]. Linear regression analysis was used to estimate the prediction of the selected variables. The effects of statin treatment on variables were analysed by unpaired twotailed Student's $t$-test.

\section{Results}

Baseline characteristics of the 36 patients with coronary artery disease are summarized in Table 1.

\section{Correlation between serum nitrotyrosine and MMP-2 or MMP-9 activities}

We have determined whether serum nitrotyrosine correlates with MMP-2 and MMP-9 activities in patients with CAD. MMP-9 activity correlated positively with nitrotyrosine (Fig. 2a; $r=0.535, P=0.010$ ); however, there was no significant correlation between serum nitrotyrosine and MMP-2 activity (Fig. 2b).

\section{Correlation between serum lipids and nitrotyrosine or MMPs activity}

In patients with CAD, serum total cholesterol (Fig. 3a), LDL cholesterol (Fig. 3b) and triglyceride (Fig. 3c) levels correlated positively $(r=0.582, P=0.003 ; r=0.552, P=0.008 ; r=0.471$, $P=0.023$, respectively), while HDL cholesterol negatively (Fig. 3d; $r=-0.455, P=0.033$ ) with serum nitrotyrosine. Serum MMP-2 activity correlated positively with serum total cholesterol (Fig. 3e) and LDL cholesterol (Fig. 3f) levels ( $r=0.550 P=0.015$ and $r=0.448, P=0.028$, respectively); however, neither serum triglyceride (Fig. 3g) nor HDL cholesterol (Fig. 3h) showed a significant correlation with MMP-2 activity. None of the serum lipid parameters correlated with MMP-9 activity in patients with CAD (Table 2).

\section{Correlation between myocardial function and serum nitrotyrosine or MMPs activity}

Serum nitrotyrosine level (Fig. 4a) and MMP-9 activity (Fig. 4c) correlated negatively with LVEF $(r=-0.548, P=0.010$ and $r=-0.732, P=0.0002$, respectively); however, MMP-2 activity did not correlate with LVEF (Fig. 4b) in patients with CAD. We 
Table 1 Baseline characteristics of the 36 patients with coronary artery disease

\begin{tabular}{|c|c|}
\hline Variables & $\begin{array}{l}\text { Mean } \pm \text { SD or Occurrence } \\
\text { (number of individuals) }\end{array}$ \\
\hline \multicolumn{2}{|l|}{ Biographic and anamnestic variables } \\
\hline Age (years) & $67 \cdot 4 \pm 10 \cdot 5$ \\
\hline Gender, m/f & $19 / 17$ \\
\hline Type 1 diabetes & $0 / 36$ \\
\hline Type 2 diabetes & $5 / 36$ \\
\hline Statin treatment & $15 / 36$ \\
\hline ACE inhibitor treatment & $31 / 36$ \\
\hline ARB treatment & $1 / 36$ \\
\hline Nitrate treatment & $18 / 36$ \\
\hline \multicolumn{2}{|l|}{ Hemodynamic variables } \\
\hline Systolic blood pressure (mmHg) & $141 \cdot 7 \pm 11 \cdot 1$ \\
\hline Diastolic blood pressure (mmHg) & $89.8 \pm 21 \cdot 4$ \\
\hline Heart rate (beats/min) & $70 \cdot 4 \pm 12 \cdot 1$ \\
\hline LVEF (\%) & $56 \cdot 0 \pm 10 \cdot 5$ \\
\hline Coronary stenosis $(\%)$ & $63 \cdot 5 \pm 8 \cdot 0$ \\
\hline Occurrence of hypertension & $29 / 36$ \\
\hline \multicolumn{2}{|l|}{ Serum variables } \\
\hline Total cholesterol (mmol/L) & $4.6 \pm 0.9$ \\
\hline LDL cholesterol (mmol/L) & $2.5 \pm 0.8$ \\
\hline HDL cholesterol (mmol/L) & $1.3 \pm 0.4$ \\
\hline Triglycerides (mmol/L) & $1.8 \pm 0.8$ \\
\hline 3-nitrotyrosine (ng/mL) & $17 \cdot 4 \pm 11 \cdot 3$ \\
\hline Urea nitrogen (mmol/L) & $5 \cdot 9 \pm 2 \cdot 4$ \\
\hline Creatinine $(\mu \mathrm{mol} / \mathrm{L})$ & $86.3 \pm 27.5$ \\
\hline
\end{tabular}

did not find any correlation between serum lipid parameters and LVEF (data not shown).

\section{Serum nitrotyrosine or MMPs activity in statin- treated patients}

Fifteen of the 36 patients with CAD involved in this study were treated with different types of statins. In statin-treated patients, a significantly reduced serum nitrotyrosine level (Fig. 5a) was found (from $23.5 \pm 4.5 \mathrm{ng} / \mathrm{mL}$ to $13.6 \pm 5.1 \mathrm{ng} / \mathrm{mL} ; P<0.05$ ) as compared to statin-naive patients. MMP-2 and MMP-9 activities did not show any difference between statin-treated and statin-naive patients (Fig. 5b,c).
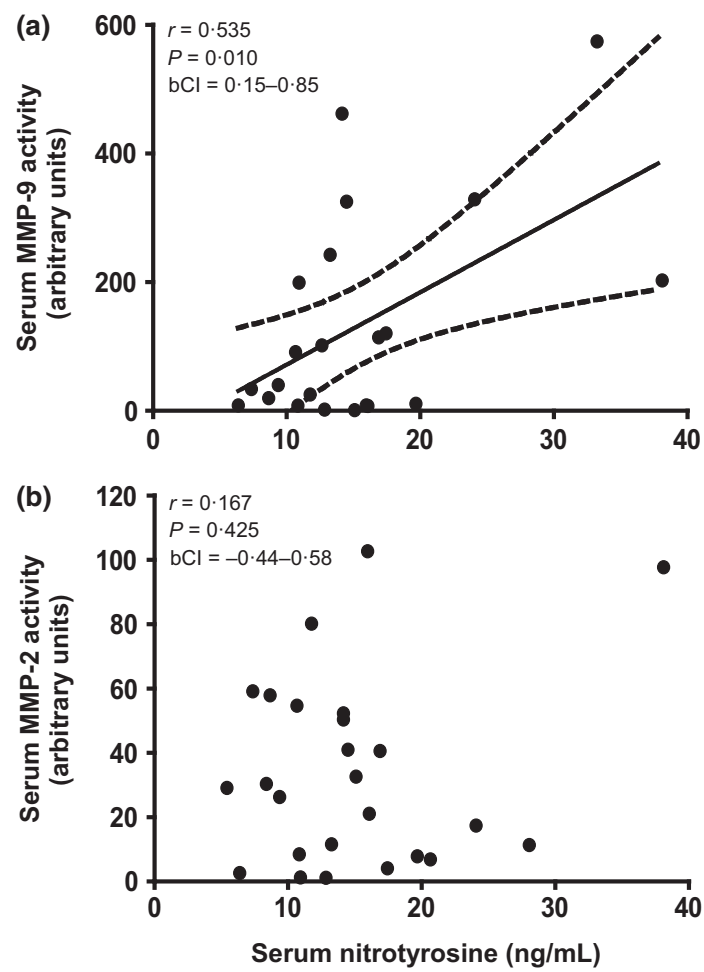

Figure 2 Correlation of serum nitrotyrosine content with MMP-2 and MMP-9 activities. Serum MMP-9 activity correlated positively with serum nitrotyrosine (a). Serum MMP-2 activity (b) did not correlate with serum nitrotyrosine. Continuous line: linear regression of data; dotted line: $95 \%$ confidence interval. $r$. Pearson's correlation coefficient, $P$ : significance, $\mathrm{bCl}$ : bootstrapped confidence interval of correlation coefficient.

\section{Correlation between renal function and serum nitrotyrosine or MMPs activity}

In addition, we tested the correlation of renal function parameters with markers of peroxynitrite-MMP pathway and also with LVEF. Serum creatinine correlated positively with nitrotyrosine ( $r=0.422, P=0.036$; Fig. 6a), but not with MMP-2 and MMP-9 activities (Table 3). Urea nitrogen level correlated positively with MMP-9 activity $(r=0.423, P=0.035$; Fig. 6b), but not with nitrotyrosine or MMP-2 activity (Table 3$)$. Serum creatinine correlated negatively with LVEF ( $r=-0.503$, $P=0.009$; Fig. 6c); however, urea nitrogen did not correlate with LVEF (Table 3).

\section{Discussion}

In the present pilot study, we have demonstrated for the first time in the literature that (i) serum nitrotyrosine correlates with MMP-9 activity, (ii) serum lipid parameters correlate with nitrotyrosine level and MMP-2 activity, (iii) myocardial function correlates with 

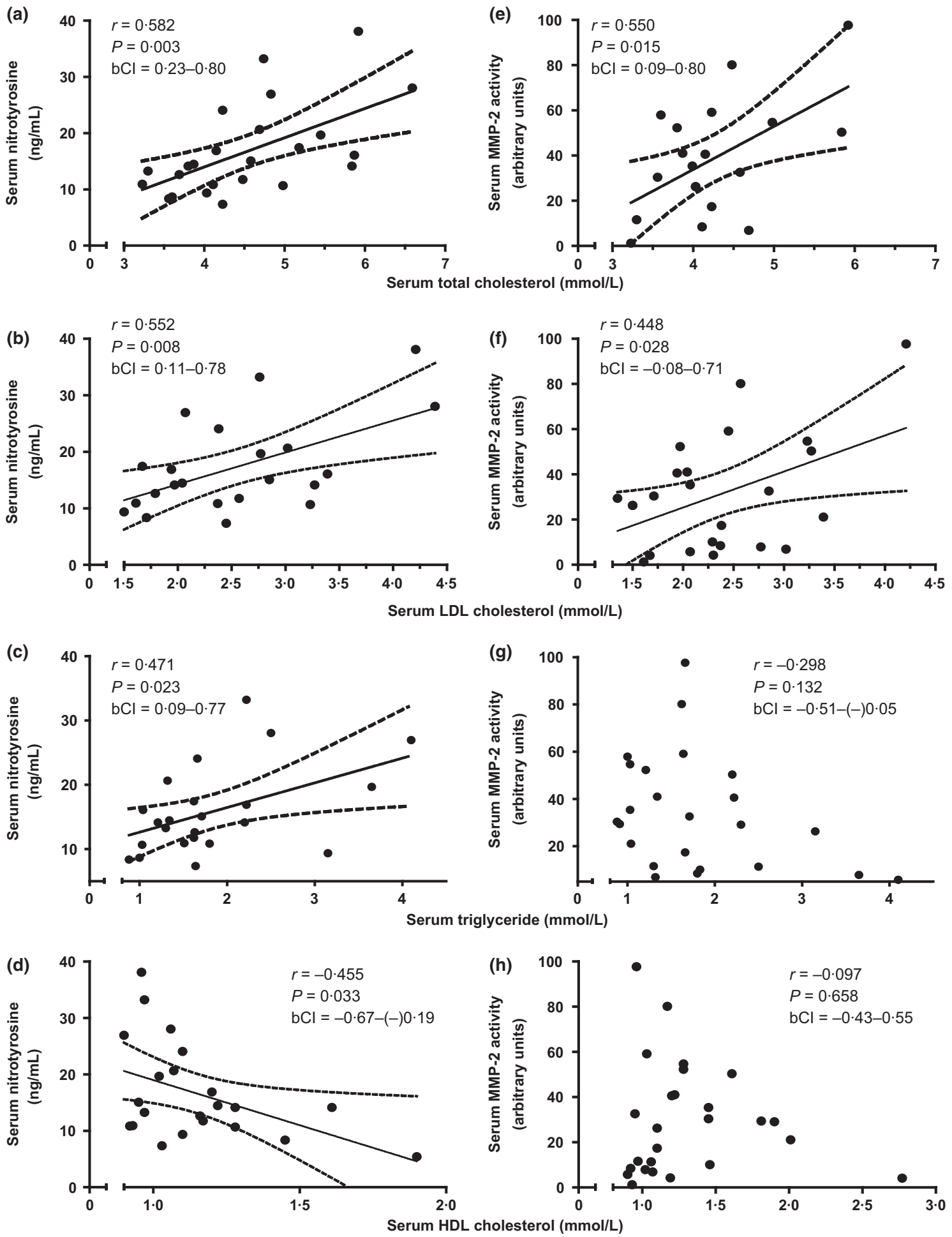

Figure 3 Correlation of serum nitrotyrosine and MMP-2 activities with serum lipids. Serum nitrotyrosine level correlated positively with total (a) and LDL cholesterol (b) as well as with triglyceride (c) and correlated negatively with HDL cholesterol (d). Serum MMP-2 activity correlated positively with serum total (e) and LDL cholesterol levels (f). Neither serum triglyceride ( $g$ ) nor HDL cholesterol ( $h$ ) showed a significant correlation with serum MMP-2 activity. Continuous line: linear regression of data; dotted line: $95 \%$ confidence interval. $r$. Pearson's correlation coefficient, $P$ : significance, $\mathrm{bCl}$ : bootstrapped confidence interval of correlation coefficient. 
Table 2 Correlations between serum MMP-9 activity and lipid parameters

\begin{tabular}{llllll}
\hline & & \multicolumn{3}{c}{$\begin{array}{l}\text { Bootstrapped } \\
\text { confidence }\end{array}$} & \\
Pearson's & $\begin{array}{l}\text { intervals } \\
\text { correlation } \\
\text { of correlation }\end{array}$ & \\
Cariables & & coefficient & coefficient & $P$ \\
\hline MMP-9/ & Total cholesterol & 0.171 & -0.27 to 0.49 & 0.436 \\
MMP-9/ & LDL cholesterol & 0.020 & -0.38 to 0.30 & 0.939 \\
MMP-9/ & HDL cholesterol & 0.050 & -0.31 to 0.59 & 0.840 \\
MMP-9/ & Triglyceride & 0.024 & -0.34 to 0.40 & 0.913
\end{tabular}

nitrotyrosine, MMP-9 activity as well as with creatinine, and (iv) creatinine correlates with nitrotyrosine and urea nitrogen correlates with MMP-9 activity in patients with CAD.

\section{Serum nitrotyrosine correlates with MMP activity}

Here, we found a positive correlation of serum nitrotyrosine with MMP-9 activity, but not with MMP-2 activity. This suggests that peroxynitrite activates MMPs in humans as well. Previously, a positive correlation between nitrotyrosine content and MMP-9 expression was found in instable atherosclerotic plaques derived from patients with ischaemic heart disease, which supports our present results [20]. However, the reason why we have not found a significant correlation between peroxynitrite and MMP-2 activity is not known. A plausible explanation is that MMP-2 activation and release can be less sensitively detected in the serum than that of MMP-9. While MMP-9 is an abundant enzyme in different cells and tissues including macrophages and leukocytes, MMP-2 is an intracellular enzyme occurring mainly in contractile tissues that can be activated and released; for example, due to acute myocardial ischaemia/reperfusion and infarction [8,21-24]. However, our CAD patient population did not have severe ischaemia at the time of tissue sampling.

\section{Serum lipids correlate with nitrotyrosine and MMPs activity}

Hyperlipidaemia is a well-characterized risk factor for cardiovascular diseases, and it has been also demonstrated that it contributes to elevated nitro-oxidative stress in humans $[10,25]$. We have previously shown in rats and in apoB-100 transgenic mice that hypercholesterolaemia increases nitro-oxidative stress, which leads to myocardial functional deterioration $[26,27]$. Here, we have also examined the correlation pattern of serum lipids with nitrotyrosine in patients with CAD and shown that nitrotyrosine correlated positively with triglyceride, total and LDL cholesterol levels, and negatively with HDL cholesterol. In a previous study [28], an increased serum
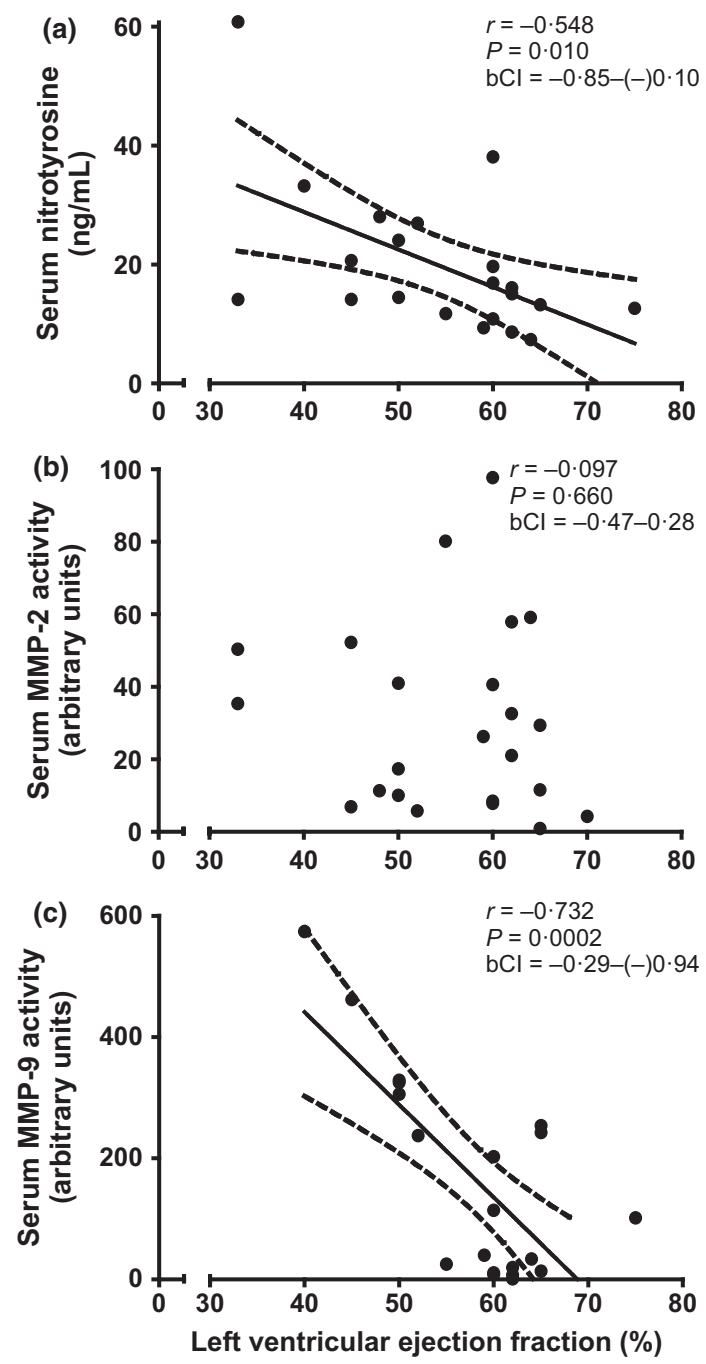

Figure 4 Correlation of left ventricular ejection fraction (LVEF) with serum nitrotyrosine, and serum MMP-2 and MMP-9 activities. Serum nitrotyrosine (a) and MMP-9 (c) activity correlated negatively with LVEF. Serum MMP-2 activity did not correlate with LVEF (b). Continuous line: linear regression of data; dotted line: 95\% confidence interval. $r$. Pearson's correlation coefficient, $P$ : significance, bCl: bootstrapped confidence interval of correlation coefficient.

nitrotyrosine level was reported in hypercholesterolaemic patients, wherein only LDL cholesterol showed significant positive correlation with nitrotyrosine. In patients with CAD, a minor correlation was found between only serum proteinbound nitrotyrosine and triglyceride [10]. A similar correlation was shown by others in patients with metabolic syndrome [29]. In our present study, we have measured serum-free nitrotyrosine, which seems to be a more sensitive marker for systemic peroxynitrite generation. 

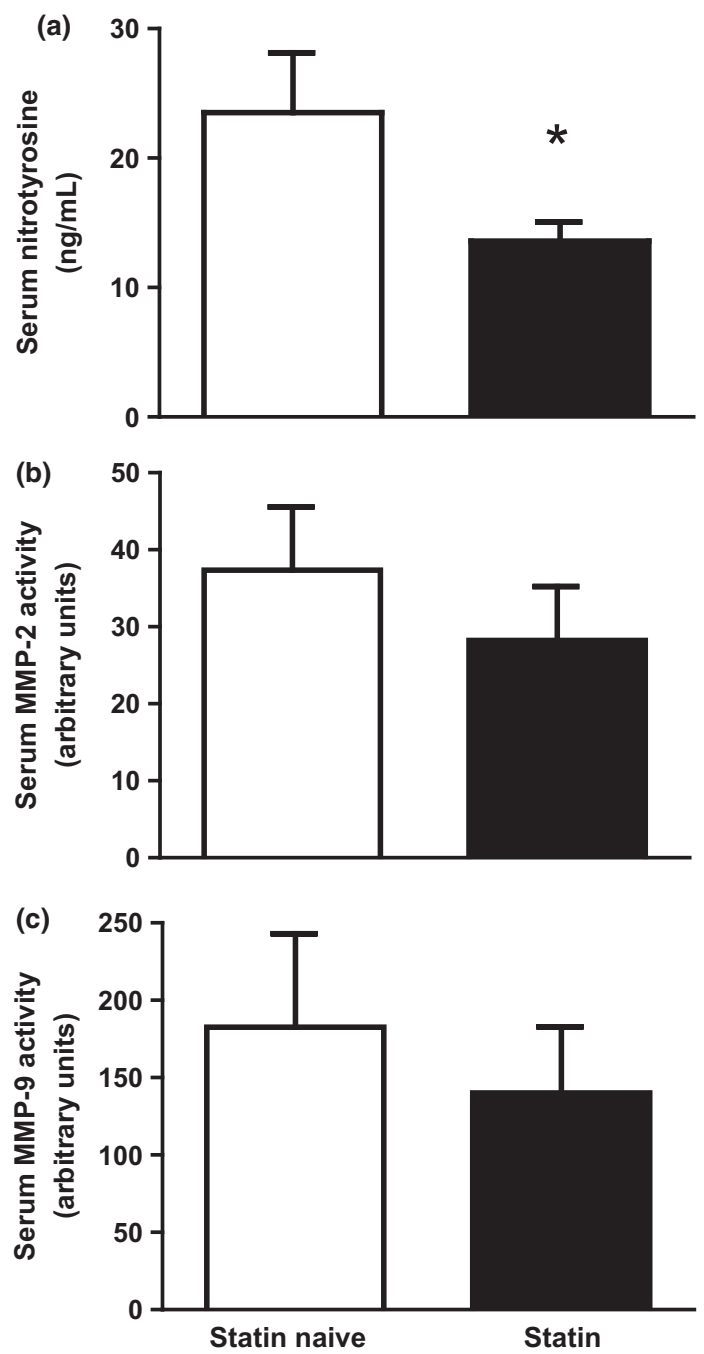

Figure 5 Serum nitrotyrosine levels (a) and serum MMP-2 (b) and MMP-9 (c) activities in statin-treated and statin-naive patients with CAD. Serum nitrotyrosine was significantly reduced in statin-treated patients with CAD as compared to statin-naive patients $(* P<0.05$, data are shown as mean \pm SEM). MMP-2 and MMP-9 activities were not changed in statin-treated patients with $C A D$ as compared to statin naive ones $(P=0.409$ and $P=0.564$, respectively).

Here, we have found that serum MMP-2 activity correlated positively with total and LDL cholesterol levels. However, neither HDL cholesterol, nor triglyceride levels correlated with MMP-2 activity. According to our best knowledge, MMP-2 activity has been investigated by only one previous study in patients with CAD [30], in which a negative correlation between serum MMP-2 activity and HDL cholesterol was found; however, other correlations were not assessed. In another study [31], plasma MMP-2 protein level was shown
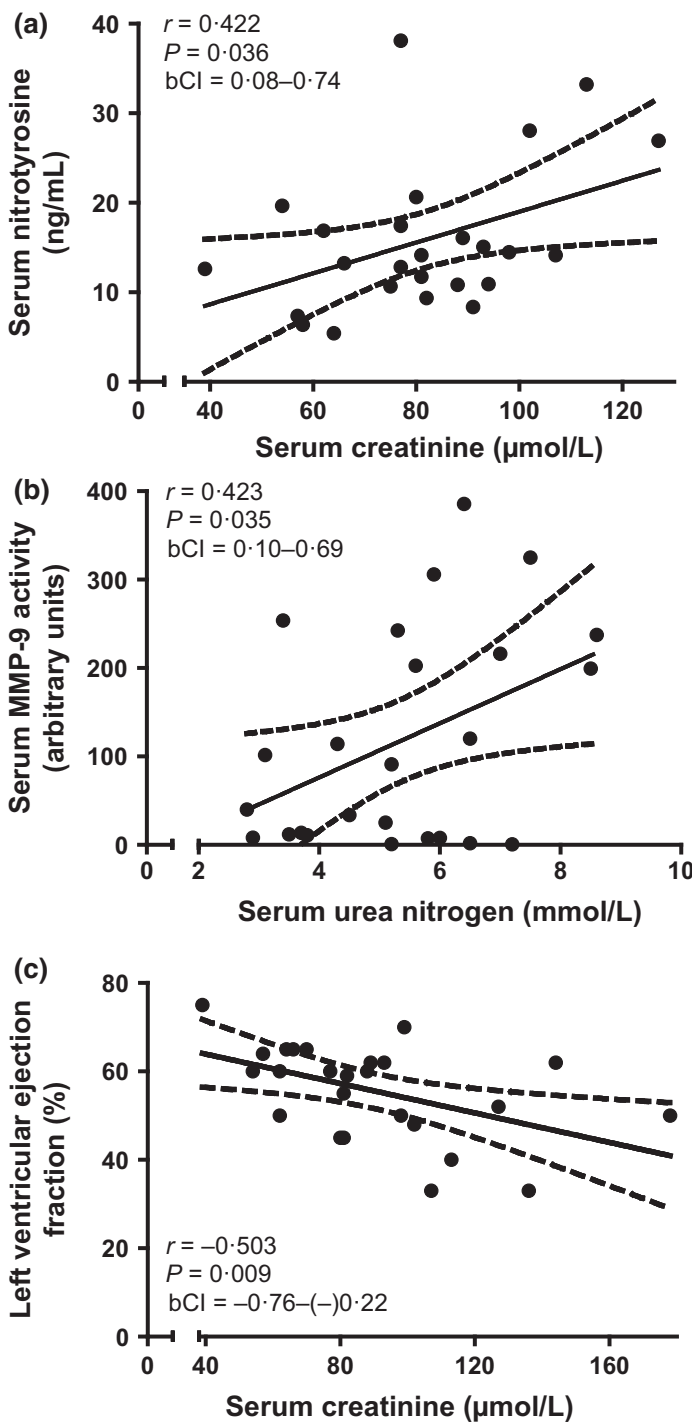

Figure 6 Correlation of renal function with serum nitrotyrosine, MMP activities and myocardial function. Serum nitrotyrosine correlated positively with serum creatinine (a). Serum MMP-9 activity correlated positively with urea nitrogen level (b). Continuous line: linear regression of data; dotted line: 95\% confidence interval. $r$. Pearson's correlation coefficient, $P$ : significance, $\mathrm{bCl}$ : bootstrapped confidence interval of correlation coefficient.

to correlate negatively with HDL cholesterol in patients with CAD. Noji et al. [32] measured plasma MMP-2 in patients with CAD several days before coronary intervention and interestingly found a positive correlation between MMP-2 protein level and HDL cholesterol; however, they did not assess MMP-2 activity. In our present study, serum MMP-9 activity did not show correlation with any of the serum 
Table 3 Correlations between serum nitrotyrosine level, MMPs activities or LVEF, and renal function parameters

\begin{tabular}{llcll}
\hline & & $\begin{array}{l}\text { Pearson's } \\
\text { correlation } \\
\text { coefficient }\end{array}$ & $\begin{array}{l}\text { Bootstrapped } \\
\text { confidence intervals } \\
\text { of correlation } \\
\text { coefficient }\end{array}$ & Pariables \\
MMP-2/ & Creatinine & 0.125 & -0.20 to 0.45 & 0.504 \\
MMP-9/ & Creatinine & 0.118 & -0.30 to 0.48 & 0.550 \\
NTyr/ & BUN & 0.105 & -0.22 to 0.39 & 0.602 \\
MMP-2/ & BUN & 0.071 & -0.20 to 0.42 & 0.700 \\
LVEF/ & BUN & -0.250 & -0.57 to 0.00 & 0.217
\end{tabular}

lipids. A similar finding was published previously in hypercholesterolaemic patients [33]. Two independent studies in patients with CAD and acute coronary syndrome showed that MMP-9 protein level positively correlated with LDL cholesterol [31,32]. Furthermore, correlation of plasma MMP-9 protein content with triglyceride level has been also shown [31]. However, in these studies, the authors did not measure MMP-9 activities, only MMP-9 protein immunoreactivity.

\section{Myocardial function correlates with serum nitrotyrosine and MMPs activity}

Here, we have demonstrated first time in the literature in patients with CAD that cardiac function characterized by LVEF showed a significant negative correlation with serum nitrotyrosine. This may suggest that the nitro-oxidative stress is detrimental to cardiac function in humans, which is in accordance with preclinical studies. Furthermore, we have found here that LVEF correlated negatively with MMP-9 activity; however, there was no correlation with MMP-2 activity. This is partly in accordance with previous findings that both MMP-2 and MMP9 protein levels correlate with LVEF or left ventricular enddiastolic volume index in cardiac patients with acute myocardial infarction or heart failure [34-36]. We have also examined here the correlation of serum cholesterol and triglyceride levels with LVEF; however, we did not observe any significant correlation among these data. In contrast, Wang et al. [37] described a positive correlation of LVEF with serum HDL cholesterol and a negative correlation with serum triglyceride in patients with angina.

\section{Decreased serum nitrotyrosine in statin-treated patients}

Most CAD patients are treated with various statins. Statins are well-characterized inhibitors of endogenous cholesterol syn- thesis, and it has been also described that they attenuate nitrooxidative stress [38] as assessed by plasma nitrotyrosine level in patients with CAD [10]. Accordingly, we found here a reduced serum nitrotyrosine level in statin-treated CAD patients as compared to statin naive ones.

Here, we have found that MMP-2 and MMP-9 activities were not significantly different in statin-treated patients with CAD as compared to statin naives, although a tendency of decrease was found. In contrast, It has been shown in 48 patients with CAD undergone coronary artery bypass surgery that protein levels and activities of MMP-2 and MMP-9 measured both in plasma and in pericardial fluid were reduced after 2-month pravastatin therapy as compared to untreated patients [39]. Other authors have also reported a reduction in plasma MMP-2 and/or MMP9 protein levels after statin treatment of cardiac patients; however, in these studies, only MMP protein levels were measured [34-36,40].

\section{Renal function correlates with serum nitrotyrosine and MMPs activity}

It has been previously described that renal dysfunction may develop and contribute to mortality in patients with myocardial infarction [41]. It is also well known that ischaemic coronary disease is a leading cause of death in uraemic patients [42]. Although uraemic patients and patients with severe left ventricular dysfunction were not enrolled into the present study, we have shown a significant negative correlation between serum creatinine level and LVEF for the first time in the literature in patients with CAD. Moreover, we have found a positive correlation between serum creatinine and nitrotyrosine as well as between urea nitrogen and MMP-9 activity in patients with CAD. These results suggest that both increased nitrotyrosine level and MMP-9 activity may have diagnostic values for the development of an incipient renal dysfunction after myocardial infarction even when the patients have creatinine and/or urea nitrogen levels near or within the normal range.

\section{Limitations}

The present manuscript provides data from a pilot study; therefore, the number of the enrolled patients is relatively low. However, bootstrap analysis of the correlation coefficients was performed, which is a widely accepted statistical method of making robust estimates of the coefficients in case of small sample sizes. The correlations we found were relatively weak, but statistically significant. This may show that there might be several other players in the interactions between the parameters we correlated in the present study. Indeed, MMP activity is determined by several confounding factors, such as level of the endogenous tissue inhibitors of MMPs (TIMPs), $\mathrm{Zn}^{2+}$ availability, phosphorylation status of 
MMPs and redox state; for example, TIMPs may dissociate from MMPs during electrophoresis; therefore, TIMP-free or TIMP-bound MMPs in the serum cannot be assessed by zymography. Nevertheless, our results show that serum MMP-2 and MMP-9 activities as measured by zymography are valuable diagnostic markers.

\section{Conclusions}

This is the first demonstration that serum (i) nitrotyrosine correlates with MMP-9 activity, (ii) lipid parameters correlate with nitrotyrosine level and MMP-2 activity, (iii) myocardial function correlates with nitrotyrosine, MMP-9 activity and creatinine, and (iv) creatinine correlates with nitrotyrosine and urea nitrogen correlates with MMP-9 activity in patients with CAD. These findings suggest that nitrotyrosine and MMP-2 and MMP-9 activities may be of diagnostic values in cardiac and renal function of patients with CAD, and attenuation of nitrooxidative stress and MMP activities may provide therapeutic benefits in this patient population. Thus, to study markers of peroxynitrite-MMP pathway in large prospective studies may reveal their diagnostic avails.

\section{Acknowledgements}

This project was supported by the following grants: Hungarian Ministry of Health [ETT 476/2009], the National Office for Research and Technology [NKFP_06_A1-MMP_2006, HURO/ 0901/137/2.2.2 - HU-RO TRANS-MED, TÁMOP-4.2.1/B-09/ 1/KONV-2010-0005, TÁMOP-4.2.2/B-10/1-2010-0012, TÁMOP-4.2.2.A-11/1/KONV-2012-0035 and BAROSS-DA07DA-TECH-07-2008-0041]. P. Bencsik and T. Csont hold a János Bolyai Research Scholarship of the Hungarian Academy of Sciences, and P. Ferdinandy holds a Szentágothai Fellowship (TÁMOP-4.2.4.A/2-11/1-2012-0001) of the National Excellence Program of Hungary.

\section{Conflict of interest}

The authors declare that they have no conflict of interest.

\section{Address}

Cardiovascular Research Group, Department of Biochemistry, University of Szeged, Dom ter 9, H-6720 Szeged, Hungary (P. Bencsik, K. Kiss, K. Kupai); Metabolic Diseases and Cell Signaling Research Group, Department of Biochemistry, University of Szeged, Dom ter 9, H-6720 Szeged, Hungary (T. Csont) Pharmahungary Group, Dom ter 9, H-6720 Szeged, Hungary (P. Bencsik, P. Ferdinandy); Division of Invasive Cardiology, Second Department of Internal Medicine and Center of Cardiology, University of Szeged, Korányi fasor 6, H-6720 Szeged, Hungary (V. Sasi, I. Ungi); MTA-SE Cardiovascular Imaging Research Group, Heart and Vascular Center, Semmelweis
University, Varosmajor ut 68, H-1122 Budapest, Hungary (M. Kolossvary, P. Maurovich-Horvat, B. Merkely); Department of Pharmacology and Pharmacotherapy, Semmelweis University, Nagyvarad ter 4, H-1089 Budapest, Hungary (P. Ferdinandy).

Correspondence to: Péter Ferdinandy, Department of Pharmacology and Pharmacotherapy, Semmelweis University, Nagyvárad tér 4, Budapest 1089, Hungary. Tel.: +36 1 2104416; fax: +36 1 2427643; e-mail: peter.ferdinandy@pharmahungary. com

Received 20 November 2014; accepted 1 May 2015

\section{References}

1 Dorman G, Cseh S, Hajdu I, Barna L, Konya D, Kupai K et al. Matrix metalloproteinase inhibitors: a critical appraisal of design principles and proposed therapeutic utility. Drugs 2010;70:949-64.

2 Dorman G, Kocsis-Szommer K, Spadoni C, Ferdinandy P. MMP inhibitors in cardiac diseases: an update. Recent Pat Cardiovasc Drug Discov 2007;2:186-94.

3 Schulz R. Intracellular targets of matrix metalloproteinase-2 in cardiac disease: rationale and therapeutic approaches. Annu Rev Pharmacol Toxicol 2007;47:211-42.

4 Nilsson L, Hallen J, Atar D, Jonasson L, Swahn E. Early measurements of plasma matrix metalloproteinase-2 predict infarct size and ventricular dysfunction in ST-elevation myocardial infarction. Heart 2012;98:31-6.

5 Ali MA, Schulz R. Activation of MMP-2 as a key event in oxidative stress injury to the heart. Front Biosci 2009;14:699-716.

6 Spinale FG. Myocardial matrix remodeling and the matrix metalloproteinases: influence on cardiac form and function. Physiol Rev 2007;87:1285-342.

7 Szabo C, Ischiropoulos H, Radi R. Peroxynitrite: biochemistry, pathophysiology and development of therapeutics. Nat Rev Drug Discov 2007;6:662-80.

8 Bencsik P, Kupai K, Giricz Z, Gorbe A, Huliak I, Furst S et al. Cardiac capsaicin-sensitive sensory nerves regulate myocardial relaxation via S-nitrosylation of SERCA: role of peroxynitrite. $\mathrm{Br} \mathrm{J}$ Pharmacol 2008;153:488-96.

9 Ferdinandy P. Peroxynitrite: just an oxidative/nitrosative stressor or a physiological regulator as well? Br J Pharmacol 2006;148:1-3.

10 Shishehbor MH, Aviles RJ, Brennan ML, Fu X, Goormastic M, Pearce GL et al. Association of nitrotyrosine levels with cardiovascular disease and modulation by statin therapy. JAMA 2003;289:1675-80.

11 Nguyen VH, McLaughlin MA. Coronary artery disease in women: a review of emerging cardiovascular risk factors. Mt Sinai J Med 2002;69:338-49.

12 Warnholtz A, Mollnau H, Oelze M, Wendt M, Munzel T. Antioxidants and endothelial dysfunction in hyperlipidemia. Curr Hypertens Rep 2001;3:53-60.

13 Ferdinandy P, Schulz R, Baxter GF. Interaction of cardiovascular risk factors with myocardial ischemia/reperfusion injury, preconditioning, and postconditioning. Pharmacol Rev 2007;59:418-58.

14 Ungi I, Ungi T, Ruzsa Z, Nagy E, Zimmermann Z, Csont T et al. Hypercholesterolemia attenuates the anti-ischemic effect 
of preconditioning during coronary angioplasty. Chest 2005;128:1623-8.

15 Kupai K, Szucs G, Cseh S, Hajdu I, Csonka C, Csont T et al. Matrix metalloproteinase activity assays: importance of zymography. J Pharmacol Toxicol Methods 2010;61:205-9.

16 Radak Z, Ogonovszky H, Dubecz J, Pavlik G, Sasvari M, Pucsok J et al. Super-marathon race increases serum and urinary nitrotyrosine and carbonyl levels. Eur J Clin Invest 2003;33:726-30.

17 Csont T, Csonka C, Onody A, Gorbe A, Dux L, Schulz R et al. Nitrate tolerance does not increase production of peroxynitrite in the heart. Am J Physiol Heart Circ Physiol 2002;283:H69-76.

18 Campos CM, van KD, Farooq V, Simonton CA, Kappetein AP, Sabik JF III et al. Long-term forecasting and comparison of mortality in the evaluation of the xience everolimus eluting stent vs. Coronary Artery Bypass Surgery for Effectiveness of Left Main Revascularization (EXCEL) trial: prospective validation of the SYNTAX Score II. Eur Heart J 2015; In press.

19 Yotti R, Bermejo J, Benito Y, Antoranz JC, Desco MM, RodriguezPerez $\mathrm{D}$ et al. Noninvasive estimation of the rate of relaxation by the analysis of intraventricular pressure gradients. Circ Cardiovasc Imaging 2011;4:94-104.

20 Sigala F, Kotsinas A, Savari P, Filis K, Markantonis S, Iliodromitis EK et al. Oxidized LDL in human carotid plaques is related to symptomatic carotid disease and lesion instability. J Vasc Surg 2010;52:704-13.

21 Gao CQ, Sawicki G, Suarez-Pinzon WL, Csont T, Wozniak M, Ferdinandy $\mathrm{P}$ et al. Matrix metalloproteinase-2 mediates cytokineinduced myocardial contractile dysfunction. Cardiovasc Res 2003;57:426-33.

22 Polewicz D, Cadete VJ, Doroszko A, Hunter BE, Sawicka J, Szczesna-Cordary D et al. Ischemia induced peroxynitrite dependent modifications of cardiomyocyte MLC1 increases its degradation by MMP-2 leading to contractile dysfunction. J Cell Mol Med 2011;15:1136-47.

23 Sung MM, Schulz CG, Wang W, Sawicki G, Bautista-Lopez NL, Schulz R. Matrix metalloproteinase-2 degrades the cytoskeletal protein alpha-actinin in peroxynitrite mediated myocardial injury. J Mol Cell Cardiol 2007;43:429-36.

24 Wang W, Sawicki G, Schulz R. Peroxynitrite-induced myocardial injury is mediated through matrix metalloproteinase-2. Cardiovasc Res 2002;53:165-74.

25 Munzel T, Gori T, Bruno RM, Taddei S. Is oxidative stress a therapeutic target in cardiovascular disease? Eur Heart J 2010;31:2741-8.

26 Onody A, Csonka C, Giricz Z, Ferdinandy P. Hyperlipidemia induced by a cholesterol-rich diet leads to enhanced peroxynitrite formation in rat hearts. Cardiovasc Res 2003;58:663-70.

27 Csont T, Bereczki E, Bencsik P, Fodor G, Gorbe A, Zvara A et al. Hypercholesterolemia increases myocardial oxidative and nitrosative stress thereby leading to cardiac dysfunction in apoB-100 transgenic mice. Cardiovasc Res 2007;76:100-9.

28 Pirro M, Schillaci G, Mannarino MR, Savarese G, Vaudo G, Siepi $\mathrm{D}$ et al. Effects of rosuvastatin on 3-nitrotyrosine and aortic stiffness in hypercholesterolemia. Nutr Metab Cardiovasc Dis 2007;17:436-41.

29 Esposito K, Ciotola M, Schisano B, Misso L, Giannetti G, Ceriello A et al. Oxidative stress in the metabolic syndrome. J Endocrinol Invest 2006;29:791-5.

30 Muzzio ML, Miksztowicz V, Brites F, Aguilar D, Repetto EM, Wikinski $\mathrm{R}$ et al. Metalloproteases 2 and 9, Lp-PLA(2) and lipoprotein profile in coronary patients. Arch Med Res 2009;40:48-53.

31 Derosa G, D'Angelo A, Scalise F, Avanzini MA, Tinelli C, Peros E et al. Comparison between metalloproteinases-2 and -9 in healthy subjects, diabetics, and subjects with acute coronary syndrome. Heart Vessels 2007;22:361-70.

32 Noji Y, Kajinami K, Kawashiri MA, Todo Y, Horita T, Nohara A et al. Circulating matrix metalloproteinases and their inhibitors in premature coronary atherosclerosis. Clin Chem Lab Med 2001;39:380-4.

33 Nilsson L, Eriksson P, Cherfan P, Jonasson L. Effects of simvastatin on proinflammatory cytokines and matrix metalloproteinases in hypercholesterolemic individuals. Inflammation 2011;34:225-30.

34 Nakaya R, Uzui H, Shimizu H, Nakano A, Mitsuke Y, Yamazaki T et al. Pravastatin suppresses the increase in matrix metalloproteinase-2 levels after acute myocardial infarction. Int $J$ Cardiol 2005;105:67-73.

35 Yan AT, Yan RT, Spinale FG, Afzal R, Gunasinghe HR, Arnold M et al. Plasma matrix metalloproteinase-9 level is correlated with left ventricular volumes and ejection fraction in patients with heart failure. J Card Fail 2006;12:514-9.

36 Yasuda S, Miyazaki S, Kinoshita H, Nagaya N, Kanda M, Goto Y et al. Enhanced cardiac production of matrix metalloproteinase-2 and -9 and its attenuation associated with pravastatin treatment in patients with acute myocardial infarction. Clin Sci 2007;112:43-9.

37 Wang TD, Lee CM, Wu CC, Lee TM, Chen WJ, Chen MF et al. The effects of dyslipidemia on left ventricular systolic function in patients with stable angina pectoris. Atherosclerosis 1999;146:117-24.

38 Davignon J, Jacob RF, Mason RP. The antioxidant effects of statins. Coron Artery Dis 2004;15:251-8.

39 Fujiwara T, Saito S, Osanai T, Kameda K, Abe N, Higuma T et al. Decreased plasma and cardiac matrix metalloproteinase activities in patients with coronary artery disease and treated with pravastatin. Eur J Pharmacol 2008;594:146-51.

40 Koh KK, Son JW, Ahn JY, Choi YM, Jin DK, Park GS et al. Non-lipid effects of statin on hypercholesterolemic patients established to have coronary artery disease who remained hypercholesterolemic while eating a step-II diet. Coron Artery Dis 2001;12:305-11.

41 Anavekar NS, McMurray JJ, Velazquez EJ, Solomon SD, Kober L, Rouleau JL et al. Relation between renal dysfunction and cardiovascular outcomes after myocardial infarction. $N$ Engl J Med 2004;351:1285-95.

42 Vaitkus PT. Current status of prevention, diagnosis, and management of coronary artery disease in patients with kidney failure. Am Heart J 2000;139:1000-8. 


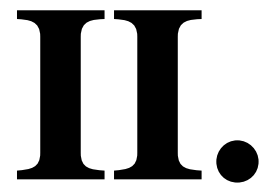




\title{
Novel, selective EPO receptor ligands lacking erythropoietic activity reduce infarct size in acute myocardial infarction in rats
}

\author{
Krisztina Kiss $^{\mathrm{a}, 1}$, Csaba Csonka ${ }^{\mathrm{b}, 1}$, János Pálóczi ${ }^{\mathrm{a}, \mathrm{c}}$, Judit Pipis ${ }^{\mathrm{a}, \mathrm{c}}$, Anikó Görbe ${ }^{\mathrm{a}, \mathrm{c}}$, \\ Gabriella F. Kocsis ${ }^{\mathrm{a}, \mathrm{c}}$, Zsolt Murlasits ${ }^{\mathrm{c}, \mathrm{d}}$, Márta Sárközy ${ }^{\mathrm{b}}$, Gergő Szücs ${ }^{\mathrm{b}}$, \\ Christopher P. Holmes ${ }^{\mathrm{f}}$, Yijun Pan ${ }^{\mathrm{f}}$, Ashok Bhandari ${ }^{\mathrm{f}}$, Tamás Csont ${ }^{\mathrm{b}}$, Mehrdad Shamloo ${ }^{\mathrm{e}}$, \\ Kathryn W. Woodburn ${ }^{\mathrm{f}, \mathrm{g}}$, Péter Ferdinandy ${ }^{\mathrm{a}, \mathrm{c}, \mathrm{h}, *, 1}$, Péter Bencsik ${ }^{\mathrm{a}, \mathrm{c}, 1}$ \\ a Cardiovascular Research Group, Department of Biochemistry, University of Szeged, Dom ter 9, Szeged H-6720, Hungary \\ ${ }^{\mathrm{b}}$ Department of Biochemistry, University of Szeged, Dom ter 9, Szeged H-6720, Hungary \\ c Pharmahungary Group, Dom ter 9, Szeged H-6720, Hungary \\ d Sports Science Program, Qatar University, Doha 00974, Qatar \\ e Stanford University School of Medicine, Department of Neurosurgery, 1050 Arastradero Road, Building A, Palo Alto, CA 94304, United States \\ ${ }^{\mathrm{f}}$ Affymax, Inc., 4015 Miranda Ave Fl 1, Palo Alto, CA 94304, United States \\ ${ }^{g}$ Avalanche Biotechnologies, 1035 O'Brien Drive, Menlo Park, CA 94025, United States \\ ${ }^{\mathrm{h}}$ Department of Pharmacology and Pharmacotherapy, Semmelweis University, Nagyvarad ter 4, Budapest H-1089, Hungary
}

\section{A R T I C L E I N F O}

\section{Article history:}

Received 30 October 2015

Accepted 9 August 2016

Available online 10 August 2016

Chemical compounds studied in this article: Na-pentobarbital (PubChem CID:4737) Erythropoietin, Darbepoetin, B-type natriuretic peptide (PubChem CID:16132422)

Cyclosporine A (PubChem CID:16404350) Trypan blue (PubChem CID:6364561) Evans blue dye (PubChem CID:5359386)

2,3,5-Triphenyltetrazolium chloride

(PubChem CID:9283)

Keywords:

Acute myocardial infarction

Cardioprotection

Erythropoietin

Darbepoetin

Non-erythropoietic EPO receptor ligand

B-type natriuretic peptide

\begin{abstract}
A B S T R A C T
Erythropoietin (EPO) has been shown to protect the heart against acute myocardial infarction in preclinical studies, however, EPO failed to reduce infarct size in clinical trials and showed significant safety problems. Here, we investigated cardioprotective effects of two selective non-erythropoietic EPO receptor ligand dimeric peptides (AF41676 and AF43136) lacking erythropoietic activity, EPO, and the prolonged half-life EPO analogue, darbepoetin in acute myocardial infarction (AMI) in rats. In a pilot study, EPO at $100 \mathrm{U} / \mathrm{mL}$ significantly decreased cell death compared to vehicle $(33.8 \pm 2.3 \%$ vs. $40.3 \pm 1.5 \%, \mathrm{p}<0.05)$ in rat neonatal cardiomyocytes subjected to simulated ischemia/reperfusion. In further studies (studies 1-4), in vivo AMI was induced by 30 min coronary occlusion and 120 min reperfusion in male Wistar rats. Test compounds and positive controls for model validation (B-type natriuretic peptide, BNP or cyclosporine A, CsA) were administered iv. before the onset of reperfusion. Infarct size (IS) was measured by standard TTC staining. In study $1,5000 \mathrm{U} / \mathrm{kg}$ EPO reduced infarct size significantly compared to vehicle $(45.3 \pm 4.8 \%$ vs. $59.8 \pm 4.5 \%, \mathrm{p}<0.05)$. In study 2 , darbepoetin showed a U-shaped dose-response curve with maximal infarct size-reducing effect at $5 \mu \mathrm{g} / \mathrm{kg}$ compared to the vehicle $(44.4 \pm 5.7 \% \mathrm{vs}$. $65.9 \pm 2.7 \%, \mathrm{p}<0.01$ ). In study $3, \mathrm{AF} 41676$ showed a U-shaped dose-response curve, where $3 \mathrm{mg} / \mathrm{kg}$ was the most effective dose compared to the vehicle $(24.1 \pm 3.9 \%$ vs. $44.3 \pm 2.5 \%, \mathrm{p}<0.001)$. The positive control BNP significantly decreased infarct size in studies $1-3$ by approximately $35 \%$. In study 4 , AF43136 at $10 \mathrm{mg} / \mathrm{kg}$ decreased infarct size, similarly to the positive control CsA compared to the appropriate vehicle ( $39.4 \pm 5.9 \%$ vs. $58.1 \pm 5.4 \%$ and $45.9 \pm 2.4 \%$ vs. $63.8 \pm 4.1 \%, \mathrm{p}<0.05$, respectively). This is the first demonstration that selective, non-erythropoietic EPO receptor ligand dimeric peptides AF41676 and
\end{abstract}

\footnotetext{
* Corresponding author at: Department of Pharmacology and Pharmacotherapy, Semmelweis University, Nagyvárad tér 4, Budapest 1089, Hungary.

E-mail addresses: kiss.krisztina.1@med.u-szeged.hu (K. Kiss), csonka.csaba@med.u-szeged.hu (C. Csonka), janos.paloczi@pharmahungary.com

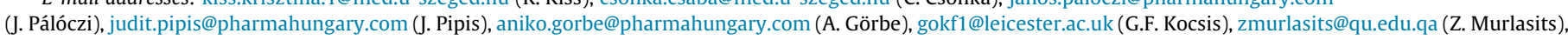
sarkozy.marta@med.u-szeged.hu (M. Sárközy), szucs.gergo@med.u-szeged.hu (G. Szücs), chrisholmes64@gmail.com (C.P. Holmes), yijunpan@hotmail.com (Y. Pan), a.bhandari@protagonist-inc.com (A. Bhandari), csont.tamas@med.u-szeged.hu (T. Csont), mshamloo@stanford.edu (M. Shamloo), kathrynwoodburn@yahoo.com (K.W.Woodburn), peter.ferdinandy@pharmahungary.com (P. Ferdinandy), peter.bencsik@pharmahungary.com (P. Bencsik).

1 These authors have contributed equally to the present study.
} 
AF43136 administered before reperfusion are able to reduce infarct size in a rat model of AMI. Therefore, non-erythropoietic EPO receptor peptide ligands may be promising cardioprotective agents.

\section{Introduction}

Erythropoietin (EPO) and its analogue with prolonged half-life, darbepoetin alpha (Dpa) are the main components of anemia treatment in chronic kidney disease and in cancer patients with anemia [1]. However, EPO is a pleiotropic cytokine, as EPO receptors (EpoR) are expressed in several different tissues (e.g. bone marrow, skeletal muscle, kidney, pancreas, heart, etc. [for review see [2]]).

It is well known that EPO receptors are present in rat cardiomyocytes [3], and also in human atrial and ventricular cardiomyocytes, as well as in cardiac endothelial cells [4]. Stress (e.g. hypoxia) induces EPO receptors and beta-common receptors (also known as CD131, which provides increased ligand-binding affinity to the receptor complex) to form the heterocomplex, EpoR-ßcR [5-7]. Then via this complex, EPO is able to reduce apoptosis and inflammation, and induce tissue repair [6]. Therefore, it is highly plausible that EPO has the capacity to protect the heart against acute or chronic myocardial ischemia [2]. EPO and Dpa have been shown to decrease myocardial infarct size, prevent myocyte loss and hypertrophy, improve cardiac contractility and ejection fraction, and increase capillary density after transient or permanent coronary artery occlusion in different animal models [8,9].

Based on the results of preclinical experiments, EPO and Dpa were evaluated for their effectiveness in the treatment of acute myocardial infarction (AMI) or heart failure in patients. Although, EPO improved left ventricular ejection fraction and NYHA functional class in patients with anemia and heart failure, Dpa had no effect on myocardial function in this population [10]. In most clinical trials, EPO or Dpa administered before or after percutaneous coronary intervention have failed to reduce infarct size in ST Segment Elevation Myocardial Infarction (STEMI) patients [2,11]. This lack of clinical effectiveness likely arises from the immediate hematopoietic activity of EPO analogues. Hematopoiesis is activated by association with homodimeric (i.e. erythropoietic) receptors before erythropoietic EPO analogues would exert their tissue-protective effects via heterocomplex receptors. Thereby, due to enhanced erythropoiesis, high-dose or long-term EPO or Dpa treatments may lead to thrombotic and/or thromboembolic adverse events (e.g. stent thrombosis, stroke, etc.), [2], and increased mortality in ischemic heart disease patients [12-14]. Another synthetic erythropoiesis-stimulating agent, peginesatide is a dimeric peptide without sequence homology to EPO. Peginesatide binds selectively and with high affinity to the EPO receptor [15]. It was indicated for the treatment of anemia until voluntarily withdrawal from the market shortly after its commercialization in 2013 due to 49 cases of anaphylaxis, including 7 fatalities [16]. Subsequently, an evaluation of the multi-use vials utilized, revealed large concentrations of subvisible particulates linked to hypersensitivity.

Therefore, it is feasible that non-hematopoietic EPO analogues, such as asialoerythropoietin (asialoEpo) or carbamylated EPO (CEPO), may provide EpoR-mediated cardioprotection without concurrent hematopoietic safety issues. These analogues bind to EpoR-ßcR heteroreceptors, but not to the "classical" homodimeric form of EpoR, thereby maintaining their protective effects without stimulating hematopoiesis [2]. In preclinical studies, CEPO or asialoEpo protect different tissues including myocardium by reducing apoptosis or inducing cardiac neovascularization with less adverse effects on procoagulant/haemopoetic activity [17-20]. However, because the structure of asialoEpo and CEPO mimics the three dimensional structure of EPO, clinical evaluation of potential immunogenicity and long-term stability is warranted [6,21]. In contrast, a small peptide ligand may attenuate the aforementioned disadvantages (i.e. via reduction in the number of possible epitopes) and may serve as a suitable alternative compound to evoke cardioprotection by coupling to EPO receptors.

Based on the promising results in cardioprotection by using nonerythropoietic EPO analogues, the aim of the present study was to test the effects of two novel, selective EPO receptor ligand dimeric peptides, AF41676 and AF43136, which are structurally related to the peptide portion of peginesatide, but lacking erythropoietic activity, on infarct size in a rat model of AMI.

\section{Materials and methods}

The investigation conforms to the Guide for the care and use of laboratory animals published by the US National Institutes of Health (NIH publication No. 85-23, revised 1996) and was approved by the Ethics Committee at the University of Szeged and, when necessary, the Affymax Institutional Animal Care and Use Committee (IACUC).

\subsection{Animals and test compounds}

Male Wistar rats (225-370 g) purchased from Toxi-Coop Toxicological Research Center Zrt., Dunakeszi, Hungary and Charles-River (Budapest, Hungary) were housed in a room maintained at $12 \mathrm{~h}$ light-dark cycles and at a constant temperature of $22 \pm 2^{\circ} \mathrm{C}$. The animals had free access to standard laboratory chow and drinking water.

Test compounds (including acetate vehicle) were synthetized and provided by Affymax except for Erythropoietin (Procrit ${ }^{\circledR}$, Amgen, Inc., Thousand Oaks, CA), Darbepoetin alpha (Aranesp ${ }^{\circledR}$, Amgen Europe b.v., ZK Breda, The Netherlands), B-type natriuretic peptide (BNP; Sigma-Aldrich, Budapest, Hungary) and Cyclosporine A (CsA; Sandimmun Neoral ${ }^{\circledR}$, Novartis Hungária, Budapest, Hungary). Acetate vehicle consisted of $40 \mathrm{mM}$ acetate and $4.3 \%$ sorbitol, pH 5.0 .

\subsection{Structure of EPO receptor ligands}

The two selective EPO receptor ligand dimeric peptides, AF41676 and AF43136, were synthetized as their acetate salts using a combination of solid phase peptide techniques to prepare the individual peptide chains followed by solution phase conjugation to the bifunctional linkers. The peptides were purified by reverse-phase preparative chromatography and characterized by mass spectrometry. Their erythropoietic activity has been significantly reduced by key amino acid substitutions. The amino acid sequence of AF41676 is

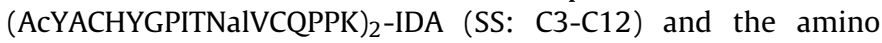
acid sequence of AF43136 is (AcLYLCRYGRVHNalECQPLRK) $)_{2}$ DIG (SS:C4-C13). 1Nal is 1-naphthyalanine. Peptide dimer linkers are iminodiacetic acid (IDA) and 1,1'-[oxybis[(1-oxo-2, 1-ethanediyl)oxy]]bis-2,5-pyrrolidinedione (DIG), and the paren- 
Table 1

Study design.

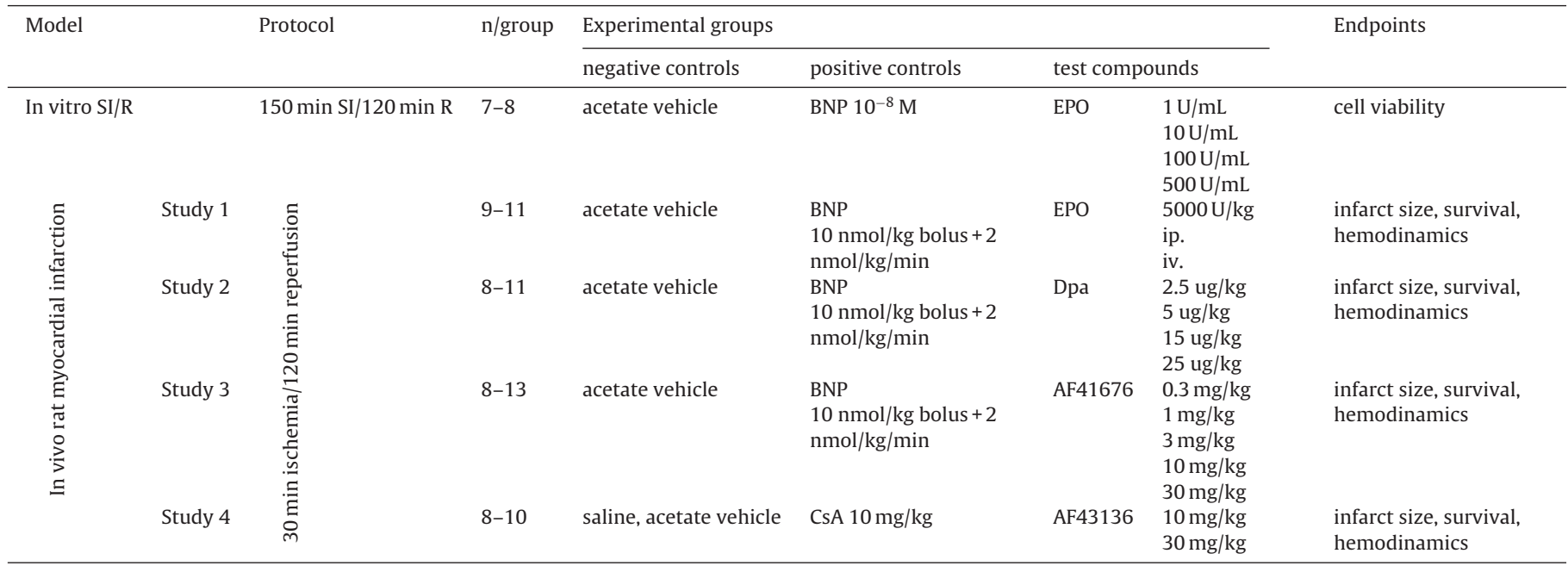

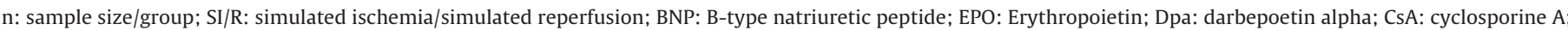
iv: intravenous; ip: intraperitoneal.

theses indicate two cyclic peptide chains linked to their respective linkers via the epsilon amine on the side chain of lysine.

\subsection{EPO receptor binding assay}

The competition binding assay was carried out by incubating $100 \mathrm{pg}$ of HuEPOr-Fc (R\&D Systems) with serial dilutions of competitor and $20,000 \mathrm{cpm}^{125} \mathrm{IEPO}$, followed by incubation, addition of Protein $\mathrm{G}$ beads, washing, and counting, using conditions based on a method for the detection of anti-EPO antibodies [22]. The specificity of the binding properties of EPO, Dpa, AF41676, and AF43136 were evaluated by MDS Pharma Services (Taipei, Taiwan) in a screen of 66 diverse receptors, including both homo- an heterodimeric EPO receptors (LeadProfilingScreen).

\subsection{Erythroid (BFU-E) colony assay}

Erythroid colony assay was performed as described previously [23]. Briefly, human CD34+ cells (Cambrex, Walkersville, MD, USA) were resuspended at 15,000 cells/mL in IMDM with $10 \%$ FBS. EPO, Dpa, AF41676 and AF43136 were added to a methylcellulose-based colony assay media (MethoCult GF H4534, StemCell Technologies, Vancouver, BC, Canada) supplemented with rhSCF, rhGM-CSF, and rhIL-3. Cells were added to the methylcellulose and plated with subsequent incubation at $37^{\circ} \mathrm{C}$, in a $5 \% \mathrm{CO}_{2}$ incubator for $12-14$ days. Colonies containing over 50 cells were counted by phasecontrast microscopy.

\subsection{Investigation of erythropoietic activity}

To evaluate erythropoiesis EPO, Dpa, AF41676 and AF43136 were examined for their potential to induce reticulocytosis in normocythemic male Sprague-Dawley rats $(n=4)$. We administered a single intravenous (iv.) dose of EPO at $5000 \mathrm{U} / \mathrm{kg}$, Dpa at $10 \mu \mathrm{g} / \mathrm{kg}$, AF41676 at $10 \mathrm{mg} / \mathrm{kg}, \mathrm{AF} 43136$ at $10 \mathrm{mg} / \mathrm{kg}$ and acetate vehicle $(5 \mathrm{~mL} / \mathrm{kg})$ via the tail vein, respectively. Blood $(0.5 \mathrm{~mL})$ was collected for determination of reticulocyte number by retro-orbital puncture of metoxyflurane-anesthetized rats into EDTA-containing tubes at baseline (pre-dose) and 5 days following administration as described previously [23].

\subsection{Study design}

2.6.1. Investigation of direct cardio-cytoprotective effect by EPO

To determine the direct, non-erythropoietic effect of EPO on cardiomyocytes, we tested different doses of EPO $(1,10,100$, $500 \mathrm{U} / \mathrm{mL}$ ) on neonatal rat cardiomyocyte cell culture subjected to 150 min simulated ischemia followed by 120 min simulated reperfusion. BNP at $10^{-8} \mathrm{M}$ was used as the positive control. Cell death was compared to acetate vehicle-treated cells (Table 1).

\subsubsection{Investigation of myocardial infarct size limiting effect of $E P O$ and EPO analogues}

In a further series of in vivo studies (studies 1-4, see below), animals were randomly assigned to the different experimental groups with a total number of 8-13 animals per group. Each test compound was administered before the onset of reperfusion (Table 1). During the individual studies, all-cause mortality was registered to compare the survival among the controls and the drug-treated groups.

Study 1: We have administered EPO at $5000 \mathrm{U} / \mathrm{kg}$ [used successfully for cardioprotection several times in the literature; for review see Ref. [24]] bolus injection $5 \mathrm{~min}$ before the onset of reperfusion intraperitoneally or intravenously to compare different ways of administration. Positive control BNP was administered iv. at $10 \mathrm{nmol} / \mathrm{kg}$ bolus $+2 \mathrm{nmol} / \mathrm{kg} / \mathrm{min}$ infusions for $15 \mathrm{~min}$ starting at the 25th min of ischemia. This dose was derived from a previous publication where $10 \mathrm{nM}$ BNP was cardioprotective ex vivo [25], and due to its short half-life [26] a maintenance infusion ( $2 \mathrm{nmol} / \mathrm{kg} / \mathrm{min}$ ) was applied in our in vivo model. The vehicle was used as the negative control and comprised $40 \mathrm{mM}$ acetate with $4.3 \%$ sorbitol, pH 5.0 and was administered iv. 5 min before the onset of reperfusion.

Study 2: To investigate the dose dependence of the EPO analogue, darbepoetin, Dpa was administered at the 15 th min of ischemia, in 2.5, 5, 15 and $25 \mu \mathrm{g} / \mathrm{kg}$ boluses administered iv. The positive control BNP and the negative control acetate vehicle were administered identically to Study 1 . The reason for Dpa administration 10 min earlier than EPO (i.e. at the 15 th min of ischemia) was its prolonged half-life.

Study 3: Dose dependence of AF41676 was tested at 0.3, 1, 3, 10 and $20 \mathrm{mg} / \mathrm{kg}$ doses administered as iv. bolus injection $5 \mathrm{~min}$ before the onset of reperfusion. Negative control acetate vehicle was administered accordingly to Study 1 . 
Study 4: In an exploratory study, we tested AF43136, a slightly modified version of AF41676 (see above for structural differences) in two doses in order to monitor potential hypotensive effects, which have occurred previously with EPO analogues. AF43136 was administered at 10 and $30 \mathrm{mg} / \mathrm{kg}$ doses iv. as a bolus infusion for 5 min starting at the 25th min of ischemia at a final volume load of $6 \mathrm{~mL} / \mathrm{kg}$ due to the high concentration being administered (30 mg/kg). Saline and the positive control CsA $(10 \mathrm{mg} / \mathrm{kg}$, diluted in saline) were administered intravenously as a bolus infusion for 5 min starting at the 25 th min of ischemia at a final volume load of $1 \mathrm{~mL} / \mathrm{kg}$. Acetate vehicle was administered same as test compounds at a final volume load of $6 \mathrm{~mL} / \mathrm{kg}$.

\subsection{Simulated ischemia/reperfusion in cultured neonatal cardiac myocytes}

Neonatal cardiomyocyte isolation and culture method was described previously in detail [27,28]. In brief, newborn Wistar rats were disinfected with $70 \%$ ethanol and sacrificed by cervical dislocation. Hearts were excised and transferred to cold, sterile phosphate buffered saline pH 7.2 (PBS). Ventricles were separated from atria, minced gently with sterile forceps and collected in $0.25 \%$ trypsin solution (Invitrogen, Life Technologies Hungary Ltd., Budapest, Hungary). At the end of digestion, cell suspension was centrifuged for $15 \mathrm{~min}$ at $2000 \mathrm{rpm}$ at $4^{\circ} \mathrm{C}$, supernatant was removed gently and the pellet was re-suspended in complete growth medium and plated onto 6-well plates to eliminate fibroblasts (pre-plating). Supernatants were collected in fresh Falcon tubes and cells were counted manually in a Burker chamber. Then cells of the supernatant were re-plated into 24-well fresh plates: $10^{5}$ cells/well supplemented with $1 \mathrm{~mL}$ growth medium and incubated under normoxic conditions $\left(37^{\circ} \mathrm{C}\right.$, in $95 \%$ air and $5 \% \mathrm{CO}_{2}$ gas mixture) in a standard $\mathrm{CO}_{2}$ incubator. Growth medium was changed the following day. Cultures were used for treatment at the 3-day-old stage.

The simulated ischemic group was treated during the experimental protocol using a combination of hypoxic chamber and hypoxic solution [28] to simulate tissue ischemia. In treated groups, $\operatorname{EPO}(1,10,100,500 \mathrm{U} / \mathrm{mL})$ and $\operatorname{BNP}\left(10^{-8} \mathrm{M}\right)$ or acetate vehicle were administered into the hypoxic solution and plates were kept in a hypoxic chamber (gassed with $95 \% \mathrm{~N}_{2}$ and $5 \% \mathrm{CO}_{2}$ at $37 \mathrm{C}$ ) for 150 min. Following treatments, 120 min of simulated reperfusion was applied in growing medium (mixed with treating compounds) and the plates were kept in a normoxic incubator.

\subsection{Cell viability measurement}

At the end of the experiments, viability tests were performed in all groups with trypan blue staining after simulated reperfusion. Treating solutions were removed and cells were detached with trypsin. Single cell suspensions were collected into Eppendorf tubes and centrifuged at $2000 \mathrm{rpm}$ for $15 \mathrm{~min}$ at $4{ }^{\circ} \mathrm{C}$. Supernatants were removed and the pellets were re-suspended in $50 \mu \mathrm{L}$ PBS solution and mixed with $50 \mu \mathrm{L} 0.4 \%$ trypan blue and incubated for $5 \mathrm{~min}$. Cells were counted in a Burker chamber and the ratio of dead (blue) cells to total cell count was calculated and plotted.

\subsection{Experimental model of in vivo myocardial infarction}

Myocardial infarction in rats was described previously in detail [29]. Rats were anesthetized by intraperitoneal injection of pentobarbital (Euthasol, Produlab Pharma b.v., Raamsdonksveer, The Netherlands; $60 \mathrm{mg} / \mathrm{kg}$ bolus dose followed by $15-20 \mathrm{mg} / \mathrm{kg}$ when required during the experiment). The rats were weighed and stomach and chest area shaved. Body temperature was maintained using a constant-temperature heating pad. The trachea was intubated with a cannula connected to a rodent ventilator. The animals were ventilated with room air $(6.2 \mathrm{~mL} / \mathrm{kg}, 70 \pm 5$ breath $/ \mathrm{min})$. Blood pressure, surface-lead ECG, and body core temperature were monitored throughout the experiments to ensure the stability of the preparation (Haemosys data acquisition system, Experimetria, Budapest, Hungary), while hemodynamic data were collected at baseline, 29 th min of ischemia and 120th min of reperfusion. The right carotid artery was cannulated for measurement of blood pressure and the right femoral vein was cannulated for the administration of the test compounds. A thoracotomy was performed at the 5 th intercostal space and the heart was exposed through the fifth intercostal space. The pericardium was incised and a 5-0 Prolene suture was placed around the left descending coronary artery.

The coronary artery was then occluded for $30 \mathrm{~min}$ by placing the ligature through a small piece of plastic tubing and pulling the snare tightly in place using a hemostat. After $30 \mathrm{~min}$ of coronary occlusion, reperfusion was initiated by releasing the snare and then continued for $120 \mathrm{~min}$.

All-cause mortality was monitored throughout the entire study, i.e. from the anesthesia to the end of reperfusion. The cause of death was determined as follows: irreversible ventricular arrhythmias or hypotension.

\subsection{Infarct size measurement}

At the end of the 120 min reperfusion, the heart was excised and infarct size was determined [30]. Briefly, the left anterior descending coronary artery was re-occluded and the heart was perfused with $4 \mathrm{~mL}$ of $0.3 \%(\mathrm{w} / \mathrm{v})$ Evans-blue dye (Sigma-Aldrich, Budapest, Hungary) with a constant $100 \mathrm{cmH}_{2} \mathrm{O}$ pressure into the aorta to delineate the area at risk zone. Stained hearts were rapidly frozen (at $-20^{\circ} \mathrm{C}$ for at least $30 \mathrm{~min}$ ), cut into $2 \mathrm{~mm}$ thick slices, and each slice was incubated at $37{ }^{\circ} \mathrm{C}$ in $1.5 \mathrm{~mL}$ of $1 \%(\mathrm{w} / \mathrm{v}) 2,3,5-$ triphenyltetrazolium-chloride (TTC, Merck Biosciences, Budapest, Hungary) dissolved in $50 \mathrm{mM}$ phosphate buffer ( $\mathrm{pH} 7.4$ ) for 10 min. Slices were then transferred into $10 \%$ formalin solution for 5-10 min, rinsed, and then scanned between glass plates. The differently stained areas of the images were quantified by digital planimetry (Infarctsize ${ }^{\mathrm{TM}} 2.5$, Pharmahungary, Szeged, Hungary). Evaluation of all images was carried out in a blinded manner by an experienced investigator throughout the study. Area at risk zone (AAR) was expressed as the percentage of total ventricular area (LV), and infarct size (IS) was expressed as a percentage of the AAR.

\subsection{Statistical analysis}

Infarct size was expressed as a percentage of the AAR as mean \pm standard error of the mean (S.E.M). Relative changes in infarct size due to treatments were also presented as a percentage of the respective untreated control groups. Differences among means of IS/AAR (\%) were analyzed by One-way analysis of variance (ANOVA) followed by Fisher LSD post hoc test to compare each group to the control when appropriate. To analyze the reticulocyte stimulation test, One-way ANOVA was used followed by Tukey post hoc test, where means of reticulocyte number/L of EPO and Dpa were compared to the vehicle, while means of the AF test compounds were compared to EPO. Statistical significance was accepted at $\mathrm{p}<0.05$. Mortality was analyzed with Chi-square test followed by Fisher's exact test. CsA group was compared to the saline control group by Student's $t$-test. 
Table 2

Data for erythroid colony assay and EPO receptor binding assay of the test compounds.

\begin{tabular}{lll}
\hline Test compounds & Binding $\left(\mathrm{EC}_{50}, \mathrm{pM}\right)$ & $\mathrm{BFU}-\mathrm{E}(\mathrm{pM})$ \\
\hline EPO & 7 & 2 \\
Dpa & 12 & 14 \\
AF41676 & 1240 & 34680 \\
AF43136 & 27 & 2623
\end{tabular}

BFU-E: Erythroid blood forming unit; $\mathrm{EC}_{50}$ : Half maximal effective concentration; EPO: Erythropoietin; Dpa: darbepoetin alpha.

Table 3

Data for reticulocyte stimulation test measured 5 days after administration of the test compounds.

\begin{tabular}{ll}
\hline Test compounds & Reticulocytes $\left(10^{9} / \mathrm{L}\right)$ \\
\hline Acetate vehicle & $373 \pm 24.3$ \\
EPO $(5000 \mathrm{U} / \mathrm{kg})$ & $762 \pm 146^{*}$ \\
$\mathrm{Dpa}(10 \mu \mathrm{g} / \mathrm{kg})$ & $1056 \pm 104^{*}$ \\
$\mathrm{AF} 41676(10 \mathrm{mg} / \mathrm{kg})$ & $284 \pm 51.3^{\#}$ \\
AF43136 $(10 \mathrm{mg} / \mathrm{kg})$ & $286 \pm 57.0^{\#}$
\end{tabular}

Data are expressed as mean $\pm \mathrm{SD}$.

${ }^{*} \mathrm{p}<0.05$ vs. acetate vehicle.

\# $\mathrm{p}<0.05$ vs. EPO.

\section{Results}

\subsection{EPO receptor binding and erythroid colony formation} abilities for EPO, Dpa and AF peptides

EPO, Dpa and AF43136 bound to the EPO receptor with high affinity (with AF41676 exhibiting modest affinity), AF41676 and AF43136 did not show in vitro erythropoietic activity (Table 2). EPO and Dpa differentiated CD $34^{+}$cells into erythroid precursors with high efficiency $\left(\mathrm{EC}_{50}=2\right.$ to $\left.14 \mathrm{pM}\right)$, whereas AF41676 and AF43136 required vastly greater amounts (Table 2) (approximately 3-4 orders of magnitude).

\subsection{The effects of EPO, Dpa and AF peptides on erythropoiesis}

Reticulocytosis, a predictive marker of erythropoiesis, was significantly stimulated 5 days following administration of EPO at $5000 \mathrm{U} / \mathrm{kg}$ and Dpa at $10 \mu \mathrm{g} / \mathrm{kg}$, but not by administration of AF41676 and AF43136 compared to acetate vehicle (Table 3). For more details, see Data supplement Fig. S1 in the online version, at http://dx.doi.org/10.1016/j.phrs.2016.08.013.

\subsection{The effects of EPO on cell death}

Erythropoietin showed a U-shaped response curve on cell viability in cultured neonatal rat cardiomyocytes subjected to simulated ischemia/reperfusion (Fig. 1B). EPO at $100 \mathrm{U} / \mathrm{mL}$ significantly decreased the ratio of dead cells (by approx. 16\%) compared to the vehicle control group. The positive control BNP reduced cell death compared to the controls by approx. 30\% (Fig. 1B).

\subsection{The effects of EPO on infarct size and hemodynamics (Study 1)}

Different EPO dosing regimens were evaluated. EPO at $5000 \mathrm{U} / \mathrm{kg}$ administered intravenously, before the onset of reperfusion decreased infarct size significantly compared to the vehicle by approximately $24 \%$, while intraperitoneal administration was less effective (approximately $11 \%$ non-significant decrease) (Fig. 2B, Table 4). The positive control BNP (10 nmol/ $\mathrm{kg}+2 \mathrm{nmol} / \mathrm{kg}$ infusion for $15 \mathrm{~min}$ ) decreased infarct size significantly compared to the vehicle by approx. $47 \%$ (Fig. $2 \mathrm{~B}$, Table 4 ). There was no dif-
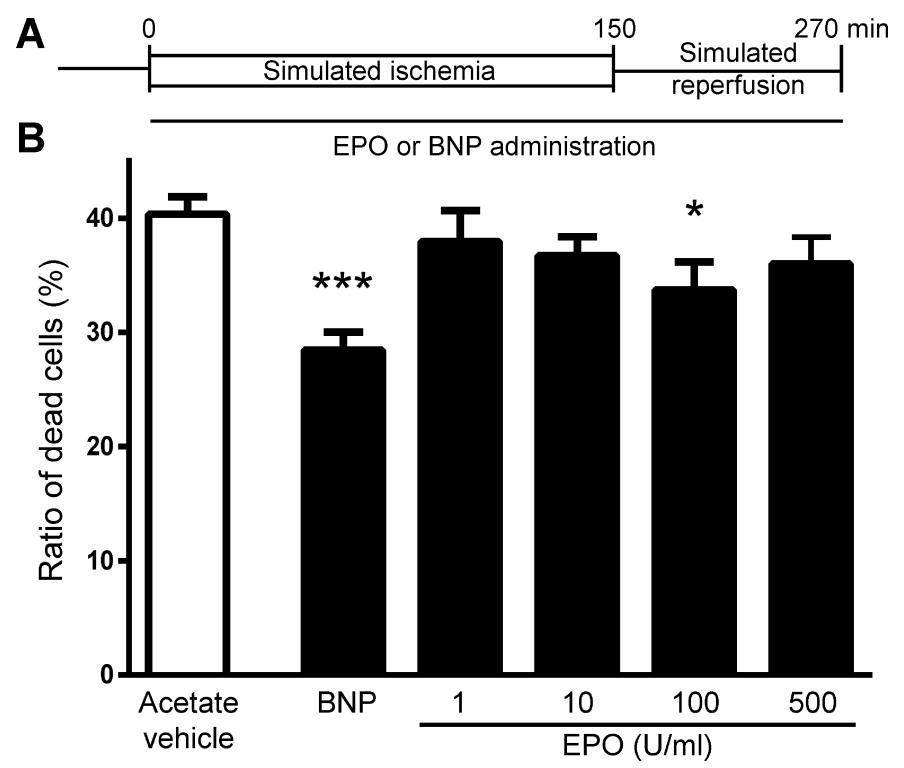

Fig. 1. Panel A: Experimental protocol for the pilot study.

Panel B: Dose-response relationships for EPO and the effect of BNP on cell death in cultured neonatal rat cardiac myocytes subjected to 150 min simulated ischemia followed by $120 \mathrm{~min}$ simulated reperfusion. Data are expressed as mean \pm S.E.M., ${ }^{*} \mathrm{p}<0.05,{ }^{* * *} \mathrm{p}<0.001$ vs. simulated ischemia/reperfusion $(\mathrm{SI} / \mathrm{R})$ control; $\mathrm{n}=7-8$ wells.

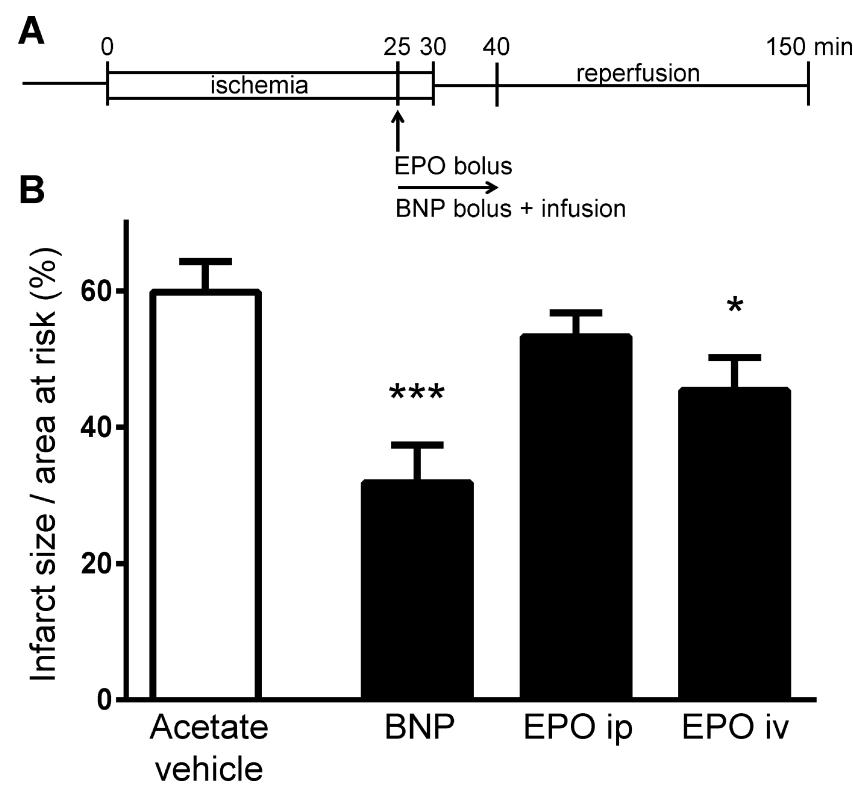

Fig. 2. Panel A: Experimental protocol for Study 1

Panel B: The effects of BNP and EPO on infarct size in rats subjected to in vivo 30-min coronary occlusion followed by $120 \mathrm{~min}$ reperfusion. EPO was administered either intraperitoneally (EPO ip) or intravenously (EPO iv) for rats. Data are expressed as means \pm S.E.M., ${ }^{*} \mathrm{p}<0.05,{ }^{* * *} \mathrm{p}<0.001$ vs. vehicle control; $\mathrm{n}=8-9$.

ference in area at risks among the groups (Table 4). BNP reduced mean arterial blood pressure (MABP) significantly during ischemia compared to the vehicle, whereas EPO did not show any significant effect on MABP or heart rate (HR). (Table 4). There was no significant difference in survival among the groups (data not shown).

\subsection{The effects of darbepoetin on infarct size and hemodynamics (Study 2)}

Different doses of darbepoetin were administered intravenously at the 15 th min of ischemia. Dose-response relationship of darbe- 
Table 4

Hemodynamic parameters, area at risk and infarct size data for study 1 .

\begin{tabular}{|c|c|c|c|c|c|c|c|c|c|}
\hline & \multirow[t]{2}{*}{$\mathrm{n}$} & \multirow[t]{2}{*}{ AAR/LV (\%) } & \multirow[t]{2}{*}{ IS/AAR (\%) } & \multicolumn{3}{|c|}{ mean arterial blood pressure (mmHg) } & \multicolumn{3}{|c|}{ heart rate (beats/min) } \\
\hline & & & & $\mathrm{BL}$ & ISCH & REP & $\mathrm{BL}$ & ISCH & REP \\
\hline Vehicle (ac) & 9 & $34.3 \pm 2.7$ & $59.8 \pm 4.2$ & $142 \pm 7$ & $119 \pm 7$ & $107 \pm 6$ & $404 \pm 10$ & $399 \pm 14$ & $400 \pm 14$ \\
\hline $\mathrm{BNP}$ & 8 & $38.8 \pm 5.5$ & $31.8 \pm 5.2^{* * *}$ & $124 \pm 10$ & $89 \pm 5^{*}$ & $91 \pm 6$ & $401 \pm 14$ & $405 \pm 6$ & $413 \pm 11$ \\
\hline Epo ip & 8 & $33.9 \pm 2.2$ & $53.3 \pm 3.3$ & $151 \pm 7$ & $118 \pm 5$ & $108 \pm 9$ & $418 \pm 20$ & $410 \pm 18$ & $399 \pm 15$ \\
\hline Epo iv & 8 & $37.3 \pm 3.7$ & $45.3 \pm 4.5^{*}$ & $126 \pm 11$ & $115 \pm 8$ & $111 \pm 9$ & $427 \pm 6$ & $396 \pm 13$ & $403 \pm 12$ \\
\hline
\end{tabular}

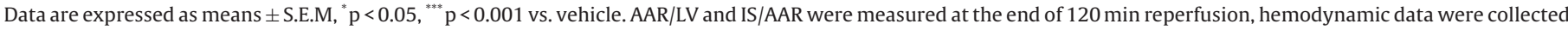

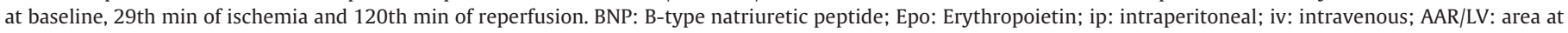
risk/left ventricle. IS/AAR: infarct size/area at risk; BL: baseline; ISCH: 29th min of ischemia; REP: 120th min of reperfusion.

Table 5

Hemodynamic parameters, area at risk and infarct size data for study 2 .

\begin{tabular}{|c|c|c|c|c|c|c|c|c|c|}
\hline & \multirow[t]{2}{*}{$\mathrm{n}$} & \multirow[t]{2}{*}{ AAR/LV (\%) } & \multirow[t]{2}{*}{ IS/AAR (\%) } & \multicolumn{3}{|c|}{ mean arterial blood pressure $(\mathrm{mmHg})$} & \multicolumn{3}{|c|}{ heart rate (beats/min) } \\
\hline & & & & $\mathrm{BL}$ & ISCH & REP & $\mathrm{BL}$ & ISCH & REP \\
\hline Vehicle (ac) & 8 & $41.5 \pm 3.3$ & $65.9 \pm 2.7$ & $115 \pm 4$ & $95 \pm 7$ & $75 \pm 3$ & $411 \pm 11$ & $422 \pm 13$ & $389 \pm 10$ \\
\hline BNP & 7 & $51.6 \pm 1.5$ & $44.2 \pm 3.7^{*}$ & $107 \pm 5$ & $71 \pm 4^{*}$ & $75 \pm 4$ & $386 \pm 15$ & $389 \pm 18$ & $386 \pm 14$ \\
\hline Dpa $2.5 \mu \mathrm{g} / \mathrm{kg}$ & 8 & $51.5 \pm 3.0$ & $59.3 \pm 6.3$ & $112 \pm 3$ & $91 \pm 5$ & $80 \pm 4$ & $408 \pm 13$ & $437 \pm 11$ & $387 \pm 17$ \\
\hline Dpa $5 \mu \mathrm{g} / \mathrm{kg}$ & 8 & $43.3 \pm 5.3$ & $44.7 \pm 5.7^{*}$ & $123 \pm 2$ & $62 \pm 4^{*}$ & $76 \pm 6$ & $430 \pm 3$ & $378 \pm 9$ & $398 \pm 16$ \\
\hline Dpa $15 \mu \mathrm{g} / \mathrm{kg}$ & 7 & $41.3 \pm 4.1$ & $61.9 \pm 3.3$ & $126 \pm 11$ & $80 \pm 5$ & $91 \pm 4^{*}$ & $368 \pm 14^{*}$ & $418 \pm 8$ & $416 \pm 8$ \\
\hline Dpa $25 \mu \mathrm{g} / \mathrm{kg}$ & 7 & $49.9 \pm 2.5$ & $75.1 \pm 3.9$ & $127 \pm 1$ & $104 \pm 4$ & $74 \pm 4$ & $396 \pm 14$ & $420 \pm 11$ & $406 \pm 14$ \\
\hline
\end{tabular}

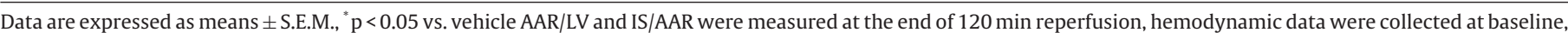

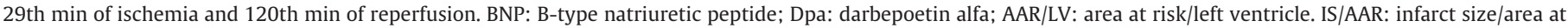
risk; BL: baseline; ISCH: 29th min of ischemia; REP: 120 th min of reperfusion.
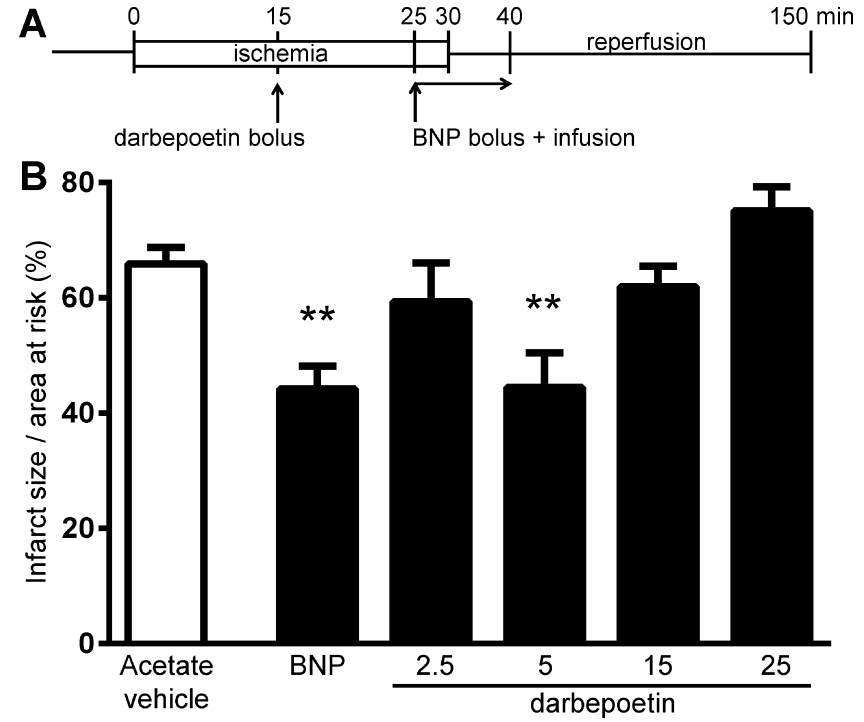

Fig. 3. Panel A: Experimental protocol for Study 2.

Panel B: Dose-response relationships for darbepoetin and the effect of BNP on infarct size in rats subjected to in vivo 30-min coronary occlusion followed by $120 \mathrm{~min}$ reperfusion. Data are expressed as means \pm S.E.M., ${ }^{* *} \mathrm{p}<0.01$ vs. vehicle control; $n=7-8$.

poetin showed a U-shaped curve with maximal infarct size limiting effect at $5 \mu \mathrm{g} / \mathrm{kg}$ compared to the vehicle (approx. 33\% reduction, Fig. 3B, Table 5). The infarct size-limiting effect of darbepoetin was comparable to that of the positive control BNP (approx. 33\% for both, Fig. 3B, Table 5). There was no significant difference in the area at risks among groups (Table 5). BNP and Dpa at $5 \mu \mathrm{g} / \mathrm{kg}$ reduced MABP significantly during ischemia, while Dpa at $15 \mu \mathrm{g} / \mathrm{kg}$ significantly improved MABP at the end of reperfusion compared to the vehicle. Neither Dpa nor BNP had any effect on HR (Table 5). There was no significant difference in survival among the groups (data not shown).
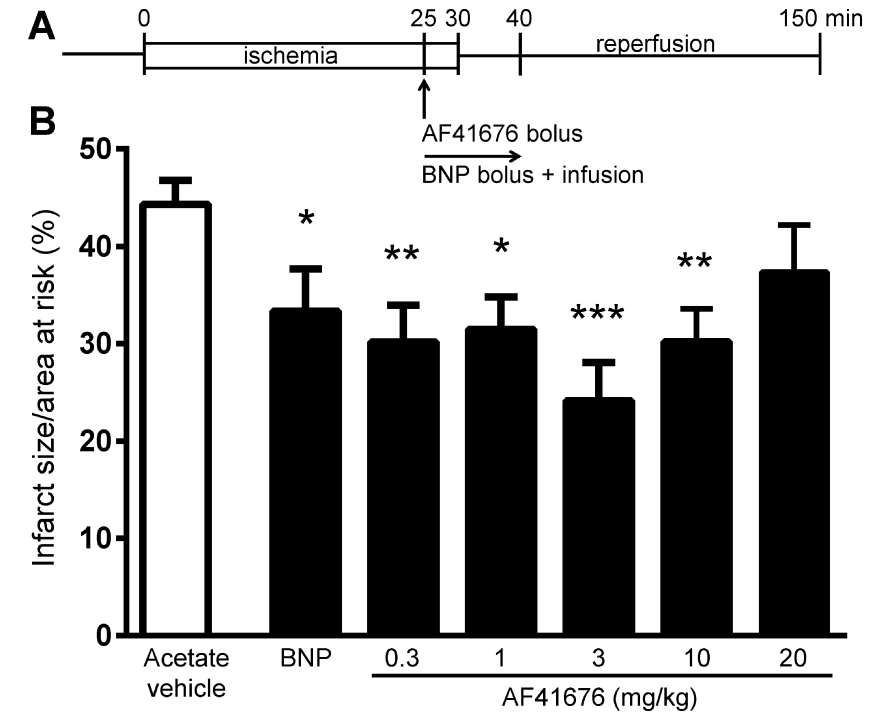

Fig. 4. Panel A: Experimental protocol for Study 3.

Panel B: Dose-response curve for AF41676 on infarct size in rats subjected to in vivo 30 -min coronary occlusion followed by $120 \mathrm{~min}$ reperfusion. Data are expressed as means \pm S.E.M., ${ }^{*} \mathrm{p}<0.05,{ }^{* *} \mathrm{p}<0.01,{ }^{* * *} \mathrm{p}<0.001$ vs. vehicle control; $\mathrm{n}=7-8$.

\subsection{The effects of AF41676 on infarct size and hemodynamics (Study 3)}

Dose-dependent efficacy of AF41676 was investigated by five different intravenously-administered doses in a bolus injection $5 \mathrm{~min}$ before the onset of reperfusion. On the U-shaped dose-effect curve, AF41676 at $0.3,1,3$ and $10 \mathrm{mg} / \mathrm{kg}$ decreased infarct size significantly, of which the $3 \mathrm{mg} / \mathrm{kg}$ dose showing the most potent infarct size limiting effect compared to the vehicle (approx. 46\% reduction, Fig. 4B, Table 6 ). BNP also reduced infarct size significantly compared to the vehicle (approx. 25\% reduction; Fig. 4B, Table 6). There was no significant difference in the area at risks among the groups (Table 6). BNP as well as 10 and $20 \mathrm{mg} / \mathrm{kg}$ AF41676 reduced MABP during ischemia compared to the vehicle (Table 6). AF41676 at $20 \mathrm{mg} / \mathrm{kg}$ reduced HR at the 29th min of 
Table 6

Hemodynamic parameters, area at risk and infarct size data for study 3.

\begin{tabular}{|c|c|c|c|c|c|c|c|c|c|}
\hline & \multirow[t]{2}{*}{$\mathrm{n}$} & \multirow[t]{2}{*}{ AAR/LV (\%) } & \multirow[t]{2}{*}{ IS/AAR (\%) } & \multicolumn{3}{|c|}{ mean arterial blood pressure $(\mathrm{mmHg})$} & \multicolumn{3}{|c|}{ heart rate (beats/min) } \\
\hline & & & & BL & ISCH & REP & BL & ISCH & REP \\
\hline Vehicle (acetate) & 8 & $33.0 \pm 3.4$ & $44.3 \pm 2.5$ & $118 \pm 9$ & $116 \pm 11$ & $100 \pm 9$ & $418 \pm 14$ & $427 \pm 16$ & $402 \pm 10$ \\
\hline BNP & 8 & $34.9 \pm 2.4$ & $33.4 \pm 3.0^{*}$ & $103 \pm 9$ & $73 \pm 6^{*}$ & $98 \pm 6$ & $396 \pm 16$ & $405 \pm 10$ & $490 \pm 18^{*}$ \\
\hline AF41676 $0.3 \mathrm{mg} / \mathrm{kg}$ & 8 & $43.3 \pm 4.0$ & $30.2 \pm 3.3^{* *}$ & $109 \pm 6$ & $111 \pm 4$ & $94 \pm 3$ & $429 \pm 5$ & $450 \pm 4$ & $423 \pm 8$ \\
\hline AF41676 $1 \mathrm{mg} / \mathrm{kg}$ & 8 & $36.7 \pm 4.0$ & $31.5 \pm 3.9^{*}$ & $114 \pm 9$ & $104 \pm 6$ & $80 \pm 8$ & $427 \pm 8$ & $433 \pm 11$ & $410 \pm 9$ \\
\hline AF41676 3 mg/kg & 8 & $44.5 \pm 2.6$ & $24.1 \pm 3.4^{* * *}$ & $125 \pm 5$ & $116 \pm 10$ & $104 \pm 5$ & $408 \pm 17$ & $418 \pm 11$ & $411 \pm 4$ \\
\hline AF41676 $10 \mathrm{mg} / \mathrm{kg}$ & 8 & $34.1 \pm 3.5$ & $30.2 \pm 4.8^{* *}$ & $122 \pm 5$ & $75 \pm 8^{*}$ & $75 \pm 8^{*}$ & $443 \pm 6$ & $393 \pm 17$ & $413 \pm 17$ \\
\hline AF41676 $20 \mathrm{mg} / \mathrm{kg}$ & 7 & $40.9 \pm 2.4$ & $37.4 \pm 2.5$ & $125 \pm 8$ & $84 \pm 1^{*}$ & $83 \pm 9$ & $413 \pm 11$ & $361 \pm 26^{*}$ & $438 \pm 16$ \\
\hline
\end{tabular}

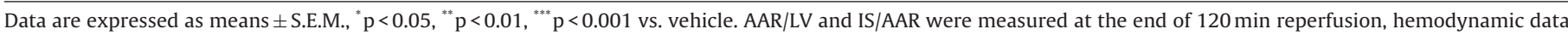

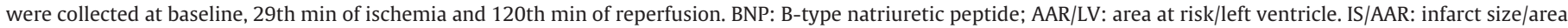
at risk; BL: baseline; ISCH: 29th min of ischemia; REP: 120th min of reperfusion.

ischemia and at $10 \mathrm{mg} / \mathrm{kg}$ reduced MABP at the end of reperfusion (Table 6). In spite of the transient hypotensive effect of the 10 and $20 \mathrm{mg} / \mathrm{kg}$ doses of AF41676, there was no significant difference in survival among the groups (data not shown).

\subsection{The effects of AF43136 on blood pressure, survival and infarct size (Study 4)}

AF43136 was administered in 10 and $30 \mathrm{mg} / \mathrm{kg}$ doses iv. as a bolus infusion for 5 min starting at the 25th min of ischemia at a final volume load of $6 \mathrm{~mL} / \mathrm{kg}$. AF43136 at $10 \mathrm{mg} / \mathrm{kg}$ dose reduced infarct size significantly by approximately $30 \%$ compared to the acetate vehicle control, however, infarct size data of $30 \mathrm{mg} / \mathrm{kg}$ AF43136 is equivocal due to the high mortality ratio and the consequent small sample size at the end of the experiments $(n=2$; Fig. $5 B$, Table 7). The positive control CsA used in study 4 decreased infarct size significantly by approximately $23 \%$ compared to the saline control (Fig. 5B, Table 7). There was no difference in the area at risks among the groups (Table 7). AF43136 at $30 \mathrm{mg} / \mathrm{kg}$ decreased mean arterial blood pressure significantly during ischemia compared to the acetate vehicle, but it did not reduce blood pressure at $10 \mathrm{mg} / \mathrm{kg}$ (Table 7). In addition, AF43136 at $10 \mathrm{mg} / \mathrm{kg}$ increased mean arterial blood pressure by the end of $120 \mathrm{~min}$ reperfusion compared to the acetate vehicle (Table 7). AF43136 at $30 \mathrm{mg} / \mathrm{kg}$ reduced survival rate significantly compared to acetate vehicle (Fig. 5C).

\section{Discussion}

Here, we have shown that two novel selective non-erythropoietic EPO receptor ligand dimeric peptides, AF41676 and AF43136, reduce infarct size in a rat model of acute myocardial infarction. This is the first demonstration that these EPO receptor ligand peptides are cardioprotective in a rat model of AMI, and their effects are comparable with that of EPO and Dpa.

In the present study, we demonstrated that EPO, independently of its erythropoietic activity, protected cultured neonatal cardiac myocytes against simulated ischemia/reperfusion. Our findings confirm previous studies that EPO has cytoprotective- [31] and anti-apoptotic effects on cardiac myocytes [32].

In in vivo coronary occlusion/reperfusion experiments, we found that iv., but not ip. administration of the same dose of EPO before the onset of reperfusion decreased infarct size in rats, although it has been previously demonstrated that EPO reduces infarct size by both ip. [32,33] or iv. [34] administration. This discrepancy could be due to pharmacokinetic differences or different duration of treatments [35]. We also report the first time in the literature the dose-response relationship of Dpa administered before the onset of reperfusion. Although, the infarct size-limiting dose of Dpa administered before reperfusion varies widely (from 2.5 [36] to $30 \mu \mathrm{g} / \mathrm{kg}$ [37] in other studies), our results point out that a lower dose range
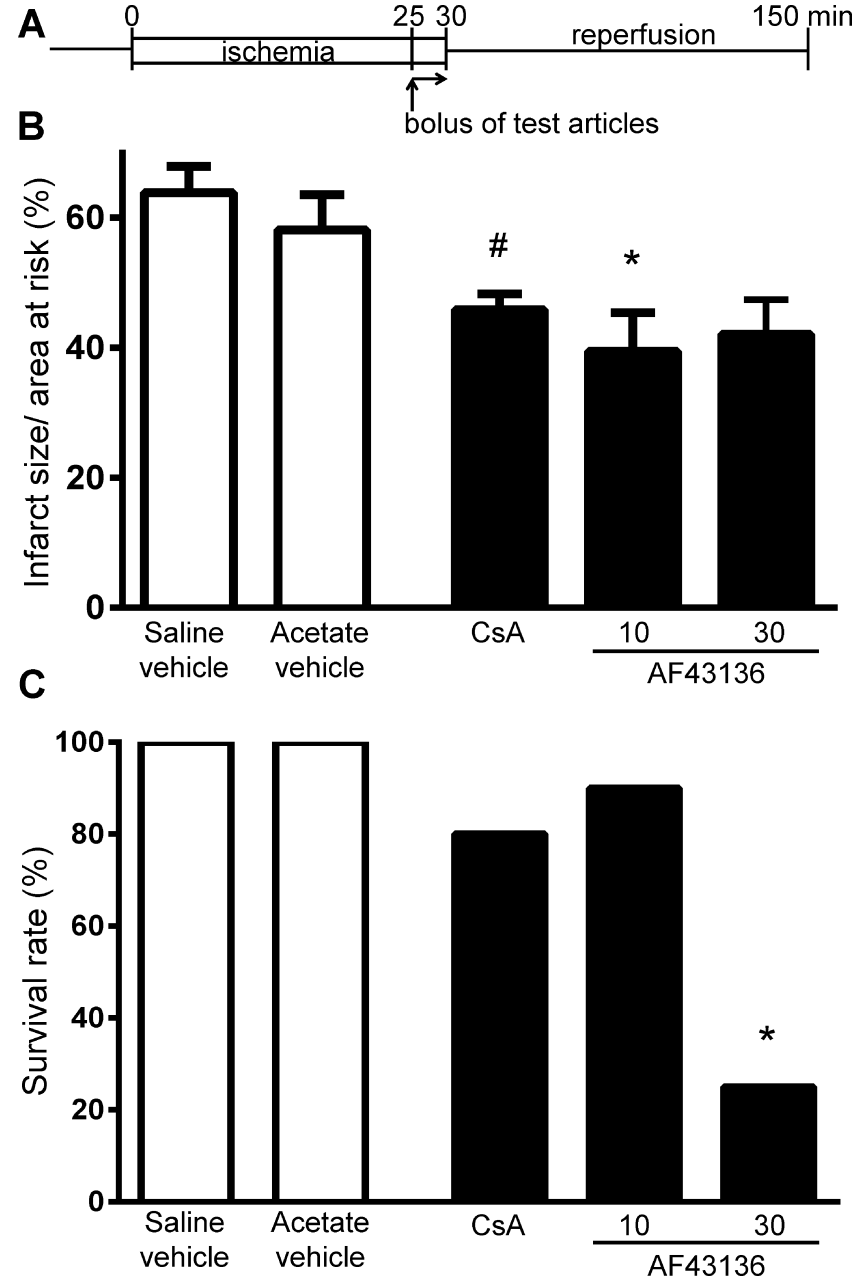

Fig. 5. Panel A: Experimental protocol for Study 4.

Panel B: The effect of 2 doses of AF43136 and cyclosporine A (CsA) on infarct size in rats subjected to in vivo 30 -min coronary occlusion followed by $120 \mathrm{~min}$ reperfusion. Data are expressed as means \pm S.E.M., ${ }^{*} \mathrm{p}<0.05$ vs. vehicle control, ${ }^{*} \mathrm{p}<0.05$ vs. saline control; $\mathrm{n}=7-8$. Infarct size data of $30 \mathrm{mg} / \mathrm{kg}$ AF43136 contains only $2 \mathrm{sam}$ ples because of high mortality rate (see in Panel C).

Panel C: The effect of 2 doses of AF43136 and cyclosporine A (CsA) on survival. Data are expressed as means \pm S.E.M., ${ }^{*} p<0.01$ vs. vehicle control.

of Dpa is sufficient to reduce infarct size in a rat model of AMI with maximal effect at $5 \mu \mathrm{g} / \mathrm{kg}$.

Noteworthy, in the present study, B-type natriuretic peptide (BNP) and cyclosporine A (CsA) administration before reperfusion served as appropriate positive controls to reduce infarct size. Previous studies have shown that BNP treatment maintained dur- 
Table 7

Hemodynamic parameters, area at risk and infarct size data for study 4 .

\begin{tabular}{|c|c|c|c|c|c|c|c|c|c|}
\hline & \multirow[t]{2}{*}{$\mathrm{n}$} & \multirow[t]{2}{*}{$\mathrm{AAR} / \mathrm{LV}(\%)$} & \multirow[t]{2}{*}{ IS/AAR (\%) } & \multicolumn{3}{|c|}{ mean arterial blood pressure $(\mathrm{mmHg})$} & \multicolumn{3}{|c|}{ heart rate (beats/min) } \\
\hline & & & & $\mathrm{BL}$ & ISCH & REP & $\mathrm{BL}$ & ISCH & REP \\
\hline Vehicle (saline) & 8 & $27.9 \pm 2.6$ & $63.8 \pm 4.1$ & $110 \pm 5$ & $91 \pm 4$ & $72 \pm 3$ & $416 \pm 9$ & $432 \pm 23$ & $440 \pm 21$ \\
\hline Vehicle (acetate) & 8 & $30.6 \pm 3.1$ & $58.1 \pm 5.4$ & $106 \pm 4$ & $90 \pm 6$ & $67 \pm 4$ & $433 \pm 15$ & $427 \pm 20$ & $415 \pm 17$ \\
\hline CsA & 7 & $34.5 \pm 2.5$ & $45.9 \pm 2.4^{*}$ & $99 \pm 6$ & $82 \pm 6$ & $76 \pm 5$ & $445 \pm 12$ & $425 \pm 22$ & $434 \pm 12$ \\
\hline AF43136 $10 \mathrm{mg} / \mathrm{kg}$ & 8 & $28.2 \pm 5.5$ & $39.4 \pm 5.9^{*}$ & $111 \pm 6$ & $105 \pm 3$ & $88 \pm 5^{*}$ & $394 \pm 11$ & $413 \pm 12$ & $426 \pm 13$ \\
\hline $\mathrm{AF} 4313630 \mathrm{mg} / \mathrm{kg}$ & 8 & $20.3 \pm 4.8^{\$}$ & $42.1 \pm 5.4^{\$}$ & $96 \pm 6$ & $47 \pm 9^{*}$ & $54 \pm 18^{\$}$ & $438 \pm 15$ & $383 \pm 19$ & $437 \pm 15^{\$}$ \\
\hline
\end{tabular}

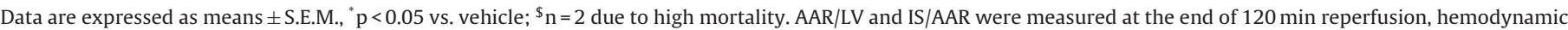

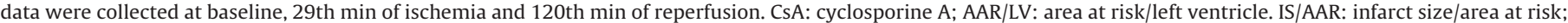
BL: baseline; ISCH: 29th min of ischemia; REP: 120th min of reperfusion.

ing the entire reperfusion reduces myocardial infarct size [38,39], however, there is no evidence about shorter, targeted BNP administration for reducing reperfusion injury in in vivo AMI models. The cardioprotective capabilities of CsA against reperfusion injury, especially in rats, are still inconsistent. Several reports support our data $[40,41]$ (for review see [42]), but others have shown that CsA is not effective in reducing myocardial infarct size [42,43]; the reason for that is not exactly understood.

The major finding of our present study is that two novel selective non-erythropoietic EPO receptor ligand dimeric peptides, AF41676 and AF43136, reduce infarct size significantly when administered before reperfusion in an in vivo rat model of AMI. AF41676 was effective in reducing infarct size at a wide dose-range $(0.3-10 \mathrm{mg} / \mathrm{kg}$ ). Although, high doses ( 10 and $20 \mathrm{mg} / \mathrm{kg}$ ) of AF41676 decreased mean arterial blood pressure, they did not influence survival, and we did not register any severe side effects during the experiments. In contrast, AF43136 reduced infarct size, but it was lethal in higher doses due to a rapid decline in mean arterial blood pressure during its administration. As analogs of the peptide portion of peginesatide, AF41676 and AF43136 were initially prepared as an attempt to define non-erythropoietic agents. These analogs exhibit realiable binding to the extracellular portion of the EPO receptor, however, do not stimulate erythropoiesis suggesting that they may act as cell protectants.

It has been previously demonstrated that the modified EPO analogues, CEPO and asialoEpo, preserve the tissue protective effects of EPO, such as infarct size reduction, prevention of cardiac hypertrophy and improvement of cardiac function [7,17-20], without any erythropoietic safety problems [2]. However, these EPO analogues are unfavorable due to their potential for high antigenicity, inadequate long-term stability and relatively high costs of production $[6,21]$. Therefore, previously, a small EPO analogue, pyroglutamate helix B surface peptide (pHBSP or ARA 290) consisting of 11 amino acids of the beta-chain of EPO, was generated to substitute EPO or its large peptide analogues to achieve cardioprotection [44] without inducing erythropoiesis. PHBSP is a small fragment of EPO, and one would assume that when excised out of the cytokine, it would only randomly adopt the appropriate conformation and thus be a very poor binder to the receptor. So far, only one study has demonstrated that pHBSP reduces infarct size in acute coronary ligation in rats [45]. In contrast, AF peptides were structured via the linker and disulfide bonds to wrap around each other, and present a surface that is highly complementary to the EPO receptor (EPOR). The two AF peptides are structurally related to the peptide portion of peginesatide and therefore expected to bind EPOR tightly. These features support our findings, that non-erythropoietic EPO analogue dimeric peptides may be promising cardioprotective agents against acute myocardial infarction.

However, there are some limitations in the present study. Direct translational conclusion to human cardioprotection cannot be drawn from these preclinical results. Several previous preclin- ical studies showed significant cardioprotection after treatments with EPO or its derivatives (e.g. darbepoetin; 8-9), however, in clinical trials they failed to improve any hard endpoints (i.e. survival, cardiac function, or infarct size) in AMI patients $[2,46]$. The reason for the failure of translation is not known, however, the possible mechanisms for the lack of EPO-induced cardioprotection in humans has been extensively reviewed elsewhere [2]. Despite the negative results of EPO-cardioprotection in humans, modulation of EPO receptor stimulation by novel receptor ligands should be a target of continued investigations as a promising cardioprotective strategy. Indeed, others have developed several non-erythorpoietic EPO-analogues (e.g. CEPO, asialoEPO, ARA290) to preserve EPO's cytoprotective effects without erythropoietic activity [2,17-20,47]. Their common potential target is to interact selectively with the innate repair receptor of EPO, which mediates tissue protection [48]. Recent human data showed the safety of ARA290 in patients with type 2 diabetes [48] or Friedreich's ataxia [49]. Moreover, the protective effect of ARA290 has also been shown in a porcine model of renal ischemia/reperfusion injury [50], and by improving the regeneration capacity of corneal small nerve fibers in sarcoidosis patients [51].

\section{Conclusions}

Our study demonstrates for the first time that selective non-erythropoietic EPO receptor ligand dimeric peptides AF41676 and AF43136 administered before the onset of reperfusion are able to reduce infarct size in a rat model of acute coronary occlusion/reperfusion. Therefore, non-erythropoietic EPO receptor ligands may be potential cardioprotective agents in acute myocardial infarction. Further safety and translational studies will be needed to ensure the safety and efficacy of these agents as viable clinical treatments.

\section{Conflict of interest}

The authors declare that they have no conflict of interest. The study was supported financially by Affymax, however, data were not influenced by either Pharmahungary or Affymax, thus they have also no conflict of interest regarding the present manuscript.

\section{Acknowledgments}

This paper (P. Bencsik and C. Csonka) was supported by the János Bolyai Research Scholarships of the Hungarian Academy of Sciences. G Szucs was supported by the Postdoctoral Research Program of the Hungarian Academy of Sciences. P. Ferdinandy held a Szentágothai Fellowship (TÁMOP-4.2.4.A/2-11/1-2012-0001) of the National Excellence Program of Hungary. 


\section{References}

[1] C. Bokemeyer, M.S. Aapro, A. Courdi, et al., EORTC guidelines for the use of erythropoietic proteins in anaemic patients with cancer: 2006 update, Eur. J. Cancer 43 (2007) 258-270.

[2] F. Sanchis-Gomar, J.L. Garcia-Gimenez, H. Pareja-Galeano, M. Romagnoli, C. Perez-Quilis, G. Lippi, Erythropoietin and the heart: physiological effects and the therapeutic perspective, Int. J. Cardiol. 171 (2014) 116-125.

[3] G.L. Wright, P. Hanlon, K. Amin, C. Steenbergen, E. Murphy, M.O. Arcasoy, Erythropoietin receptor expression in adult rat cardiomyocytes is associated with an acute cardioprotective effect for recombinant erythropoietin during ischemia-reperfusion injury, FASEB J. 18 (2004) 1031-1033.

[4] R. Depping, K. Kawakami, H. Ocker, et al., Expression of the erythropoietin receptor in human heart, J. Thorac. Cardiovasc. Surg. 130 (2005) 877-878.

[5] M. Brines, G. Grasso, F. Fiordaliso, et al., Erythropoietin mediates tissue protection through an erythropoietin and common beta-subunit heteroreceptor, Proc. Natl. Acad. Sci. U. S. A. 101 (2004) 14907-14912.

[6] M. Collino, C. Thiemermann, A. Cerami, M. Brines, Flipping the molecular switch for innate protection and repair of tissues: long-lasting effects of a non-erythropoietic small peptide engineered from erythropoietin, Pharmacol. Ther. 10 (2015).

[7] K. Xu, I. George, S. Klotz, et al., Erythropoietin derivate improves left ventricular systolic performance and attenuates left ventricular remodeling in rats with myocardial infarct-induced heart failure, J. Cardiovasc. Pharmacol. 56 (2010) 506-512.

[8] R. Latini, M. Brines, F. Fiordaliso, Do non-hemopoietic effects of erythropoietin play a beneficial role in heart failure, Heart Fail. Rev. 13 (2008) 415-423.

[9] E. Lipsic, R.G. Schoemaker, P. van der Meer, A.A. Voors, D.J. van Veldhuisen, W.H. van Gilst, Protective effects of erythropoietin in cardiac ischemia: from bench to bedside, J. Am. Coll. Cardiol. 48 (2006) 2161-2167.

[10] A. Palazzuoli, G. Ruocco, M. Pellegrini, et al., The role of erythropoietin stimulating agents in anemic patients with heart failure: solved and unresolved questions, Ther Clin Risk Manag 10 (2014) 641-650, http://dx.doi. org/10.2147/TCRM.S61551, eCollection.

[11] M. Leist, P. Ghezzi, G. Grasso, et al., Derivatives of erythropoietin that are tissue protective but not erythropoietic, Science 305 (2004) 239-242.

[12] A. Besarab, W.K. Bolton, J.K. Browne, et al., The effects of normal as compared with low hematocrit values in patients with cardiac disease who are receiving hemodialysis and epoetin, N. Engl. J. Med. 339 (1998) 584-590.

[13] S.S. Najjar, S.V. Rao, C. Melloni, et al., Intravenous erythropoietin in patients with ST-segment elevation myocardial infarction: REVEAL: a randomized controlled trial, JAMA 305 (2011) 1863-1872.

[14] I. Ott, S. Schulz, J. Mehilli, et al., Erythropoietin in patients with acute ST-segment elevation myocardial infarction undergoing primary percutaneous coronary intervention: a randomized, double-blind trial, Circ. Cardiovasc. Interv. 3 (2010) 408-413.

[15] Q. Fan, K.K. Leuther, C.P. Holmes, et al., Preclinical evaluation of Hematide, a novel erythropoiesis stimulating agent, for the treatment of anemia, Exp. Hematol. 34 (2006) 1303-1311.

[16] C.L. Bennett, S. Jacob, J. Hymes, L.A. Usvyat, F.W. Maddux, Anaphylaxis and hypotension after administration of peginesatide, N. Engl. J. Med. 370 (2014) 2055-2056.

[17] F. Fiordaliso, S. Chimenti, L. Staszewsky, et al., A nonerythropoietic derivative of erythropoietin protects the myocardium from ischemia-reperfusion injury, Proc. Natl. Acad. Sci. U. S. A. 102 (2005) 2046-2051.

[18] C. Moon, M. Krawczyk, D. Paik, et al., Erythropoietin, modified to not stimulate red blood cell production, retains its cardioprotective properties, J. Pharmacol. Exp. Ther. 316 (2006) 999-1005.

[19] T. Takeyama, G. Takemura, H. Kanamori, et al., Asialoerythropoietin, a nonerythropoietic derivative of erythropoietin, displays broad anti-heart failure activity, Circ. Heart Fail. 5 (2012) 274-285.

[20] X. Xu, Z. Cao, B. Cao, et al., Carbamylated erythropoietin protects the myocardium from acute ischemia/reperfusion injury through a PI3K/Akt-dependent mechanism, Surgery 146 (2009) 506-514.

[21] M. Brines, A. Cerami, Erythropoietin-mediated tissue protection: reducing collateral damage from the primary injury response, J. Intern. Med. 264 (2008) 405-432.

[22] N. Casadevall, J. Nataf, B. Viron, et al., Pure red-cell aplasia and antierythropoietin antibodies in patients treated with recombinant erythropoietin, N. Engl. J. Med. 346 (2002) 469-475.

[23] Q. Fan, K.K. Leuther, C.P. Holmes, et al., Preclinical evaluation of Hematide, a novel erythropoiesis stimulating agent, for the treatment of anemia, Exp. Hematol. 34 (2006) 1303-1311.

[24] D. Burger, A. Xenocostas, Q.P. Feng, Molecular basis of cardioprotection by erythropoietin, Curr. Mol. Pharmacol. 2 (2009) 56-69.

[25] D.S. Burley, G.F. Baxter, B-type natriuretic peptide at early reperfusion limits infarct size in the rat isolated heart, Basic Res. Cardiol. 102 (2007) 529-541.

[26] H. Kemperman, M. van den Berg, H. Kirkels, N. de Jonge, B-type natriuretic peptide (BNP) and N-terminal proBNP in patients with end-stage heart failure supported by a left ventricular assist device, Clin. Chem. 50 (2004) 1670-1672.

[27] T. Csont, A. Gorbe, E. Bereczki, et al., Biglycan protects cardiomyocytes against hypoxia/reoxygenation injury: role of nitric oxide, J. Mol. Cell. Cardiol. 48 (2010) 649-652.
[28] A. Görbe, Z. Giricz, A. Szunyog, et al., Role of cGMP-PKG signaling in the protection of neonatal rat cardiac myocytes subjected to simulated ischemia/reoxygenation, Basic Res. Cardiol. 105 (2010) 643-650.

[29] P. Bencsik, J. Paloczi, G.F. Kocsis, et al., Moderate inhibition of myocardial matrix metalloproteinase-2 by ilomastat is cardioprotective, Pharmacol. Res. 80 (2014) 36-42, http://dx.doi.org/10.1016/j.phrs.2013.12.007, Epub.

[30] C. Csonka, K. Kupai, G.F. Kocsis, et al., Measurement of myocardial infarct size in preclinical studies, J. Pharmacol. Toxicol. Methods 61 (2010) 163-170.

[31] L. Calvillo, R. Latini, J. Kajstura, et al., Recombinant human erythropoietin protects the myocardium from ischemia-reperfusion injury and promotes beneficial remodeling, Proc. Natl. Acad. Sci. U. S. A. 100 (2003) 4802-4806.

[32] E. Lipsic, P. van der Meer, R.H. Henning, et al., Timing of erythropoietin treatment for cardioprotection in ischemia/reperfusion, J. Cardiovasc. Pharmacol. 44 (2004) 473-479.

[33] A.J. Bullard, P. Govewalla, D.M. Yellon, Erythropoietin protects the myocardium against reperfusion injury in vitro and in vivo, Basic Res. Cardiol. 100 (2005) 397-403.

[34] M. Nishihara, T. Miura, T. Miki, et al., Erythropoietin affords additional cardioprotection to preconditioned hearts by enhanced phosphorylation of glycogen synthase kinase-3 beta, Am. J. Physiol. Heart Circ. Physiol. 291 (2006) H748-H755.

[35] P.A. Statler, R.J. McPherson, L.A. Bauer, B.A. Kellert, S.E. Juul, Pharmacokinetics of high-dose recombinant erythropoietin in plasma and brain of neonatal rats, Pediatr. Res. 61 (2007) 671-675.

[36] J.E. Baker, D. Kozik, A.K. Hsu, X. Fu, J.S. Tweddell, G.J. Gross, Darbepoetin alfa protects the rat heart against infarction: dose-response, phase of action, and mechanisms, J. Cardiovasc. Pharmacol. 49 (2007) 337-345.

[37] E. Gao, M. Boucher, J.K. Chuprun, R.H. Zhou, A.D. Eckhart, W.J. Koch, Darbepoetin alfa, a long-acting erythropoietin analog, offers novel and delayed cardioprotection for the ischemic heart, Am. J. Physiol. Heart Circ. Physiol. 293 (2007) H60-H68.

[38] B. Ren, H. Wu, R. Yin, et al., B-type natriuretic peptide pretreatment attenuates heart ischemia-reperfusion injury in rats, Transplant. Proc. 42 (2010) 4496-4498.

[39] B. Wu, H. Jiang, R. Lin, B. Cui, H. Wen, Z. Lu, Pretreatment with B-type natriuretic peptide protects the heart from ischemia-reperfusion injury by inhibiting myocardial apoptosis, Tohoku J. Exp. Med. 219 (2009) 107-114.

[40] J. Fang, L. Wu, L. Chen, Postconditioning attenuates cardiocyte ultrastructure injury and apoptosis by blocking mitochondrial permeability transition in rats, Acta Cardiol. 63 (2008) 377-387.

[41] R. Huhn, A. Heinen, N.C. Weber, M.W. Hollmann, W. Schlack, B. Preckel, Hyperglycaemia blocks sevoflurane-induced postconditioning in the rat heart in vivo: cardioprotection can be restored by blocking the mitochondrial permeability transition pore, Br. J. Anaesth. 100 (2008) 465-471.

[42] W.Y. Lim, C.M. Messow, C. Berry, Cyclosporin variably and inconsistently reduces infarct size in experimental models of reperfused myocardial infarction: a systematic review and meta-analysis, Br. J. Pharmacol. 165 (2012) 2034-2043.

[43] D. De Paulis, P. Chiari, G. Teixeira, et al., Cyclosporine A at reperfusion fails to reduce infarct size in the in vivo rat heart, Basic Res. Cardiol. 108 (2013) 379.

[44] M. Brines, N.S. Patel, P. Villa, et al., Nonerythropoietic, tissue-protective peptides derived from the tertiary structure of erythropoietin, Proc. Natl. Acad. Sci. U. S. A. 105 (2008) 10925-10930.

[45] I. Ahmet, H.J. Tae, M. Juhaszova, et al., A small nonerythropoietic helix B surface peptide based upon erythropoietin structure is cardioprotective against ischemic myocardial damage, Mol. Med. 17 (2011) 194-200.

[46] S. Ali-Hassan-Sayegh, S.J. Mirhosseini, M. Tahernejad, et al., Administration of erythropoietin in patients with myocardial infarction: does it make sense? An updated and comprehensive meta-analysis and systematic review, Cardiovasc. Revasc. Med. 16 (2015) 179-189.

[47] W.G. van Rijt, G.H. van, R.J. Ploeg, H.G. Leuvenink, Erythropoietin-mediated protection in kidney transplantation: nonerythropoietic EPO derivatives improve function without increasing risk of cardiovascular events, Transpl. Int. 27 (2014) 241-248.

[48] M. Brines, A.N. Dunne, V.M. van, et al., ARA 290, a nonerythropoietic peptide engineered from erythropoietin, improves metabolic control and neuropathic symptoms in patients with type 2 diabetes, Mol. Med. 20 (2015) 658-666, http://dx.doi.org/10.2119/molmed.2014.00215.

[49] S. Boesch, W. Nachbauer, C. Mariotti, et al., Safety and tolerability of carbamylated erythropoietin in Friedreich's ataxia, Mov. Disord. 29 (2014) 935-939.

[50] W.G. van Rijt, G.J. Nieuwenhuijs-Moeke, G.H. van, et al., ARA290, a non-erythropoietic EPO derivative, attenuates renal ischemia/reperfusion injury, J. Transl. Med. 11 (2013) 9, http://dx.doi.org/10.1186/1479-5876-11-9.

[51] A. Dahan, A. Dunne, M. Swartjes, et al., ARA 290 improves symptoms in patients with sarcoidosis-associated small nerve fiber loss and increases corneal nerve fiber density, Mol. Med. 19 (2013) 334-345, http://dx.doi.org/ 10.2119/molmed.2013.00122. 


\section{Supplementary material}

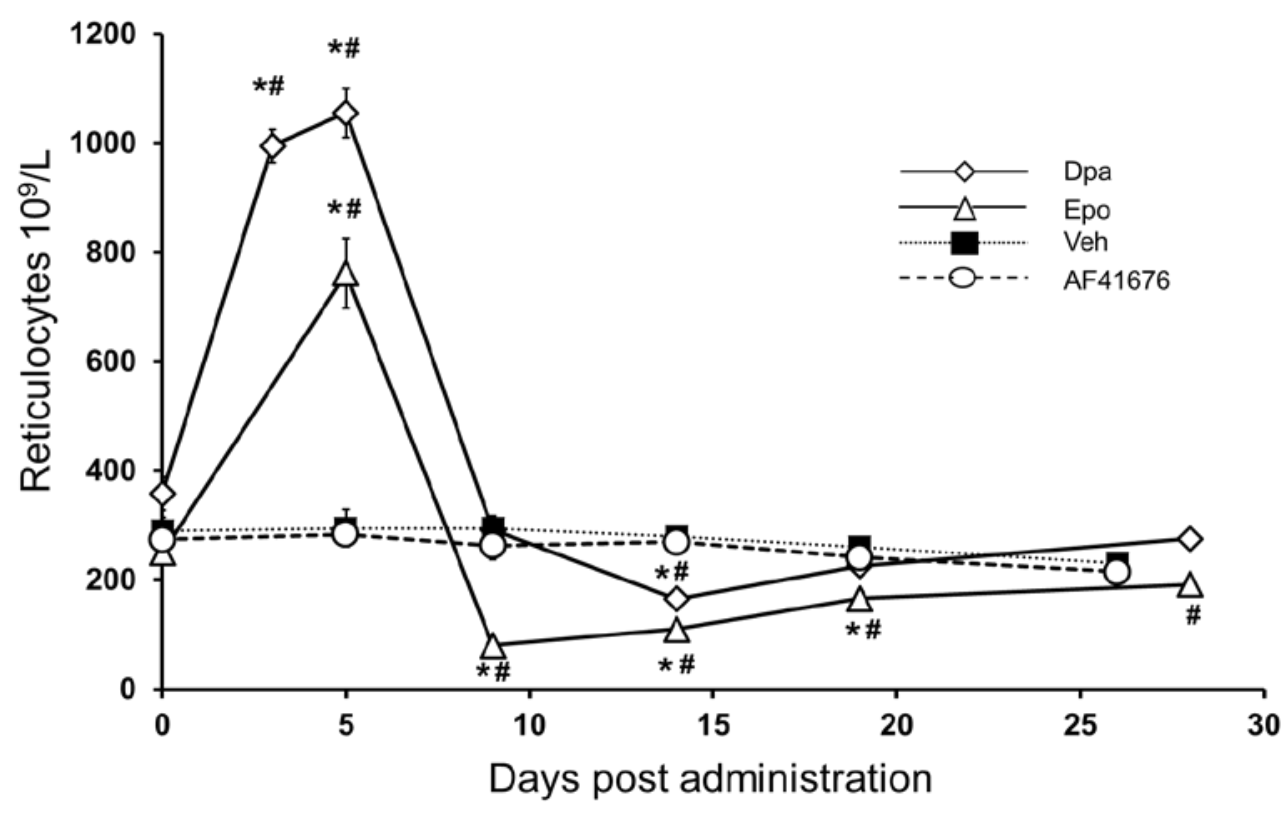

Supplementary Figure 1: The effects of 5,000 Units/kg EPO, $10 \mu \mathrm{g} / \mathrm{kg} \mathrm{Dpa,} 10 \mathrm{mg} / \mathrm{kg}$ AF41676, and acetate vehicle on reticulocytes number following administration of single iv. boluses. Data are expressed as mean $\pm S D,{ }^{*} p<0.05$ vs. vehicle, ${ }^{*} p<0.05$ vs. baseline analyzed by repeated measures ANOVA, $n=4$ rats per time point/ group. 